\title{
A puberdade altera a responsividade à insulina do tecido adiposo assim como sua capacidade lipogênica
}

\author{
Tese apresentada ao Programa \\ de Pós-Graduação em Fisiologia \\ Humana do Instituto de Ciências \\ Biomédicas da Universidade de \\ São Paulo, para a obtenção do \\ Título de Doutor em Ciências.
}


AMANDA BARON CAMPAÑA

\section{A PUBERDADE ALTERA A RESPONSIVIDADE À INSULINA DO TECIDO ADIPOSO ASSIM COMO SUA CAPACIDADE LIPOGÊNICA}

Tese apresentada ao Programa de Pós-Graduação em Fisiologia Humana do Instituto de Ciências Biomédicas da Universidade de São Paulo, para a obtenção do Título de Doutor em Ciências.

Área de Concentração: Fisiologia Humana

Orientador: Prof. Dr. Fábio Bessa Lima

Versão original 
DADOS DE CATALOGAÇÃO NA PUBLICAÇÃO (CIP)

Serviço de Biblioteca e Informação Biomédica do

Instituto de Ciências Biomédicas da Universidade de São Paulo

reprodução não autorizada pelo autor

Campanã, Amanda Baron.

A puberdade altera a responsividade à insulina do tecido adiposo assim como sua capacidade lipogênica / Amanda Baron Campanã. -São Paulo, 2013.

Orientador: Prof. Dr. Fábio Bessa Lima.

Tese (Doutorado) - Universidade de São Paulo. Instituto de Ciências Biomédicas. Departamento de Fisiologia e Biofísica. Área de concentração: Fisiologia Humana. Linha de pesquisa: Metabolismo do tecido adiposo.

Versão do título para o inglês: Puberty alters adipose tissue insulin responsiveness and its lipogenic capacity.

$\begin{array}{lll}\text { 1. Tecido adiposo 2. Metabolismo de carboidrato } 3 \text {. Puberdade } & \end{array}$ 4. Captação de glicose 5. Lipogênese 6. Intolerância à glicose I. Lima, Prof. Dr. Fábio Bessa II. Universidade de São Paulo. Instituto de Ciências Biomédicas. Programa de Pós-Graduação em Fisiologia Humana III. Título. 
Candidato(a): $\quad$ Amanda Baron Campanã.

Título da Tese: $\quad$ A puberdade altera a responsividade à insulina do tecido adiposo assim como sua capacidade lipogênica.

Orientador(a): $\quad$ Prof. Dr. Fábio Bessa Lima.

A Comissão Julgadora dos trabalhos de Defesa da Tese de Doutorado, em sessão pública realizada a considerou
( ) Aprovado(a)
( ) Reprovado(a)








UNIVERSIDADE DE SÃO PAULO

INSTITUTO DE CIÊNCIAS BIOMÉDICAS

Cidade Universitária "Armando de Salles Oliveira"

Av. Prof. Lineu Prestes, 2415 - CEP, 05508-000 Săo Paulo, SP - Brasil

Telefone:(55) (011) 3091.7733 - telefax : (55) (011) 3091.7438

e-mail: cep@icb.usp.br

\section{Certificado}

Certificamos que o protocolo registrado sob $n^{\circ} 106$ nas fls. 61 do livro 02 para uso de animais em experimentação, sob a responsabilidade de Fábio Bessa Lima, Coordenador(a) da Linha de pesquisa "O papel do hormônio do crescimento (GH) e da testosterona no gênese da resistência á insulina e o perfil adipogênico na puberdade em ratos" do qual participou(aram) o(s) Amanda Baron Campaña, André Ricardo Gomes de Proença, Ariclécio Cunha de Oliveira, Maria Isabel Cardoso Alonso Vale, Natalie Carolina de Castro, Rogério Antonio Laurato Sertié, Talita da Silva Mendes de Farias, está de acordo com os Principios Éticos de Experimentação Animal adotado pelo Colégio Brasileiro de Experimentação Animal (COBEA) e foi aprovado pela COMISSÃO DE ÉTICA EM EXPERIMENTAÇÃO ANIMAL (CEEA) em 24.11.08, com validade de 3 anos.

São Paulo, 25 de novembro de 2008.

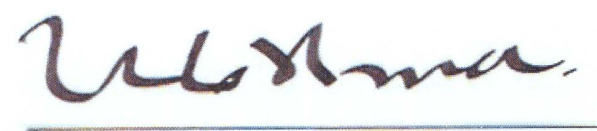

Prof. Dr. WOTHAN TAVARES DE LIMA

Coordenador

CEEA - ICB/USP

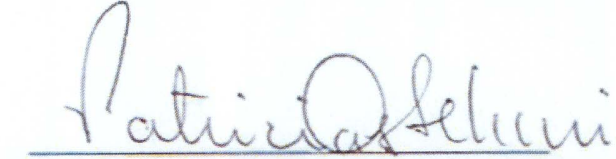

Profa. Dra. PAtricia CASTElucCI

Secretária CEEA - ICB/USP 


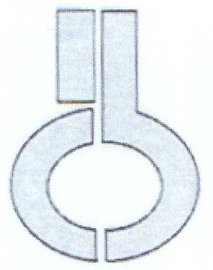

UNIVERSIDADE DE SÃO PAULO

\section{INSTITUTO DE CIÊNCIAS BIOMÉDICAS}

Cidade Universitária "Armando de Salles Oliveira"

Av. Prof. Lineu Prestes, 2415 - cep. 05508-000 Säo Paulo, SP - Brasil

Telefone :(55) (011) 3091.7733 e-mail: cep@icb.usp.br

Of.CEUA.049.12

WTL/mcgn

São Paulo, 05 de junho de 2012.

REF.: Protocolo n 106.08.

papel do hormônio do crescimento $(G H)$ e da testosterona no gênese da resistência á insulina e o perfil adipogênico na puberdade em ratos".

Prezado Professor.

Informo que a sua licença para uso de animais em experimentação, constante no protocolo em epigrafe, foi prorrogada até 24.11.2014.

Reitero que havendo alteração de metodologia e inserção de novos alunos ao projeto de pesquisa vinculado à referida licença a CEUA/ICB deverá ser informada.

Cordialmente,

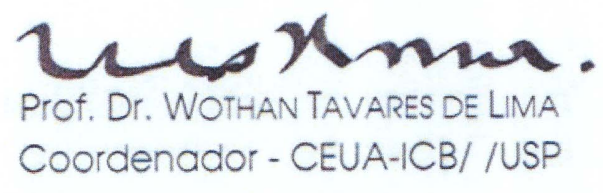

IImo.Sr.

Prof. Dr. Fabio Bessa Lima

Departamento de Fisiologia e Biofisica

Instituto de Ciências Biomédicas - USP 
Aos meus pais Marli e Luís (in memoriam) por todo o apoio, incentivo e estrutura que me permitiram chegar até aqui. À minha querida amiga e "segunda mãe" Cida, por todo seu carinho e incentivo. 


\section{AGRADECIMENTOS}

Agradeço primeiramente ao professor Fábio por me receber por todos estes anos em seu laboratório e por sua dedicada orientação. Além disso, agradeço muito por sua querida amizade e apoio em alguns momentos difíceis que a vida apresentou-me durante o percurso da minha pós-graduação. Seu amparo e compreensão foram essenciais.

Agradeço minha mãe querida, a Marli, por todo seu carinho, suporte e incentivo sem os quais não teria conseguido prosseguir neste caminho da pesquisa. Foi ela que sempre me ensinou o valor da dedicação ao estudo. Agradeço também à minha "segunda mãe", a Cida, por seu colo, amizade e todo o suporte emocional que me permitiram manter o equilíbrio frente às dificuldades da vida, eles foram imprescindíveis para eu continuar caminhando.

Agradeço à Sandra por todo o auxílio no desenvolvimento da minha pesquisa. Seu apoio na realização dos experimentos e suas sugestões foram fundamentais para o trabalho. Agradeço também por sua especial amizade e irmandade. Seu carinho e amizade foram essenciais em diversos momentos não só do processo da pesquisa, mas também da vida.

Agradeço aos queridos amigos André, Natalie, Rogério e Rennan pela colaboração nos experimentos e nas discussões dos resultados. Agradeço especialmente ao Rennan por sua dedicação, disponibilidade e entusiasmo em discutir comigo os dados da pesquisa. A amizade de vocês me prosseguir nos momentos difíceis.

Fábio, Sandra, André, Rennan, Rogério e Natalie foi um privilégio poder trabalhar com pessoas tão queridas como vocês. Agradeço a Deus por ter colocado pessoas tão especiais no meu caminho. Vocês fizeram os meus dias mais felizes!

Agradeço à Fernanda Amaral, pós-doutoranda do Prof. Dr. José Cipolla Neto por toda sua paciência e disponibilidade em me auxiliar com a teoria sobre a padronização da técnica de PCR real time. Muito obrigada! 
Agradeço à equipe do laboratório do professor Fábio que me ajudou em momentos da pesquisa: Leonardo, Arnaldo, Ariclécio, Andressa e especialmente Talita e a Patrícia.

Agradeço aos funcionários do biotério, da biblioteca, da secretaria de pósgraduação e da secretaria do departamento pela atenção, simpatia e disponibilidade em todos os momentos que precisei de auxílio.

Agradeço ao apoio financeiro da FAPESP, CAPES e CNPQ. 
"Nunca, jamais, desanimeis, embora venham ventos contrários." 


\section{RESUMO}

CAMPAÑA, A.B. A puberdade altera a responsividade à insulina do tecido adiposo assim como sua capacidade lipogênica. 2013. 90f. Tese (Doutorado em Fisiologia Humana) - Instituto de Ciências Biomédicas, Universidade de São Paulo, São Paulo, 2013.

O tecido adiposo é essencial para a manutenção da homeostase energética do organismo desempenhando importantes funções neste contexto. Além disso, este tecido tem uma função essencial para a maturação do eixo hipotálamo-hipófisegônadas através da leptina. Esta adipocina desempenha um papel permissivo para o amadurecimento deste eixo e, portanto, para a capacitação do indivíduo para a vida reprodutiva. Apesar da importância do tecido adiposo para a puberdade, pouco se sabe a respeito do processo de formação deste tecido neste período da vida.Muitas pesquisas realizadas em humanos têm descrito a presença de resistência à insulina no período puberal. Assim, frente à importância do tecido adiposo para a puberdade somada à possibilidade de um quadro puberal de resistência à insulina, estudamos o metabolismo de glicose no tecido adiposo.O objetivo do trabalho foi investigar a resposta do tecido adiposo à ação da insulina no período puberal,uma vez que ele é essencial para a puberdade.Foram utilizados dois coxins adiposos: um anatomicamente mais relacionado às gônadas e, possivelmente, à função reprodutiva, o coxim periepididimal $(\mathrm{PE})$, e outro sem relação direta com as gônadas, o coxim subcutâneo (SC).No início do período puberal (5 $5^{\text {a }}$ semana) os animais apresentaram intolerância à glicose. Neste período, a capacidade de resposta à insulina sobre a captação de glicose apresentou-se normal e, portanto, não houve prejuízo da responsividade aeste hormônio nos tecidos adiposos SC e PE. Além disso, houve maior capacidade de incorporação de glicose em lipídeos na $5^{\underline{a}}$ e $6^{\underline{a}}$ semanas no coxim SC e na $5^{a}$, $6^{\underline{a}}$ e $7^{\text {a }}$ semanas no coxim PE. Assim, na puberdade, paralelamente à intolerância à glicose transitória que ocorre nas semanas iniciais, e, portanto, prejuízo da utilização da glicose pelos tecidos insulino-dependentes, o tecido adiposo (SC e $\mathrm{PE}$ ) têm sua responsividade normal à insulina e uma melhor capacidade de incorporação de glicose em lipídeos o que leva a crer que há um desvio da utilização deste substrato energético, a glicose, para a formação do tecido adiposo o qual tem um papel permissivo para maturação do eixo reprodutor. A intolerância à glicose puberal ( $5^{\underline{a}}$ semana) parece, então, promover o desvio deste substrato energético para o tecido adiposo SC e PE. Além disso, as alterações metabólicas puberais do tecido adiposo são mais evidentes no coxim SC do que no PE, ao contrário do que se poderia supor em razão da gordura PE ser anatomicamente relacionada ao sistema reprodutor.

Palavras-chave: Tecido Adiposo. Metabolismo de Carboidratos. Puberdade. Captação de glicose.Incorporação de Glicose em Lipídeos. Leptina. Intolerância à Glicose Puberal. 


\begin{abstract}
CAMPAÑA, A.B. Puberty alters adipose tissue insulin responsiveness and its lipogenic capacity.2013. 90 p. Ph. D. thesis (Human Physiology) - Instituto de Ciências Biomédicas, Universidade de São Paulo, São Paulo, 2013.

The adipose tissue is essential for the energy homeostasis in the body. In addition, this tissue is critical to puberty. Leptin, an adipokine, exerts a permissive role to hypothalamic-hypophysial-gonadal maturation and, thereby, adipose tissue is necessary to pubertal development. Despite its importance to puberty, little is known about the process of adipose tissue formation during this period of life. Researches have described insulin resistance at pubertal period in humans. The adipose tissue importance to puberty added to pubertal insulin resistance described in humans lead us to investigate the glucose metabolism in the adipose tissue at puberty. So the aim of this work was to investigate how the adipose tissue responds to insulin at this period since it is essential at this time. We assessed two distinct fat pads: one with an intimate relation with gonads and reproductive function, the epididymal fat pad (EP); and other with no direct anatomical relation to gonads, the subcutaneous one (SC). At the beginning of pubertal period (5 weeks of life), the rats showed glucose intolerance. In this period, the insulin ability to stimulate glucose transport was normal, so there was no impairment of adipose tissue responsiveness to insulin in this period of glucose intolerance at both the SC and EP fat pads. Furthermore, there was a higher capacity of glucose incorporation into lipids at the $5^{\text {th }}$ and $6^{\text {th }}$ weeks in SC fat pad and at the $5^{\text {th }}, 6^{\text {th }}$ and $7^{\text {th }}$ weeks in EP fat pad. Therefore, at the puberty, despite the temporary glucose intolerance and the constraint for glucose utilization by insulin-dependent tissues, the adipose tissue had normal insulin responsiveness plus an improved capacity to synthesize lipids from glucose which led us to hypothesize that glucose could have been deviated towards the adipose tissue in order to allow it to better exert its essential and permissive role in the maturation of the hypothalamic-hypophysial-gonadal axis. In other words, pubertal glucose intolerance seems to redirect glucose to fat tissues. Moreover, adipose tissue metabolic modifications along puberty seemed to affect SC more than EP fat, unlike one could suppose due to the intimate relation between EP fat pads and gonads.
\end{abstract}

Keywords: Adipose Tissue. Carbohydrate Metabolism. Puberty. Glucose uptake. Glucose incorporation into lipids. Leptin. Pubertal Glucose Intolerance. 


\section{SUMÁRIO}

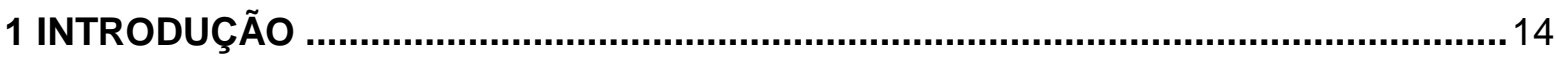

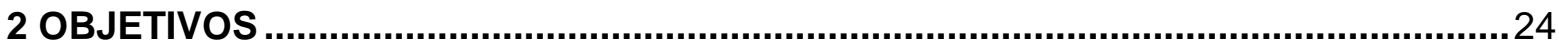

3 DESENHO EXPERIMENTAL E METODOLOGIAS...................................................25



3.2 Identificação do período de início da puberdade ....................................................25

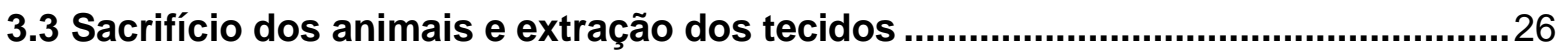

3.4 Isolamento dos adipócitos e análise morfométrica..................................................26





3.7 Determinação da concentração de testosterona ...................................................28

3.8 Determinação da concentração de leptina..........................................................28

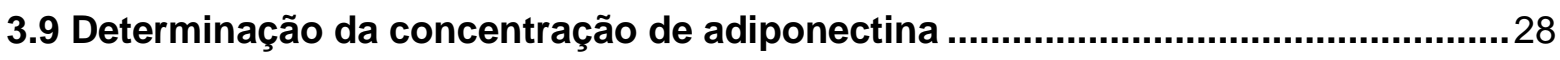

3.10 Teste oral de tolerância à glicose (G.T.T. Oral)......................................................29

3.11 Teste de captação de $\left[{ }^{3} \mathrm{H}\right]-2 \mathrm{DG}$ em adipócitos isolados ......................................2 29

3.12 Teste de incorporação de $\mathrm{D}-\left[\mathrm{U}-{ }^{14} \mathrm{C}\right]-$ glicose em triacilglicerol............................... 30

3.13 Incorporação de $\mathrm{D}-\left[\mathrm{U}-{ }^{14} \mathrm{C}\right]$-glicose em ácidos graxos de triacilglicerol .................30

3.14 Determinação da atividade de enzimas lipogênicas .............................................31

3.14.1 Atividade da enzima ácido graxo sintase (FAS) ......................................................31

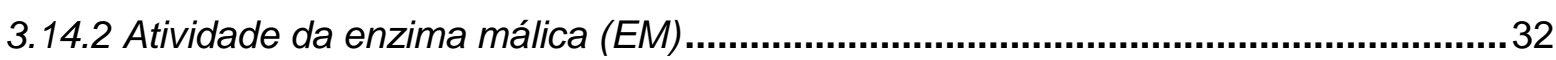

3.14.3 Atividade da enzima glicose-6-fosfato desidrogenase (G6PDH) ...........................32

3.15 Expressão Gênica de transportadores de glicose 1 e 4 (GLUT-1, GLUT-4), Leptina, Adiponectina e Receptorde Andrógeno no Tecido Adiposo...........................32

3.15.1 Extração de RNA total.........................................................................................32

3.15.2 Síntese de cDNA por transcrição reversa ............................................................33

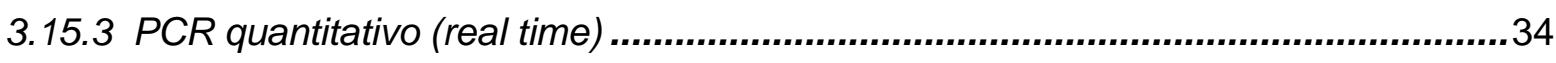

3.15.4 Quantificação relativa - método de CT comparativo $(\Delta \triangle C T)$.................................35

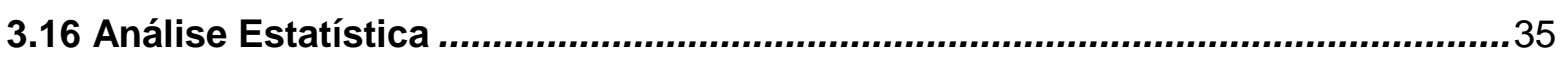

4 RESULTADOS





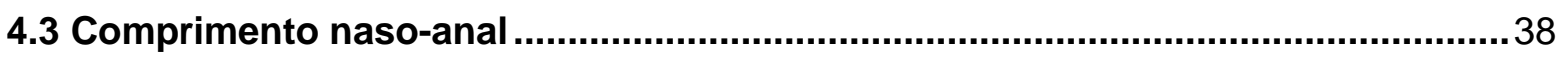

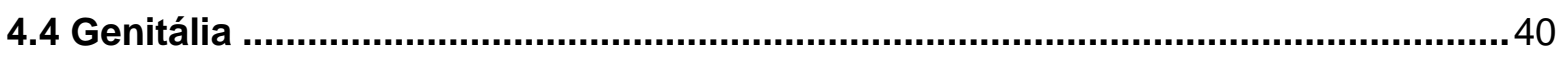

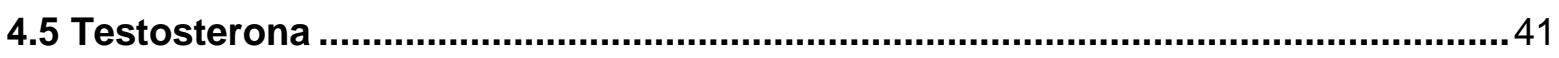


4.6 Teste oral de tolerância à glicose ........................................................................... 42

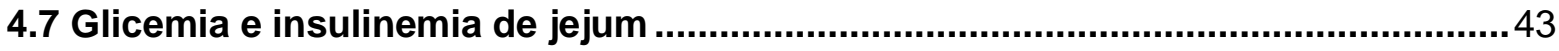

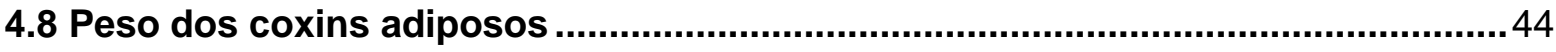

4.9 Diâmetro dos adipócitos e celularidade...................................................................... 45



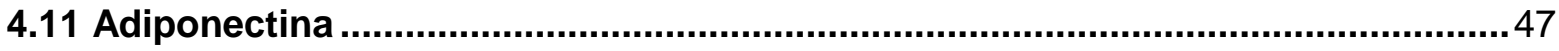

4.12 Captação específica de ${ }^{3} \mathrm{H}-2$-desoxiglicose ( $\left.{ }^{3} \mathrm{H}-2 \mathrm{DG}\right)$ em adipócitos isolados.... 48

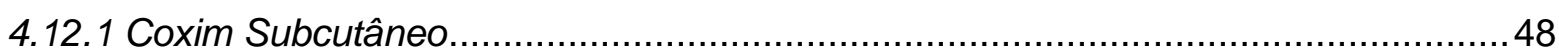

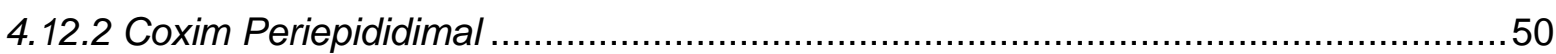

4.13 Capacidade de Incorporação de D-[U -14C]-glicose em lipídeos ......................52

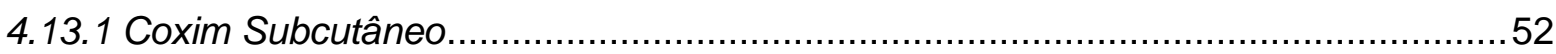

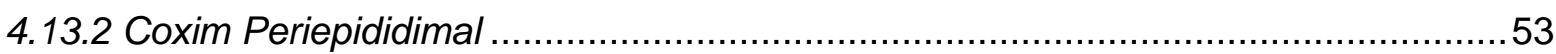

4.14 Incorporação de D-[U $\left.-{ }^{14} \mathrm{C}\right]$-glicose em glicerol e ácidos graxos do triacilglicerol........55

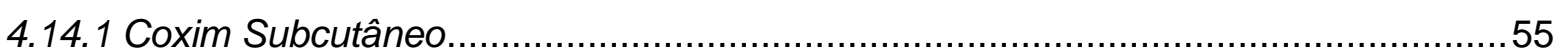

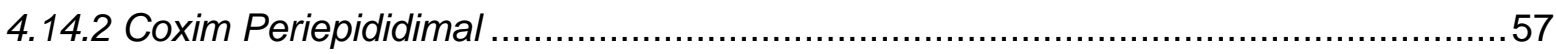

4.15 Atividade das enzimas lipogênicas - málica (EM), glicose 6- fosfato desidrogenase (G6PDH) e ácido graxo sintase (FAS) ........................................ 59

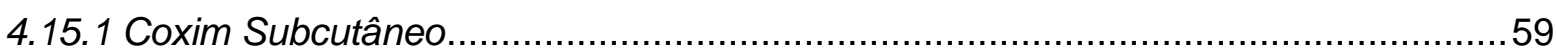

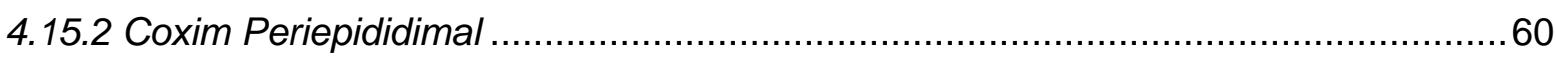

4.16 Expressão gênica de GLUT-1 e GLUT-4 ................................................. 61

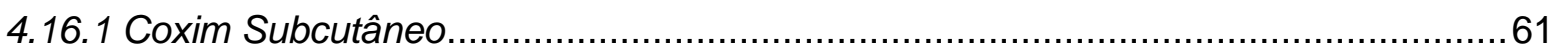

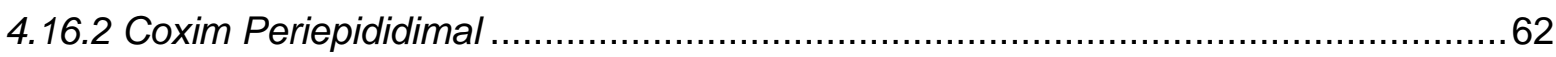

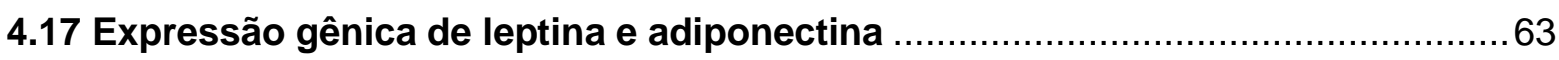

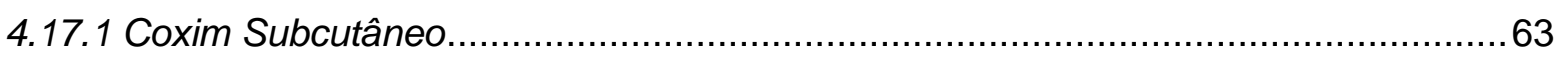

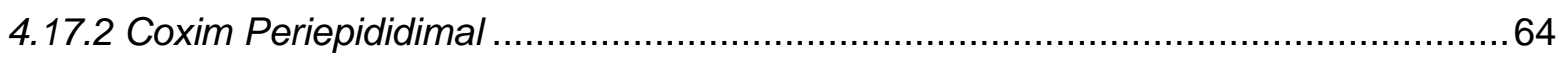

4.18 Expressão gênica do Receptor de Andrógeno ......................................... 65

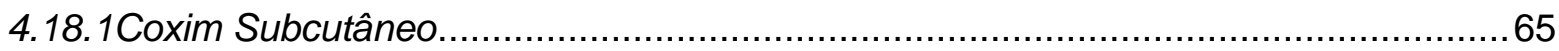

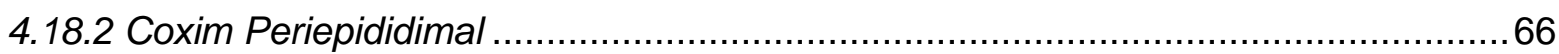

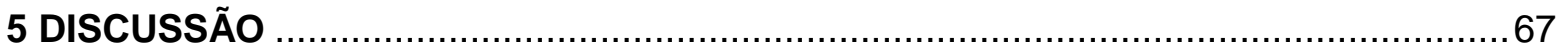

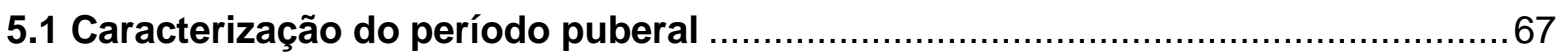

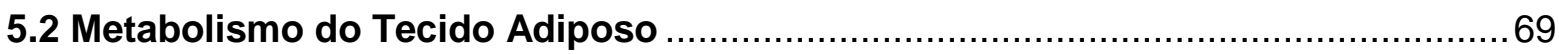

5.3 Análise Morfológica do Tecido Adiposo .............................................................. 76

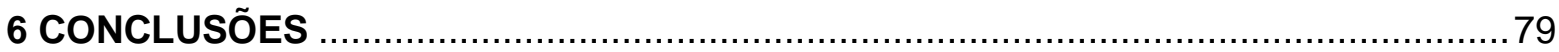

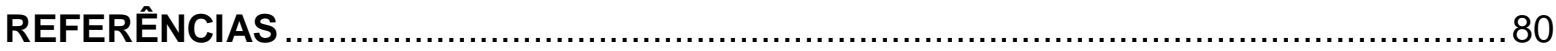




\section{INTRODUÇÃO}

O tecido adiposo é essencial para a manutenção da homeostase energética do organismo desempenhando importantes funções neste contexto. Sua função clássica é armazenar na forma de triacilglicerol o excesso de energia ingerida pelo indivíduo e liberar estes ácidos graxos em períodos de escassez de nutrientes como o jejum e intervalo entre as refeições.

$\mathrm{Na}$ década de 90, com a descoberta da leptina, compreendeu-se que a ação do tecido adiposo sobre o metabolismo é muito mais complexa do que se sabia antigamente (AHIMA, 2006; GIMENO; KLAMAN, 2005; KERSHAW; FLIER 2004; TRAYHURN; BEATTIE, 2001; WOZNIAK, 2009). O tecido adiposo responde a sinais nutricionais, neurais e hormonais e secreta proteínas e peptídeos bioativos, as adipocinas, que atuam sobre o comportamento alimentar, a termogênese, a imunidade,as funções neuroendócrinas e sobre hormônios essenciais ao metabolismo (AHIMA, 2006).

A função clássica do tecido adiposo na manutenção energética é desempenhada através dos processos de: lipogênese, onde energia é armazenada em triacilglicerol; e, lipólise, onde esta fonte de energia é quebrada oferecendo substrato energético para os tecidos em períodos de escassez.

A síntese de triacilglicerol no tecido adiposo ocorre através de dois diferentes processos: esterificação dos ácidos graxos(captados da circulação oriundos da dieta ou sintetizados na própria célula)com glicerol-3-fosfato e pela geração destea partir da glicose mediante a glicólise anaeróbia, ou de outros substratos não glicídicos (lactato, piruvato e aminoácidos) através de gliceroneogênese.

A esterificação dos ácidos graxos da dieta em triacilglicerol inicia-se com a ação da lipase de lipoproteína (LPL) que hidrolisa as lipoproteínas (quilomícrons e lipoproteínas de densidade muito baixa [VLDL]) circulantes, liberando os ácidos graxos que penetram no adipócito, por difusão facilitada mediante proteínas transportadoras,onde se esterificam ao glicerol-3-fosfato (FRAYN, 2003).

A primeira etapa da síntese do triacilglicerol é a ativação dos ácidos graxos de cadeia longa pela sua ligação com a coenzima $A$, reação catalisada pela acilCoA sintetase[ACS] (COLEMAN; LEWIN; MUOIO, 2000). O glicerol 3-fosfato sofre, 
então, duas acilações seguidas catalisadas pelas enzimas glicerol 3-fosfato aciltransferase (GPAT) e aciltransferase do ácido lisofosfatídico (LPAAT ou AGPAT) formando inicialmente ácido lisofosfatídico e depois o ácido fosfatídico que é então hidrolisado (enzima fosfadidato fosfohidrolase - PPH1) para formar diacilglicerol (DAG). O DAG sofre uma última acilação (enzima diacilglicerol aciltransferase, DGAT) para formar o triacilglicerol (TAG) (COLEMAN; LEWIN; MUOIO, 2000).

A lipogênese de novo (outro mecanismo fornecedor de ácidos graxos) iniciase com o transporte do citrato proveniente da mitocôndria para o citosol onde ele é clivado pela enzima ATP-citrato liase a oxaloacetato e acetil-CoA (HELLERSTEIN; SCHWARZ; NEESE, 1996). O acetil-CoA sofre então a ação da enzima acetil-CoA carboxilase (ACC) formando malonil-CoA. A segunda etapa é a conversão de acetil-CoA e malonil-CoA a palmitato na presença de $\mathrm{NADPH}$, reação catalisada pelo complexo enzimático ácido graxo sintetase (FAS) (WAKIL; STOOPS; JOSHI, 1983).

O NADPH necessário para a biossíntese redutora de ácidos graxos é proveniente da via das pentoses-fosfato geradas em dois momentos: oxidação de glicose-6-fosfato a 6-fosfoglicono- $\delta$-lactona pela enzima glicose-6-fosfato desidrogenase e descarboxilação oxidativa de 6-fosfogliconato a ribulose-5-fosfato pela ação da 6-fosfogliconato desidrogenase (BERG; TYMOCZKO; STRYER, 2004).Além disso, o NADPH pode ser fornecido pela ação da enzima málica na formação de piruvato a partir de malato (SUL; WANG, 1998; WISE; BALL, 1964).

A lipólise inicia-se pela ativação de adrenoreceptores $\beta$ na membrana do adipócito produzindo aumento de adenosina monofosfato cíclico (AMPc), ativação da quinase proteica $A(P K A)$ e, consequentemente, a ativação da enzima lipase hormônio sensível(HSL) que se desloca do citosol para a gota lipídica (HOLM, 2003; SU, 2003).A PKA também fosforila as perilipinas que envolvem a gota lipídica promovendo sua translocação para o citoplasma permitindo o acesso das lipases à gota lipídica (DUNCAN, 2007).

O coativador CGI-58 (Comparative Gene Identification 58) encontra-se associado à gota lipídica e perilipinas em situação basal, quando as perilipinas são fosforiladas por ação da PKA, o CGI-58 desloca-se para o citosol aonde irá se ligar à lipase de triacilglicerol (ATGL) ativando-a (WATT; SPRIET, 2010). A lipase de 
monoacilglicerol (MGL) é expressa constitutivamente no tecido adiposo (LAFONTAN; LANGIN, 2009) e não existem evidências de que a expressão gênica de MGL ou sua atividade enzimática sejam reguladas por hormônios ou pelo estado energético da célula (LASS, 2011).

A ATGL catalisa predominantemente a hidrólise da primeira ligação éster do triacilglicerol, apesar desta ligação poder ser hidrolisada também pela HSL (JAWORSKI, 2007). O diacilglicerol formado sofre então a ação da HSL formando monoacilglicerol o qual é hidrolisado pela MGL (JAWORSKI, 2007). Estas hidrólises subsequentes das ligações éster do triacilglicerol liberam os ácidos graxos para serem utilizados como substrato energético.

A função endócrina do tecido adiposo é desempenhada através da secreção de um grande número de adipocinas que incluem citocinas pró-inflamatórias como o fator de necrose tumoral alfa (TNF- $\alpha$ ) e interleucina-6 (IL-6); fatores envolvidos no controle da pressão sanguínea, como o angiotensinogênio; fatores que promovem a angiogênese como fator de crescimento endotelial vascular (VEGF); fatores mais diretamente ligados a homeostase glicêmica como a adiponectina e a leptina (AHIMA; FLIER, 2000; FONSECA-ALANIZ,2006). É através destes fatores secretados que o tecido adiposo desempenha seu importante papel no metabolismo energético.

A adiponectina está relacionada à homeostase glicêmica e lipídica (PAJVANI, 2003). Esta adipocina modula a sensibilidade à insulina (BERG, 2001; COMBS, 2002; YAMAUCHI, 2001), reduz a produção hepática de glicose (BERG, 2001; YAMAUCHI, 2002), estimula a oxidação de ácidos graxos nos músculos (FRUEBIS, 2001; YAMAUCHI, 2002) e aumenta o catabolismo de lipídeos, reduzindo a quantidade de triglicerídeos no tecido (GUERRE-MILLO, 2008).

A leptina age na regulação do gasto energético e da ingestão alimentar, assim como no controle do balanço energético de todo o organismo em roedores e humanos (HOUSEKNECHT, 1998). A expressão e a secreção de leptina correlacionam-se positivamente com a quantidade de tecido adiposo e o tamanho do adipócito (HOUSEKNECHT, 1998; JÉQUIER, 2002; MAFFEI, 1995) informando o grau de adiposidade corporal para o sistema nervoso central (SCHWARTZ, 2000; SPIEGELMAN; FLIER, 2001). 
No sistema nervoso central, a leptina inibe a ingestão alimentar agindo no hipotálamo (particularmente nos núcleos arqueado e paraventricular) modulando a concentração de neuropeptídeo $\mathrm{Y}$, de hormônio estimulador a de melanócito (melanocortina, $\alpha-\mathrm{MSH})$, de peptídeo agouti $(\mathrm{AgRP})$ e de transcrito relacionado a cocaína e anfetamina (CART) envolvidos no comportamento alimentar (GAO, 2007).

A leptina desempenha sua função de regulação do gasto energético por modulação do hormônio liberador de tireotrofina (TRH) (HUO, 2004; NILLNI, 2000) e da ativação do sistema nervoso simpático (SNS) (BATES, 2004).

Como exemplificado acima pelas funções da adiponectina e leptina, as proteínas secretadas pelo tecido adiposo desempenham funções essenciais para a manutenção da homeostase energética corporal. Desta forma, qualquer alteração na quantidade de tecido adiposo, seja seu excesso ou sua falta, causa importantes prejuízos metabólicos decorrentes da deficiência ou excesso das adipocinas resultando prejuízo do desempenho da função do tecido adiposo.

A obesidade, morbidade resultante do excesso de tecido adiposo, envolve aumento da secreção de adipocinas como TNF-a (HOTAMISLIGIL; SHARGILL; SPIEGELMAN, 1993; HOTAMISLIGIL, 1995; SETHI; HOTAMISLIGIL, 1999)além de outros mediadores do processo inflamatório caracterizando uma ampla resposta inflamatória que conjuntamente com stress oxidativo prejudicam a ação da insulina (WELLEN; HOTAMISLIGIL, 2005; XU, 2012). Além disso, a alteração da secreção normal de adipocinas, como leptina e adiponectina, contribui para a instalação do quadro metabólico característico da obesidade (MAURY; BRICHARD, 2010).

As lipodistrofias, caracterizadas por redução do tecido adiposo, apresentam quadro de resistência à insulina com consequente desenvolvimento de diabetes tipo 2 (SEIP; TRYGSTAD, 1996). A extensão da perda de tecido adiposo determina a gravidade das complicações metabólicas característica das lipodistrofias como diabetes mellitus, hipertrigliceridemia e esteatose hepática (GARG, 2011).

Assim, o quadro clínico consequente de morbidades que apresentam excesso ou perda de tecido adiposo ilustra o quão essencial é o funcionamento normal deste tecido para metabolismo energético.

Além das importantes funções sobre o metabolismo energético, o tecido adiposo tem um papel essencial no desenvolvimento do animal, pois tem um papel 
permissivo sobre a puberdade (APTER, 2003; FAROOQI, 2002; GUEORGUIEV; GOTH; KORBONITS, 2001).

A puberdade é um importante período do desenvolvimento em que ocorrem alterações hormonais e modificações na composição corporal que resultam na capacitação do indivíduo para a vida reprodutiva. Este evento é marcado pela ativação do eixo hipotálamo-hipófise-gônadas quando ocorre aumento da secreção de hormônio liberador de gonadotrofina $(\mathrm{GnRH})$, com consequente aumento da secreção dos hormônios luteinizante (LH) e folículo estimulante $(F S H)$. O LH e o FSH irão agir sobre as gônadas estimulando a diferenciação das células germinativas (ovogênese e espermatogênese) e síntese de esteroides sexuais.

A atividade do eixo reprodutor é sensível à disponibilidade das reservas metabólicas (CUNNINGHAM; CLIFTON; STEINER, 1999). Em ratos (KENNEDY; MITRA, 1963) assim como em humanos (FRISCH; REVELLE, 1970), o tamanho e peso corporal estão positivamente correlacionados com o início da puberdade mostrando-se preponderantes à idade cronológica para a determinação do início da puberdade.O balanço e a interação entre as condições metabólicas e os estágios de desenvolvimento estão envolvidos na coordenação do início da puberdade e na apropriada maturação sexual (ELIAS, 2012).

Diversos estudos indicam a leptina como responsável por relacionar o estado metabólico e a atividade do eixo reprodutor (BRANN, 2002; BUDAK, 2006;CASABIELL, 2001; GUEORGUIOV; GOTH; KORBONITS, 2001; KIESS; BLUM; AUBERT, 1998; WATANOBE; SCHIOTH, 2002;). A leptina, produto do gene ob, é um hormônio produzido pelas células adiposas e,como descrito anteriormente, o aumento de seus níveis tem sido proposto como um fator retroalimentador negativo para o cérebro, produzindo decréscimo da ingestão alimentar, aumento do gasto de energia e resistência à obesidade. Somada a esta função, que tem sido proposta como primária, a leptina circulante desempenha um importante papel sobre o eixo hipotálamo-hipófise-gônadas.

A leptina é produzida pelo tecido adiposo de forma proporcional à massa deste tecido (KLEIN, 1996).Ela apresenta alta correlação com o IMC em roedores e humanos, sendo que a perda de peso acarretada pela restrição alimentar produz redução da leptina plasmática em camundongos e animais obesos (MAFFEI, 1995). 
O quadro presente em camundongos ob/ob com total deficiência de leptina e camundongos $d b / d b$ com mutação no receptor deste hormônio corroboram a importância da leptina para o funcionamento normal do eixo reprodutor. A deficiência de leptina ou de sua ação acarretam em infertilidade e hipogonadismo somado à hiperfagia e à obesidade mórbida. $O$ tratamento crônico com leptina não reduz apenas a ingestão alimentar e o peso, mas também restabelece a puberdade e a fertilidade em camundongos ob/ob (AHIMA, 1997).

Mulheres atletas apresentam distúrbios do pulso de secreção de $\mathrm{GnRH}$ (WARREN; PERLROTH, 2001) com consequentes alterações no ciclo menstrual como oligomenorréia e amenorréia. Distúrbios da função reprodutiva em atletas ocorrem devido à deficiência da ingestão de energia frente ao aumento do gasto energético produzido pelo exercício (DE SOUZA; WILLIAMS, 2004). Mulheres atletas apresentam hipoleptinemia independentemente da ocorrência ou não de alterações no ciclo menstrual e naquelas com amenorréia, observa-se ausência do ritmo diurno da leptina (LAUGHLIN; YEN 1997).

A superalimentação em ratas resulta em aumento do peso corporal com início precoce da puberdade e aumento da expressão de leptina e kisspeptina no hipotálamo, enquanto a subnutrição produz efeitos opostos com redução do peso dos ovários e útero (CASTELLANO, 2011).

Assim, quantidade adequada de tecido adiposo é necessária para que a puberdade ocorra, já que tanto o seu excesso quanto sua falta causam hipogonadismo e atraso na puberdade (YURA, 2000).

Apesar da importância do tecido adiposo para a puberdade, pouco se sabe a respeito do processo de formação deste tecido neste período da vida.

A formação do tecido adiposo ocorre por meio do aumento do tamanho da célula pela lipogênese como já descrito anteriormente e por meio do aumento de seu número pelo processo de adipogênese.

A adipogênese é a capacidade dos pré-adipócitos, presentes no parênquima do tecido, de se diferenciarem em novos adipócitos. Células multipotentes do tecido adiposo dão origem aos pré-adipócitos que são semelhantes a fibroblastos especializados comprometidos com a formação de adipócitos. Durante a diferenciação, ocorre alteração do citoesqueleto e proteínas da matriz extracelular 
e a formação da maquinaria para a síntese de lipídios gerando o adipócito maduro (SORISKY; GAGNON, 2002).

Segundo, Rosen e Spiegelman (2000), podem-se identificar diferentes fases do processo de adipogênese. O primeiro estágio da adipogênese é o período do processo de diferenciação em que ocorre a interrupção da proliferação celular. Em cultura, o disparo do fim das mitoses se dá durante a confluência das células devido à inibição por contato. In vivo a proliferação celular cessa por influência de controle hormonal. Antes que a proliferação cesse completamente, ocorrem um ou dois ciclos adicionais da divisão mitótica denominada de expansão clonal, que consiste a segunda fase da adipogênese. Ainda, segundo Rosen e Spiegelman (2000), a última fase da adipogênese caracteriza-se pela diferenciação propriamente dita com a formação do adipócito maduro.

As diferentes etapas da adipogênese são reguladas por quatro fatores de transcrição chaves deste processo, as proteínas ligantes ao amplificador CCAAT (CEBPs) $\beta, \delta$, a e receptor yativado por proliferadores de peroxissomas (PPAR-y), expressos em uma sequência definida coordenando a série de fases da adipogênese.

CEBP $\beta$ e $\delta$ são os primeiros fatores de transcrição expressos na adipogênese, logo em sua fase inicial, mas não estão imediatamente ativos, tornando-se competentes a se ligarem ao elemento regulador de CEBP (na região promotora do CEBP-a) próximo à fase de início da expansão clonal (TANG; LANE, 1999).Este atraso da capacidade de ligação a regiões promotoras de genes difere em estudo in vivo em que o início da expressão de CEBP $\beta$ e $\delta$ coincide com sua atividade regulatória nas regiões promotoras dos genes CEBP- $\alpha$ e PPAR-y assim como dos genes específicos do adipócito (SALMA; XIAO; IMBALZANO, 2006).Durante a fase mitótica, os pré-adipócitos expressam altos níveis de CEBP- $\beta$ e CEBP-ס (CAO; UMEK; MCKNIGHT, 1991; YEH, 1995a) sendo a expressão de CEBP- $\beta$ necessária para que ocorra a fase de expansão clonal (TANG; OTTO; LANE, 2003a).

O aumento de CEBP- $\delta$ estimula a transcrição de CEBP- $\beta$ (YEH, 1995b) e ambos irão induzir a expressão de CEBP-a (LANE; TANG; JIANG, 1999; TANG, 2005), assim como de PPAR-y (TANG, 2005; WU, 1995). 
A expressão de CEBP- $\alpha$ é necessária para que a parada do crescimento celular se mantenha nas fases pós-mitóticas da adipogênese (TAO; UMEK, 2000; UMEK; FRIEDMAN; MCKNIGHT, 1991), além disso, conjuntamente com PPAR-Y têm por função ativar a região promotora de vários genes específicos dos adipócitos promovendo a formação de seu fenótipo característico (CHRISTY, 1989; MACDOUGALD; LANE, 1995;TANG; OTTO; LANE, 2003b).

A análise da capacidade de hipertrofia dos adipócitos promovida pela lipogênese assim como de sua hiperplasia resultante da adipogênese no período puberal permitem a compreensão do desenvolvimento deste tecido essencial para o desenvolvimento normal.

Neste contexto da função reprodutiva, o tecido adiposo periepididimal vem se mostrando de grande importância. Alguns trabalhos demonstram uma íntima relação entre o tecido adiposo periepididimal e a função reprodutora (CHU, 2010; FLORYK, 2011; HANSEL, 2010).

A remoção do tecido periepididimal de camundongos produz interrupção da espermatogênese com aumento da concentração de FSH sem alterações, porém, do comportamento sexual e das concentrações de LH e testosterona (CHU, 2010). Da mesma forma, as gônadas masculinas são importantes para a manutenção do tecido adiposo periepididimal uma vez que a castração produz redução deste coxim (FLORYK, 2011).

Assim, o coxim periepididimal demonstra-se importante na análise do desenvolvimento do tecido adiposo puberal, tendo sido selecionado para este estudo, assim como o coxim adiposo subcutâneo inguinal o qual não tem relação direta clara como sistema reprodutor.

No contexto da puberdade, hormônios essenciais a este período possuem modulação sobre o metabolismo do tecido adiposo.

Além de sua função sobre a maturação do eixo hipotálamo-hipófisegônadas, a leptina tem efeitos sobre o metabolismo de glicose e sensibilidade à insulina.

A leptina aumenta a sensibilidade à insulina sistêmica (BARZILAI, 1998; KAMOHARA, 1997; SIVITZ, 1997), porém tem efeitos tecido-específicos (WANG, 1999). A leptina aumenta a captação de glicose em músculos e tecido adiposo marrom, porém reduz a capacidade de captação de glicose em tecido adiposo 
branco (MULLER, 1997; WANG, 1999). A leptina estimula a lipólise no tecido adiposo branco (CHEN, 1996; FRUHBECK; GOMEZ-AMBROSI; SALVADOR, 2001) assim como inibição da lipogênese (BUETTNER, 2008; CEDDIA, 1998; CEDDIA, 2000).

Além da leptina, outros importantes hormônios da puberdade interferem com o metabolismo do tecido adiposo.

O hormônio do crescimento $(\mathrm{GH})$ destaca-se entre os vários hormônios em razão de seus importantes efeitos sobre o metabolismo do tecido adiposo. Os préadipócitos assim como os adipócitos maduros possuem receptor de $\mathrm{GH}$, embora alguns efeitos possam ser exercidos indiretamente pela secreção de fator de crescimento insulina-símile 1 (insulin like growth factor 1[IGF-1]) (CARREL;ALLEN, 2000).

$\mathrm{O}$ GH inibe a síntese de triacilglicerol no tecido adiposo pela redução da atividade da lipase de lipoproteínas (JOHANSEN, 2003; MURASE; YAMADA; MATSUZAKI, 1981; OSCARSSON; OTTOSSON; EDEN, 1999; OTTOSSON, 1995) e contribui para a redução do triacilglicerol por diminuir a inibição da insulina sobre a lipase hormônio sensível (JOHANSEN, 2003). Além disso, estimula diretamente a lipólise por aumentar a atividade da lipase hormônio sensível (DIETZ; SCHWARTZ, 1991).

$\mathrm{O} \mathrm{GH}$, ainda, modula a sensibilidade à insulina. Em situações de excesso de GH ocorre hiperinsulinemia e resistência à insulina (CLEMMONS, 2002; NG, 1990; ROSE; CLEMMONS, 2002). A sua administração exógena também produz prejuízo no metabolismo de glicose em doses fisiológicas e suprafisiológicas em humanos e animais (DOMINICI, 2005). Em situações fisiológicas, como o jejum e estresse, GH contra regula a ação da insulina.

Outro hormônio central para o desenvolvimento da puberdade é a testosterona. É um importante regulador da sensibilidade à insulina, sendo que alterações em suas concentrações fisiológicas resultam em redução da sensibilidade sistêmica à insulina (LIVINGSTONE; COLLISON, 2002).

Tanto a ausência de testosterona como seu excesso (altas concentrações) causam resistência à insulina em ratos e humanos (HOLMANG;BJORNTORP,1992; PITTELOUD, 2005). 
Em estudo realizado por Macotela e colaboradores (2009), foi demonstrado que a castração em camundongos produz aumento da sensibilidade à insulina no tecido adiposo com aumento da expressão gênica de GLUT-1 e das enzimas ácido graxo sintase (FAS) e acetil-CoA carboxilase (ACC) no coxim subcutâneo (SC), assim como aumento da capacidade lipogênica dos tecidos adiposos SC e PE.

Os estudos sobre testosterona e sensibilidade à insulina utilizam, em sua maioria, a técnica de clamp euglicêmico hiperinsulinêmico e capacidade de captação de glicose em músculos para avaliar a sensibilidade à insulina. Assim, o trabalho de Macotela e colaboradores (2009) indica que a testosterona parece ter um efeito diferente sobre $o$ tecido adiposo, pois a castração resultou em melhora da sensibilidade à insulina mensurada pelo aumento de sua capacidade lipogênica.

A testosterona em concentrações fisiológicas estimula lipólise em tecido adiposo de ratos por estimular aumento dos receptores $\beta$-adrenérgicos (ARNER, 2005; XU; DE PERGOLA; BJORNTORP, 1991; XU, 1993) e diminui a atividade da lipase de lipoproteína (HAUG, 1986) assim como a captação de ácidos graxos pelo tecido adiposo resultando, portanto, em redução da quantidade de tecido adiposo.

As alterações hormonais da puberdade devem influenciar o metabolismo do tecido adiposo refletindo em um perfil metabólico característico deste período da maturação do animal. Assim, já que este tecido desempenha um papel permissivo à maturação do eixo hipotálamo-hipófise-gônadas através da leptina é importante que se conheça suas especificidades metabólicas neste período.

Além disso, atualmente a incidência global de importantes morbidades relacionadas a alterações no tecido adiposo como a obesidade e o diabetes mellitus têm aumentado em jovens e crianças (PINHAS-HAMIEL; ZEITLER, 2005; ROSENBLOOM, 2009; WANG; MONTEIRO; POPKIN, 2002)o que reforça a importância de se compreender este tecido durante esta fase da vida.

Outro fator que corrobora a importância do estudo do tecido adiposo no período puberal éa quantidade de pesquisas que utilizam tratamentos ou mesmo indução de doenças metabólicas desde o desmame em ratos e que, portanto, englobam o período da puberdade. Desta forma, nosso estudo sobre as especificidades do metabolismo do tecido adiposo puberal contribuiria para uma melhor análise dessas pesquisas. 


\section{OBJETIVOS}

- Estudar o metabolismo de carboidratos no tecido adiposo branco durante a puberdade frente à importância deste tecido para a maturação sexual.

- Analisar a capacidade de captação de glicose pelo tecido adiposo subcutâneo e periepididimal na puberdade.

- Estudar a capacidade lipogênica dos coxins adiposos subcutâneo e periepididimal na puberdade.

- Verificar se a intolerância à glicose puberal conjuntamente com a especificidade do metabolismo do tecido adiposo neste período privilegiam a sua formação.

- Verificar se há um desenvolvimento mais intenso do coxim adiposo periepididimal relacionado à sua importância na função reprodutora. 


\section{DESENHO EXPERIMENTAL E METODOLOGIAS}

\subsection{Animais}

Todos os procedimentos experimentais realizados estão de acordo com os Princípios Éticos na Experimentação Animal e foram aprovados pela Comissão de Ética em Experimentação Animal (CEEA) do Instituto de Ciências Biomédicas da Universidade de São Paulo ( $n^{\circ} 106$ nas fls.61 do livro 02).

Foram utilizados ratos Wistar machos com 4 a12 semanas de vida fornecidos pelo Biotério Central do Instituto de Ciências Biomédicas da Universidade de São Paulo.

Os ratos foram mantidos neste biotério de experimentação em caixas coletivas (2 animais/caixa), sob condições de temperatura ambiental controlada de 25ํㅡ, ciclo de iluminação claro/escuro de 12/12 horas (período claro iniciado às 6h) e exaustão de amônia controlada. Os animais receberam ração balanceada padrão (Nuvital $^{\circledR}$, Quimtia) e água 'ad libitum'.

\subsection{Identificação do período de início da puberdade}

A identificação do momento de início da puberdade foi realizada através da análise de um perfil de desenvolvimento corporal e maturação sexual dos animais. O estudo foi desenvolvido entre $a 4^{a}$ e a $12^{a}$ semanas de vida, período durante 0 qual grupos de animais foram sacrificados semanalmente. Foram analisados 0 peso corporal, comprimento naso-anal, peso dos coxins adiposos subcutâneo (SC) e periepididimal (PE), peso dos testículos, epidídimo, canal deferente e vesículas seminais.

O consumo hídrico e alimentar assim como o aumento de peso corporal foram mensurados semanalmente em um mesmo grupo. Os outros parâmetros de desenvolvimento analisados foram determinados no dia do sacrifício, havendo, portanto um grupo representativo de cada semana de vida.

Estas observações visaram identificar o período de crescimento mais acelerado do animal com o intuito de se obter um indício sobre o momento inicial da puberdade. 
Além disso, no dia do sacrifício, foi realizada coleta de soro para posteriores dosagens dos níveis de testosterona, glicose, insulina, leptina e adiponectina.

\subsection{Sacrifício dos animais e extração dos tecidos}

Os animais foram submetidos à anestesia por tiopental sódico (Thiopentax ${ }^{\circledR}$, Cristália Químicos, Itapira, S. P., Brasil, 5 mg/ 100 g de p.c.), e sacrificados em diferentes semanas de vida (4⿳亠丷a a $12^{a}$ semana), em jejum prévio de 12 horas, por decapitação, à qual se seguiu a coleta de sangue do tronco em tubos sem anticoagulante para posterior análise das concentrações de testosterona, glicose, insulina, leptina e adiponectina. O soro foi obtido mediante a centrifugação a $4^{\circ} \mathrm{C}$ a $850 \times g$ durante 20 minutos e armazenado a $-20^{\circ} \mathrm{C}$ até a realização das dosagens. Foram coletados os tecidos adiposos brancos SC e PE e seus adipócitos foram isolados e submetidos, in vitro, a testes biológicos para avaliação das taxas basais ou maximamente estimuladas por insulina de captação de $\left[{ }^{3} \mathrm{H}\right]$-2-desoxi-D-glicose $\left({ }^{3} \mathrm{H}-2 \mathrm{DG}\right)$, de incorporação de D-[U- $\left.{ }^{14} \mathrm{C}\right]$-glicose em lipídeos e de Incorporação de D-[U- $\left.{ }^{14} \mathrm{C}\right]$-Glicose em Ácidos Graxos de Triacilglicerol. Além disso, foram coletadas as estruturas internas da genitália (testículos, epidídimo, canal deferente e vesículas seminais) para pesagem. Os testes biológicos foram realizados apenas na $5^{\underline{a}}, 6^{\underline{a}}, 7^{\underline{a}}$ e $12^{\underline{a}}$ semanas de vida dos animais, sendo que a $5^{\underline{a}}, 6^{\underline{a}}$ e $7^{\underline{a}}$ semanas representam as semanas iniciais da puberdade enquanto, na $12^{\underline{a}}$, os animais já são considerados adultos jovens.

\subsection{Isolamento dos adipócitos e análise morfométrica}

Os adipócitos do tecido adiposo SC e PE foram isolados mediante a técnica de digestão de tecido pela colagenase, descrita por Rodbell (1964), com algumas modificações para adaptar o método às nossas condições laboratoriais. Em resumo, $1 \mathrm{~g}$ do coxim adiposo SC e PE foi retirado, picado com tesoura em finos fragmentos e estes foram incubados em $4,0 \mathrm{~mL}$ de tampão digestivo [DMEM, HEPES 25 mM, BSA 4\%, colagenase tipo II (Sigma Chemical ${ }^{\circledR}$, St. Louis, Missouri, Estados Unidos) $1,25 \mathrm{mg} / \mathrm{mL}, \mathrm{pH} \mathrm{7,45]} \mathrm{por} \mathrm{cerca} \mathrm{de} 60 \mathrm{~min}$ a $37^{\circ} \mathrm{C}$ em banhomaria com agitação orbital (150 rpm). Em seguida, a amostra foi filtrada em peneira 
plástica com malha fina (que retém restos teciduais e vasos não digeridos) e lavada por três vezes com $25 \mathrm{~mL}$ de tampão EHB (sais de EARLE, HEPES 25 mM, BSA 1 \%, piruvato de sódio $1 \mathrm{mM}$, sem glicose, $\mathrm{pH} 7,45)$ mantido a $37^{\circ} \mathrm{C}$. Para a determinação do lipócrito (porcentagem de adipócitos contidos na suspensão celular total), aproximadamente $40 \mu \mathrm{L}$ da suspensão celular em tampão EHB foram colocados em capilar de vidro e submetidos à centrifugação (1000 rpm por 1 min). O volume total da suspensão corresponde a 100\% e o volume de adipócitos obtido após a centrifugação nos fornece o lipócrito da amostra. Para análise morfométrica, alíquotas de suspensão celular foram fotografadas em microscópio óptico (aumento de 100x) e as células tiveram seus diâmetros mensurados através de análise digital computadorizada realizada pelo programa Motic Image Plus 2.0. Para tal, foram medidas 50 células selecionadas aleatoriamente. A partir do diâmetro celular médio e admitindo-se que o adipócito isolado é esférico, o volume e o número de células foram calculados de acordo com as seguintes fórmulas:

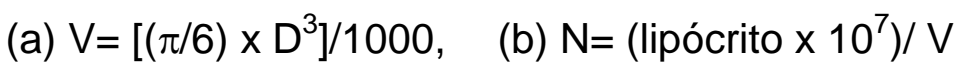

Onde $D$ é o diâmetro médio de 50 adipócitos $(\mu \mathrm{m}), \mathrm{N}$ é o número de células e $\mathrm{V}$ é o volume médio (DI GIROLAMO; MENDLINGER; FERTIG, 1971). A divisão por 1000 em (a) visa expressar o volume em picolitros ( $\mathrm{pL})$.

O cálculo indireto da celularidade dos coxins adiposos foi realizado mediante a divisão da massa total do coxim pela massa média dos adipócitos do mesmo. A massa do adipócito foi calculada segundo a seguinte fórmula:

$$
\mathbf{d}=\mathbf{m} / \mathbf{v}
$$

Em que d é a densidade média de um adipócito $(0,91 \mathrm{~g} / \mathrm{mL}), \mathbf{m}$ a massa do adipócito (em pg [10-9 $\mathrm{mg}]$ ) e $\mathbf{v}$ o volume médio do adipócito (em $\mathrm{pL}\left[10^{-9} \mathrm{~mL}\right]$ ).

\subsection{Determinação da glicemia}

A glicose sérica foi determinada através de método enzimático da glicoseoxidase (LOTT; TURNER, 1975). Este consiste na oxidação enzimática da glicose através da glicose-oxidase (GOD) gerando ácido glicônico e água oxigenada. Esta, em presença da peroxidase (POD), oxida um cromógeno com máximo de absorção em $505 \mathrm{~nm}$ de comprimento de onda, a partir da ligação oxidativa do fenol com 4aminoantipirina (4-APP). No ensaio, $10 \mu \mathrm{L}$ de amostra ou do padrão $(100 \mathrm{mg} / \mathrm{dL})$ 
foram adicionadas a $1 \mathrm{~mL}$ de reagente de cor ( $\mathrm{pH} 7,4$, fenol e GOD/POD) e, em seguida, submetidas a incubação em banho-maria a $37{ }^{\circ} \mathrm{C}$ durante 15 minutos seguido de leitura em espectrofotômetro (Biopack, Power WaveTM XS, Winooski, Vermont, Estados Unidos ) (505 nm).

\subsection{Determinação da insulinemia}

A dosagem de insulina foi realizada através de radioimunoensaio, utilizando-se o kit RI-13K (Linco Research Inc., St. Charles, Missouri, Estados Unidos), específico para insulina de rato. $O$ procedimento foi desenvolvido segundo as especificações do fabricante.

\subsection{Determinação da concentração de testosterona}

A dosagem de testosterona foi realizada pelo princípio de radioimunoensaio com o kit Coat-A-Count Total Testosterone (Siemens, Los Angeles, Califórnia, Estados Unidos), seguindo-se as recomendações do fabricante.

\subsection{Determinação da concentração de leptina}

A leptina foi dosada por radioimunoensaio utilizando-se anticorpo espécieespecífico. O kit utilizado foi o RL-83K (Linco Research, St Charles, Missouri, Estados Unidos) e o procedimento de dosagem foi realizado segundo as especificações do fabricante.

\subsection{Determinação da concentração de adiponectina}

A dosagem de adiponectina foi realizada por radioimunoensaio (mouse adiponectin RIA kit MADP - 60HK, Millipore, St. Charles, Missouri, Estados Unidos) seguindo-se as especificações do fabricante. 


\subsection{Teste oral de tolerância à glicose (G.T.T. Oral)}

Para a determinação da curva glicêmica após sobrecarga de glicose oral, os animais em jejum prévio de 12 horas receberam uma dose de glicose $(75 \mathrm{mg} / 100 \mathrm{~g}$ p.c.) por gavagem. Realizou-se a medida da glicemia capilar caudal, através de glicosímetro (One Touch Ultra, Johnson \&Johnson, New Brunswick, New Jersey), em diferentes momentos: 0 (pré-injeção), 5, 15, 20, 30, 60 e 90 minutos após a administração de glicose. Este teste foi realizado em animais com 4 a 12 semanas de vida.

\subsection{Teste de captação de $\left[{ }^{3} \mathrm{H}\right]-2 D G$ em adipócitos isolados}

As taxas de captação de ${ }^{3} \mathrm{H}-2 \mathrm{DG}$ em adipócitos isolados foram medidas na ausência (basal) e na presença de insulina em concentração efetiva máxima (10 $n M)$. A ${ }^{3} \mathrm{H}-2 \mathrm{DG}$ é captada pela célula e transformada em ${ }^{3} \mathrm{H}-2 \mathrm{DG}-6-\mathrm{P}$, porém, a partir desta etapa, não é mais metabolizada e atua como inibidor alostérico da enzima subsequente da via glicolítica, a fosfo-glico-mutase.

Alíquotas de $40 \mu \mathrm{L}$ de suspensão celular (lipócrito conhecido por amostra) foram pipetadas em tubos plásticos, contendo ou não $2 \mu \mathrm{L}$ de insulina (concentração final de $10 \mathrm{nM}$ ) e incubadas por $15 \mathrm{~min}$ a $37^{\circ} \mathrm{C}$. Em seguida, foram adicionados $10 \mu \mathrm{L}$ de ${ }^{3} \mathrm{H}-2 \mathrm{DG}$ (concentração final de $0,4 \mathrm{mM}$ e 0,05 $\mu \mathrm{Ci} /$ tubo) e, passados 3 min exatos, o transporte foi interrompido com a adição de $250 \mu \mathrm{L}$ de phloretin 0,6 mM (em tampão EHB e DMSO 0,05\%) a $4{ }^{\circ} \mathrm{C}$. Para avaliação da taxa de captação, $200 \mu \mathrm{L}$ da mistura final foram transferidos para tubos de microcentrífuga $(0,45 \mathrm{~mL})$ contendo $200 \mu \mathrm{L}$ de óleo de silicone (densidade 0,963 $\mathrm{g} / \mathrm{mL}$ ) que foram centrifugados por $10 \mathrm{~s}$ (microcentrífuga $\mathrm{E}$, Beckman Instruments, Palo Alto, Califórnia, Estados Unidos).

A centrifugação teve como objetivo separar a mistura em três fases: uma superior, contendo as células compactadas (agregado celular), uma intermediária correspondente ao óleo e uma terceira, mais inferior, constituída pelo tampão aquoso. Após a separação, a porção contendo o agregado celular foi recolhida mediante a secção do tubo com um estilete na altura da porção média da camada 
de óleo, transferida para um tubo contendo $2,5 \mathrm{~mL}$ de líquido de cintilação (EcoLume $^{T M}$, ICN Pharmaceuticals, Costa Mesa, Califórnia, Estados Unidos) e a radiação emitida foi aferida em contador beta (MicroBeta TriLux, PerkinElmer,Waltham, Massachusetts, Estados Unidos). Para a determinação da incorporação inespecífica, foram adicionados, primeiramente a suspensão celular $(40 \mu \mathrm{L})$ em um tubo de ensaio e em seguida o phloretin (inibidor do transporte de glicose), antes de se acrescentar ${ }^{3} \mathrm{H}-2 \mathrm{DG}$. Os resultados foram expressos em $\mathrm{pmol} / \mathrm{cm}^{2}$ de superfície celular e também em nmol por $10^{6}$ células.

\subsection{Teste de incorporação de $\mathrm{D}-\left[\mathrm{U}-{ }^{14} \mathrm{C}\right]$-glicose em triacilglicerol}

Adipócitos isolados foram colocados em tubos de ensaio de polipropileno 17x100 mm contendo tampão Krebs/Ringer/Fosfato/BSA 1\%/glicose 2 mM, pH 7,45 a $37{ }^{\circ} \mathrm{C}$, saturado de uma mistura gasosa de carbogênio $5 \%$ e $5 \mu \mathrm{L}$ de $\mathrm{D}-\left[\mathrm{U}-{ }^{14} \mathrm{C}\right]$ glicose (2 mM e 0,05 uCi/tubo), com ou sem insulina (10 nM) onde permaneceram por duas horas. Após este período, foi realizada a extração dos lipídeos mediante a adição de 2,5 mL de reativo de Dole (isopropanol:n-heptano: $\mathrm{H}_{2} \mathrm{SO}_{4} 8 \mathrm{~N}, 4: 1: 0,25$ v:v:v) no meio de incubação (DOLE; MEINERTZ, 1960). A mistura foi agitada por 45 vezes (sessões de 10s) em vórtex por $30 \mathrm{~min}$. Ao final desse período, foi adicionado 1,5 mL de $\mathrm{n}$-heptano e 1,5 $\mathrm{mL}$ de água deionizada seguido de agitação em vórtex. Após a mistura ter decantado, alíquotas de $0,5 \mathrm{~mL}$ da fase superior (contendo os lipídeos extraídos no $\mathrm{n}$-heptano) foram transferidas para flaconetes. Após a evaporação do n-heptano, foram adicionados $2,5 \mathrm{~mL}$ de coquetel de

cintilação biodegradável (EcoLume ${ }^{\mathrm{TM}}$, ICN Pharmaceuticals) para contagem da radioatividade beta incorporada (LIMA; BAO; GARVEY, 1994;RODBELL, 1964). Os resultados foram expressos em nmol. $10^{-6}$ cels $^{-1} \cdot \mathrm{h}^{-1}$.

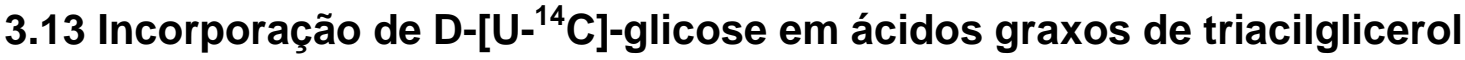

Uma fração da glicose incorporada em lipídios é resultante da síntese de AG a partir de substratos glicídicos, processo denominado lipogênese de novo. A partir disso, este teste objetiva avaliar a fração de glicose incorporada em AG de TAG. Da mistura composta por TAG, previamente obtida no teste de incorporação de D- 
$\left[\mathrm{U}-{ }^{14} \mathrm{C}\right]$-Glicose em lipídios, foram retirados $1 \mathrm{~mL}$ os quais foram submetidos a secagem completa utilizando-se $\mathrm{N}_{2}$ gasoso. Após este processo, adicionaram-se 1 $\mathrm{mL}$ de etanol (95\%) e $250 \mu \mathrm{L}$ de $\mathrm{KOH} \mathrm{(40 \% )} \mathrm{e} \mathrm{os} \mathrm{tubos} \mathrm{de} \mathrm{ensaio} \mathrm{foram}$ frouxamente tampados e colocados em banho-maria, a $60^{\circ} \mathrm{C}$ por 1 hora. Em seguida, o material foi resfriado à temperatura ambiente por aproximadamente 10 minutos e, logo após, adicionaram-se $2 \mathrm{~mL}$ de $\mathrm{HCL}(3 \mathrm{~N})$ e $2 \mathrm{~mL}$ de n-heptano. Esta mistura foi homogeneizada em vórtex e deixada em repouso por 10 minutos. Uma amostra de $1000 \mu \mathrm{L}$ da fase superior desta mistura foi retirada e transferida para um vial.Após a evaporação do n-heptano, adicionou-se2,5 mL de líquido de cintilação ao vial e finalmente levou-se ao contador beta por 5 minutos.

\subsection{Determinação da atividade de enzimas lipogênicas}

As amostras de TA foram submetidas à extração em tampão - sacarose (250 mM), EDTA (1 mM), DTT (1 mM), leupeptina $(50 \mu \mathrm{M})$ e aprotinina $(5 \mu \mathrm{M}) \mathrm{com}$ $\mathrm{pH} 7,4$ - as amostras foram homogeneizadas por 30 segundos em Polytron e submetidas a centrifugação a $20.000 \mathrm{~g}$ a $0 \stackrel{\circ}{\mathrm{C}}$ por 5 minutos. No homogenato livre de gordura (fat cake free), as atividades foram determinadas a $340 \mathrm{~nm}$, sendo 0 coeficiente de extinção para este comprimento de onda igual a 6,22, durante tempo e temperatura específicos para cada enzima. A atividade máxima enzimática foi obtida através da inclinação da curva de absorbância $x$ tempo. As proteínas foram quantificadas pelo kit de ensaio proteico BCA ${ }^{\text {TM }}$ (PIERCE Biotechnology, Rockford, Illinois, Estados Unidos). Os resultados foram expressos em $\mathrm{nmol} / \mathrm{minuto}$ por $\mathrm{mg}$ de proteína presente no extrato.

\subsubsection{Atividade da enzima ácido graxo sintase (FAS)}

A atividade da FAS foi determinada segundometodologia aplicada conforme Bazin e Ferré (2001). O tampão de ensaio utilizado (260 $\mu \mathrm{L})$ consistiu de $\mathrm{KH}_{2} \mathrm{PO}_{4}$ (100 mM), acetil-CoA $(100 \mu \mathrm{M})$ e NADPH $(200 \mu \mathrm{M}), \mathrm{pH}=6,5$. A reação foi iniciada com a adição de $10 \mu \mathrm{L}$ da solução de malonilCoA $(600 \mu \mathrm{M})$ e $\mathrm{KH}_{2} \mathrm{PO}_{4}(100 \mathrm{mM})$ ao extrato enzimático, sendo acompanhada por 10 minutos de leitura ( $\left.37^{\circ} \mathrm{C}\right)$. 


\subsubsection{Atividade da enzima málica (EM)}

Para a determinação da atividade máxima da EM foi utilizada a metodologia aplicada conforme Bazin e Ferré (2001), utilizando-se tampão de ensaio (270 $\mu \mathrm{L})$ contendo, Tris-HCL (200 mM), $\mathrm{MgCl}_{2} 6 \mathrm{H}_{2} \mathrm{O}$ (20 mM) e NADP (2 mM), pH 7,4. A reação foi iniciada com a adição de $15 \mu \mathrm{L}$ da solução de malato (100 mM), Tris$\mathrm{HCL}(200 \mathrm{mM})$ e $\mathrm{MgCl}_{2} 6 \mathrm{H}_{2} \mathrm{O}(20 \mathrm{mM}), \mathrm{pH} 7,4$ ao extrato enzimático, sendo acompanhada por 10 minutos de leitura $\left(37^{\circ} \mathrm{C}\right)$.

\subsubsection{Atividade da enzima glicose-6-fosfato desidrogenase (G6PDH)}

A atividade da G6PDH foi determinada segundo metodologia aplicada conforme Bergmeyer (1974). O tampão de ensaio utilizado $(270 \mu \mathrm{l})$ consistiu de Tris-HCL (8,6 mM) e $\mathrm{MgCl}_{2}$ (6,9 mM), NADP (0,4 mM) e Triton X-100 (1\% (v/v), pH 7,6). A reação foi iniciada com a adição de $15 \mu$ de glicose-6-fosfato $(1,2 \mathrm{mM})$ ao extrato enzimático, sendo acompanhada por 10 minutos de leitura $\left(25^{\circ} \mathrm{C}\right)$.

\subsection{Expressão Gênica de transportadores de glicose 1 e 4 (GLUT-1, GLUT-4), Leptina, Adiponectina e Receptorde Andrógeno no Tecido Adiposo}

\subsubsection{Extração de RNA total}

Amostras de $200 \mathrm{mg}$ dos tecidos adiposos PE e SC foram homogeneizadas em Polytron ${ }^{\circledR}$ (PT 3100, Kinematica AG, Lucerna, Lucerna, Suíça) por 30 segundos com Trizol na proporção de $1 \mathrm{~mL}$ para cada $100 \mathrm{mg}$ de amostra, seguindo-se as especificações do fabricante (Trizol Reagent ${ }^{\circledR}$, Invitrogen, Life Technologies, Carlsbad, Califórnia, Estados Unidos). A seguir, os homogenatos foram aliquotados em tubos de $1 \mathrm{~mL}$ e armazenados à $-70^{\circ} \mathrm{C}$ para posterior extração.

$\mathrm{Na}$ etapa da extração, as amostras foram incubadas por 5 minutos em temperatura ambiente $\left(15-25^{\circ} \mathrm{C}\right)$ para permitir a completa dissolução dos complexos nucleoproteicos. Em seguida, 0,2 $\mathrm{mL}$ de clorofórmio foi adicionado aos tubos, agitando-se vigorosamente em vórtex, por 15 segundos, com posterior incubação à temperatura ambiente por 2 a 3 min. A mistura foi centrifugada a 
$12000 \times \mathrm{g}$ por $15 \mathrm{~min}$, a $4^{\circ} \mathrm{C}$ com a formação de 3 fases. A fase aquosa superior, contendo RNA, foi transferida para outro tubo e o RNA foi precipitado pela adição de $0,5 \mathrm{~mL}$ de isopropanol. O material foi incubado por $10 \mathrm{~min}$ a temperatura ambiente e novamente centrifugado a $12000 \times \mathrm{g}$ por $10 \mathrm{~min}$ a $4^{\circ} \mathrm{C}$. O sobrenadante foi então removido e o sedimento lavado pela adição de $1 \mathrm{~mL}$ de etanol $75 \%$, com posterior centrifugação a $7000 \mathrm{xg}$ por $5 \mathrm{~min}$ a $4^{\circ} \mathrm{C}$. Posteriormente, removeu-se novamente por inversão a porção líquida do tubo e deixou-se o pellet secar ao ar, em seguida, o pellet foi dissolvido em aproximadamente $25 \mu \mathrm{L}$ de água deionizada autoclavada em dietilpirocarbonato (DEPC).

O RNA total foi quantificado em leitura espectrofotométrica a $260 \mathrm{~nm}$. Para análise da pureza do RNA, adotou-se o cálculo da razão do valor da absorbância a $260 \mathrm{~nm}$ pelo valor da absorbância a $280 \mathrm{~nm}$ (comprimento de onda definido para leitura de proteínas), onde se estipulou como razão ideal para aceitação da amostra o intervalo entre 1,6-2,0. Alíquotas de $8 \mu \mathrm{L}$ de amostras contendo $5 \mu \mathrm{g}$ de RNA total diluídos em água DEPC foram armazenadas a $-70^{\circ} \mathrm{C}$.

\subsubsection{Síntese de cDNA por transcrição reversa}

Na etapa inicial, pipetou-se $1 \mu \mathrm{L}$ de tampão de DNAse (10x) e $1 \mu \mathrm{L}$ da enzima DNAse $(1 \mathrm{U} / \mu \mathrm{L})$ em tubos contendo $5 \mu \mathrm{g}$ de RNA total. A mistura foi incubada a $25^{\circ} \mathrm{C}$ por 15 min. com a finalidade de evitar uma possível amplificação de DNA genômico que poderia contaminar o RNA extraído. A seguir, adicionou-se $1 \mu \mathrm{L}$ de EDTA $25 \mathrm{mM}$ e a mistura foi submetida a incubação a $65^{\circ} \mathrm{C}$ por $10 \mathrm{~min}$. Na etapa seguinte (síntese de DNA), pipetou-se $1 \mu \mathrm{L}$ de oligo DTs $146 \mathrm{ng} / \mu \mathrm{L}$, seguido de incubação a $70^{\circ} \mathrm{C}$ por $10 \mathrm{~min}$. Terminada a reação, $4 \mu \mathrm{L}$ de tampão da enzima transcriptase reversa $(5 \mathrm{x}), 2 \mu \mathrm{L}$ de ditiotreitol (DTT) $0,1 \mathrm{M}, 1 \mu \mathrm{L}$ de mistura de dNTPs $10 \mathrm{mM}$ foram adicionados à mistura, a qual foi então incubada a $25^{\circ} \mathrm{C}$ por 10 min. e, em seguida, a $42^{\circ} \mathrm{C}$ por $2 \mathrm{~min}$. $\mathrm{Na}$ etapa final, $1 \mu \mathrm{L}$ da enzima transcriptase reversa (SuperScript ${ }^{\circledR}$ III, Invitrogen, São Paulo, SP, Brasil) foi acrescido à mistura, submetida à incubação a $50^{\circ} \mathrm{C}$ por 50 min. e mais $5 \mathrm{~min}$. a $85^{\circ} \mathrm{C}$. As incubações foram realizadas em termociclador Mastercycler gradient (Eppendorf ${ }^{\circledR}$, 
Hamburg, HH, Alemanha). O material obtido (cDNA) foi então mantido em freezer a $-20^{\circ} \mathrm{C}$ até a realização da próxima etapa - amplificação por PCR.

\subsubsection{PCR quantitativo (real time)}

O teste de diluição das amostras (curva de diluição seriada (10X) com cinco pontos) foi realizado para identificação da melhor quantidade de cDNA para a reação de PCR. Alíquotas de $1 \mu \mathrm{L}$ de amostra de CDNA (SC - diluição 1:100 e PE - diluição 1:10) obtida a partir da reação de RT-PCR foram adicionadas a um mix contendo $5 \mu \mathrm{L}$ de Applied Biosystems ${ }^{\circledR}$ (Life Technologies, Carlsbad, Califórnia, Estados Unidos) TaqMan ${ }^{\circledR}$ Gene Expression Master Mix(contém: AmpliTaq Gold ${ }^{\circledR}$ DNA Polymerase UP (Ultra Pure), Uracil-DNA Glycosylase, dNTPs com dUTP, Passive Reference 1 e estabilizantes), $0,5 \mu \mathrm{L}$ de primer TaqMan® Gene Expression Assays e 3,5 $\mu \mathrm{L}$ de $\mathrm{H}_{2} \mathrm{O}$ DEPC autoclavada. As reações de PCR foram realizadas em aparelho StepOnePlus ${ }^{\mathrm{TM}}$ Real-Time PCR System da Applied Biosystems ${ }^{\circledR}$. A reação de PCR iniciou-se com um período 10 min a 95ํㅡ para a ativação da AmpliTaq Gold ${ }^{\circledR}$ DNA Polymerase. Esta fase só ocorre no primeiro ciclo de reação. As etapas seguintes envolvem desnaturação da fita de cDNA a temperatura de $95 \stackrel{\circ}{\circ}$ por $30 \mathrm{~s}$, fase de anelamento do primer a temperatura específica de cada primer por $30 \mathrm{~s}$ e fase de extensão da fita na temperatura de 72 oC por $30 \mathrm{~s}$. Estas 3 fases se repetem a cada ciclo e foram realizados 40 ciclos em cada corrida de PCR em tempo real.

A análise da expressão gênica foi realizada por quantificação relativa pelo método de CT comparativo $(\triangle \Delta C T)$. Foram utilizados os seguintes TaqMan ${ }^{\circledR}$ Gene Expression Assay: GLUT-1 (Rn01417099_m1), GLUT-4 (Rn00562597_m1), Leptina (Rn00565158_m1), Adiponectina (Rn00595250_m1), Receptor de Andrógeno (Rn00560747_m1), $\beta_{2}$ microglobulina - $\beta 2 \mathrm{M}$ (Rn00560865_m1), proteína ribossomal L37a - RPL-37a (Rn02114291_s1), 14-3-3 protein zeta/delta - YWHAZ (Rn00755072_m1) e Beta-actina - ACTB (Rn00667869_m1). 
3.15.4 Quantificação relativa - método de CT comparativo $(\Delta \Delta C T)$

Análise comparativa entre a expressão do gene alvo e de uma amostra calibradora, normalizadas por um controle endógeno (housekeeping).

$$
\begin{gathered}
\Delta \mathrm{C}_{\mathrm{T}}=\mathrm{C}_{\mathrm{T}} \text { (alvo) }-\mathrm{C}_{\mathrm{T}} \text { (endógeno) } \\
\Delta \mathrm{C}_{\mathrm{T}}=\mathrm{C}_{\mathrm{T}} \text { (calibrador) }-\mathrm{C}_{\mathrm{T}} \text { (endógeno) } \\
\Delta \Delta \mathrm{C}_{\mathrm{T}}=\Delta \mathrm{C}_{\mathrm{T}} \text { (amostra) }-\Delta \mathrm{C}_{\mathrm{T}} \text { (calibrador) } \\
\text { Quantidade relativa }=2^{-\Delta \Delta \mathrm{CT}}
\end{gathered}
$$

\subsection{Análise Estatística}

A análise estatística foi realizada pelo programa Graph Pad Prism, v.5.0 (GraphPad, San Diego, Califórnia, Estados Unidos) utilizando-se o teste de variância One-way ANOVA. O nível de significância foi prefixado em 95\% $(p<0,05)$. 


\section{RESULTADOS}

\subsection{Peso corporal}

Figura 1 - A. Ganho de peso corporal semanal. B. Peso Corporal.

A

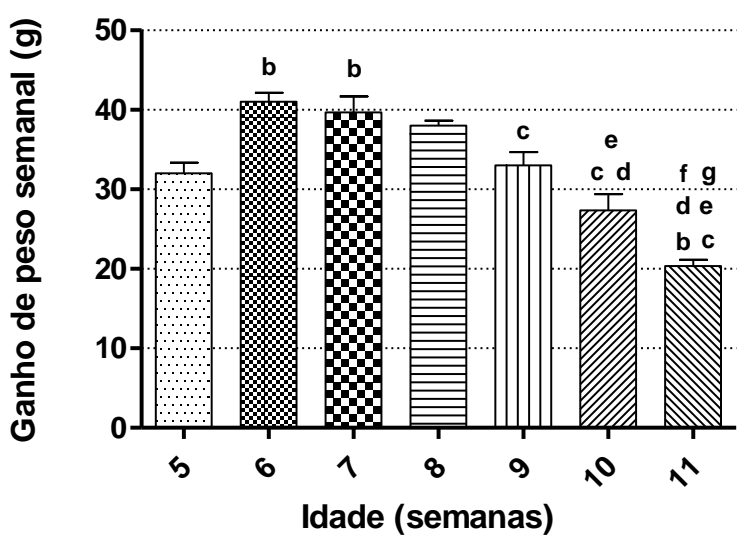

B

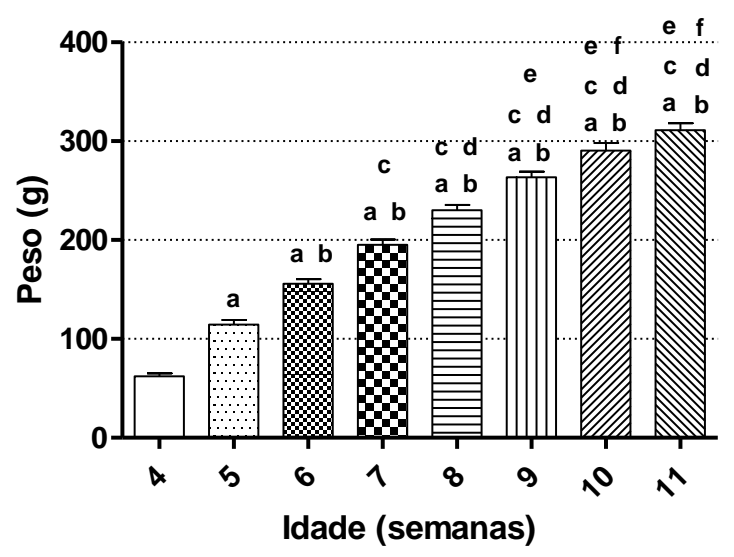

Ganho de peso mensurado em cada semana de vida em um mesmo grupo de animais $(n=6)$. Os valores expressos em gramas correspondem à média \pm EPM de cada semana do desenvolvimento do animal. (a. $p<0.05$ vs $4^{a}$ semana; b. $p<0.05$ vs $5^{\underline{a}}$ semana; $c$. $p<0.05$ vs $6^{\underline{a}}$ semana; $d$. $p<0.05$ vs $7^{\underline{a}}$ semana; e. $p<0.05$ vs $8^{\underline{a}}$ semana; f. $p<0.05$ vs $9^{\underline{a}}$ semana; $g$. $p<0.05$ vs $10^{\underline{a}}$ semana).

O peso corporal aumentou ao longo da fase de desenvolvimento estudada, com um ganho de peso mais intenso no período entre a $6^{\underline{a}}$ e a $8^{\underline{a}}$ semanas de vida havendo redução gradativa deste incremento a partir da 8 $8^{\mathbf{a}}$ semana. Assim, da $5^{\mathbf{a}}$ para a $6^{\underline{a}}$, da $6^{\underline{a}}$ para a $7^{\underline{a}}$ e da $7^{\underline{a}}$ para a $8^{\underline{a}}$ semanas, concentrou-se o período de crescimento mais acelerado que corresponde ao estirão puberal. 


\subsection{Consumo hídrico e alimentar}

Figura 2 - Consumo hídrico e alimentar semanal.A. Consumo Hídrico Semanal. B. Consumo Alimentar Semanal. C. Consumo Hídrico Semanal por Grama de Peso Corporal. D. Consumo Alimentar Semanal por Grama de Peso Corporal.

A

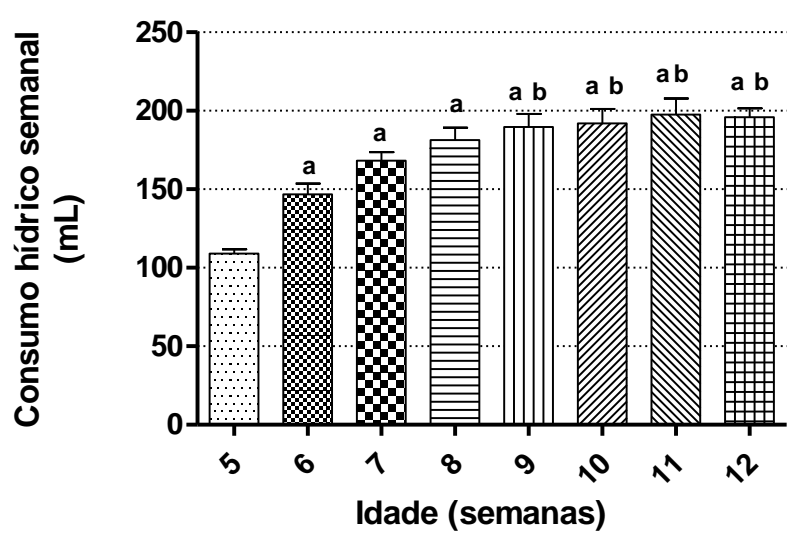

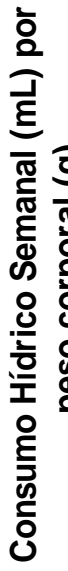

C

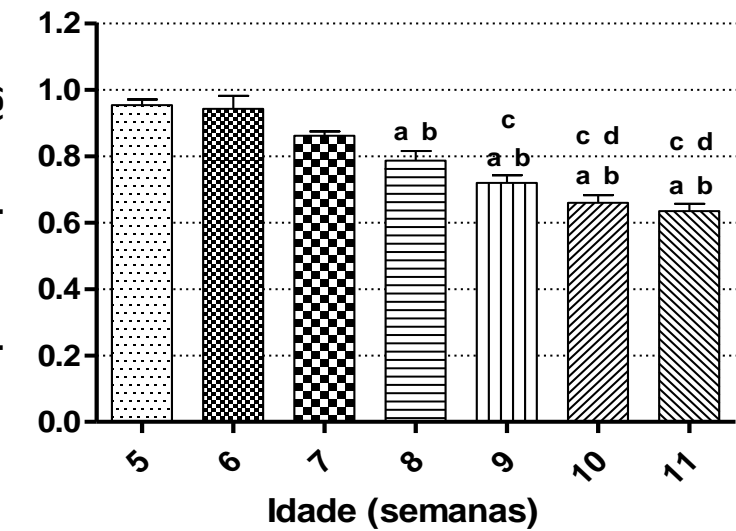

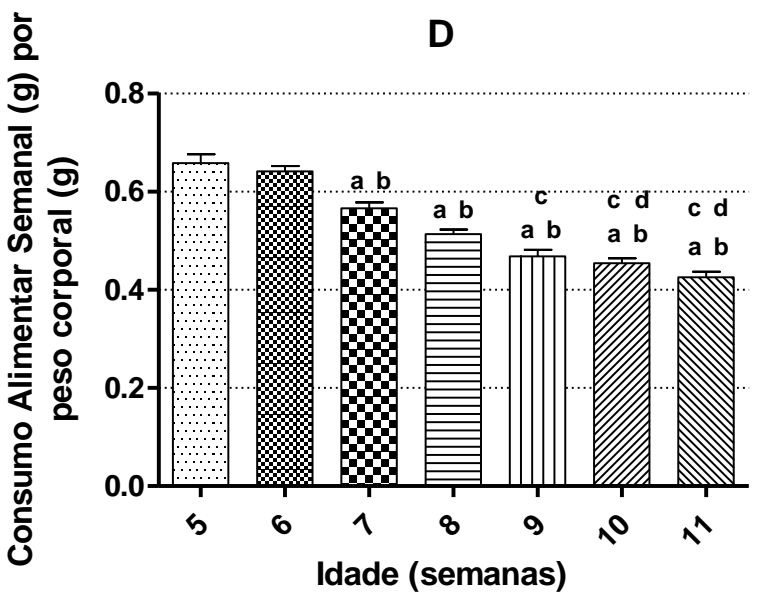

Consumo de água $(\mathrm{mL})$ e de ração $(\mathrm{g})$ mensurados em cada semana de vida em um mesmo grupo de animais $(n=6)$. Os valores expressos em mililitros e em gramas correspondem à média \pm EPM de cada semana do desenvolvimento do animal. (a. $p<0.05$ vs $5^{a}$ semana; $b$. $p<0.05$ vs $6^{\underline{a}}$ semana; c. $p<0.05$ vs $7^{a}$ semana; $d$. $p<0.05$ vs $8^{\underline{a}}$ semana; $e$. $p<0.05$ vs $9^{\underline{a}}$ semana).

Os animais apresentaram incremento gradual do consumo hídrico e alimentar ao longo das semanas de vida estudadas, com início do aumento mais 
acentuado destes parâmetros na $6^{\underline{a}}$ semana de vida, os quais se estabilizaram a partir da 9ª (consumo hídrico) e 10ª semana (consumo alimentar). A análise dos consumos por grama de peso corporal demonstraram maior consumo hídrico e alimentar por grama de peso corporal no período entre a $5^{\underline{a}}$ e $7^{\underline{a}}$ semanas de vida. Estes dados corroboraram os resultados dos consumos semanais, deixando ainda mais claro que foi nas semanas iniciais(5 $5^{\underline{a}}$ a $7^{\underline{a}}$ semanas) quando ocorreu 0 consumo mais intenso de água e ração, correspondendo ao crescimento mais acelerado verificado nesta fase (Figura 1).

\subsection{Comprimento naso-anal}

Figura 3- Comprimento naso-anal. I.Diferença entre as médias de cada semana.
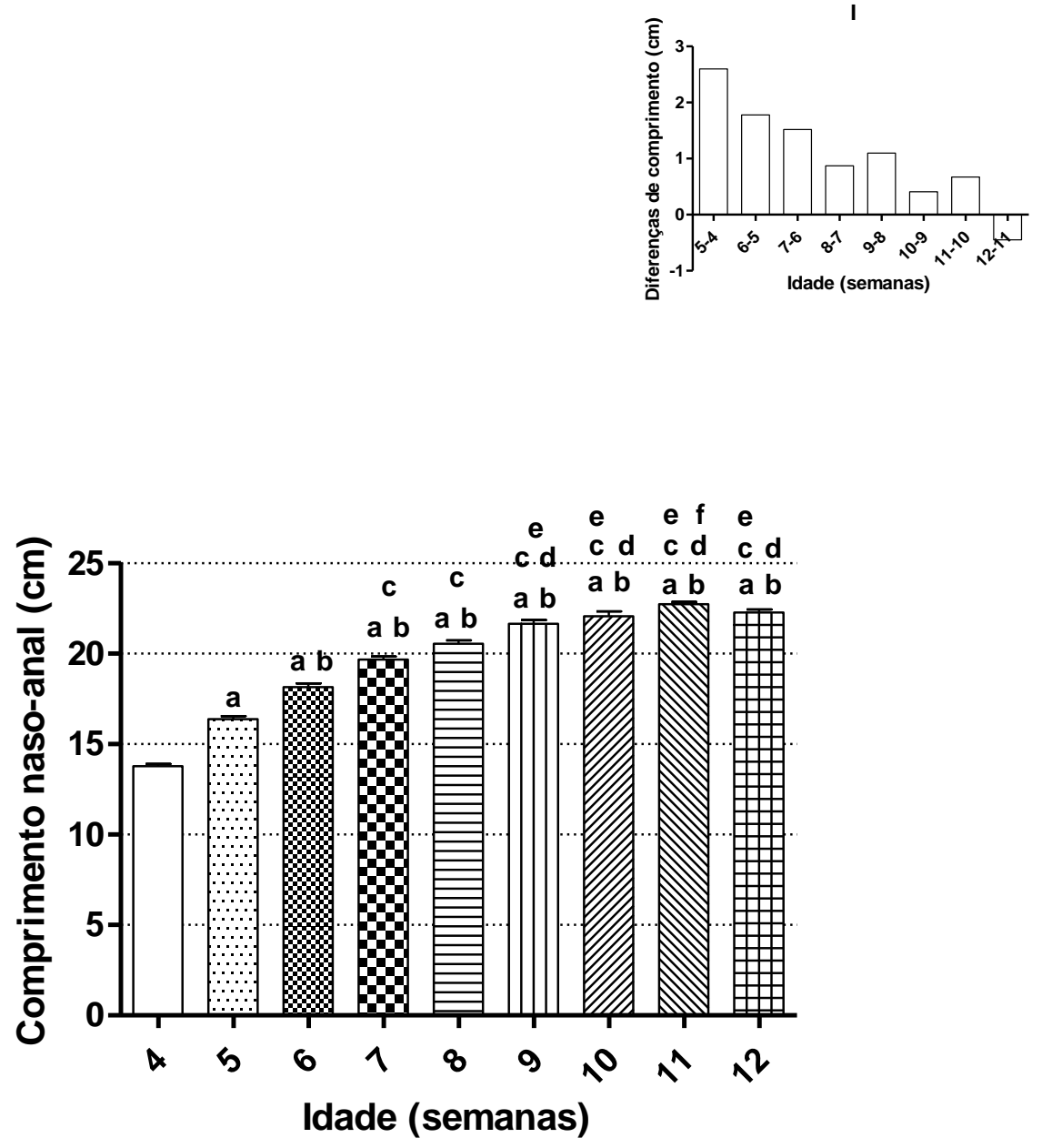

Comprimento $(\mathrm{cm})$ mensurado em diferentes grupos representativos de cada semana de vida $(\mathrm{n}=8$ 11). Os valores expressos em centímetros correspondem à média \pm EPM de cada semana do desenvolvimento do animal. (a. $p<0.05$ vs $4^{\underline{a}}$ semana; $b . p<0.05$ vs $5^{\underline{a}}$ semana; $c . p<0.05$ vs $6^{\underline{a}}$ semana; $d$. $p<0.05$ vs $7^{\underline{a}}$ semana; $e$. $p<0.05$ vs $8^{a}$ semana; $f$. $p<0.05$ vs $9^{a}$ semana). 
O aumento do comprimento naso-anal foi mais intenso nas primeiras semanas de vida (5 $5^{\underline{a}}$ a $7^{a}$ semana), acompanhando, portanto, os maiores ganhos de peso e consumo hídrico e alimentar observados nesta fase do estirão puberal. 


\subsection{Genitália}

Figura 4- Genitália Controles. A. Testículos B. Epidídimo C. Canal Deferente D. Vesículas seminais. I. Diferença entre as médias de cada semana dos testículos, II. epidídimo, III. canal deferente, IV. vesículas seminais.

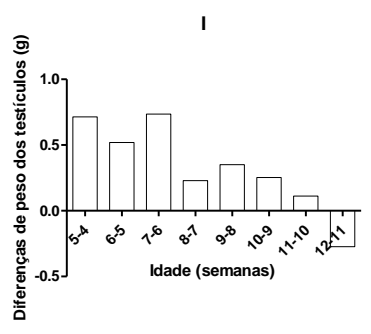

A
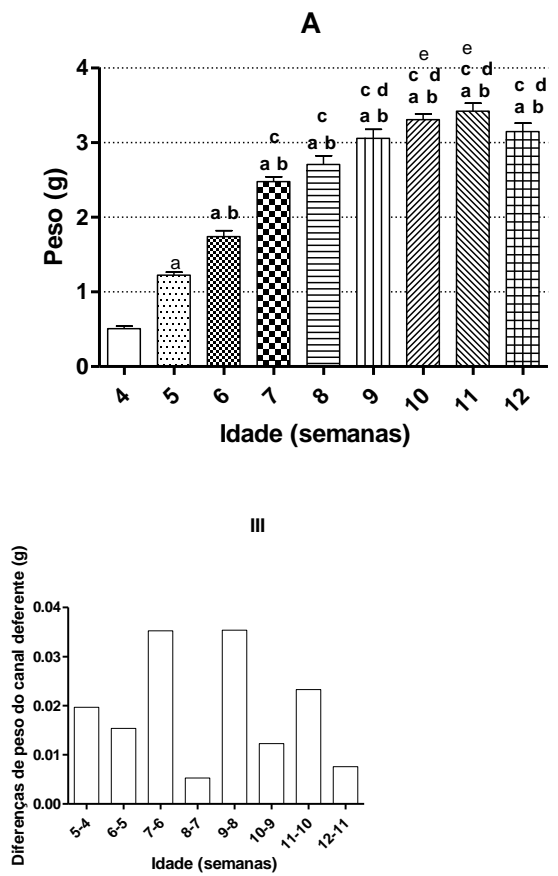

C

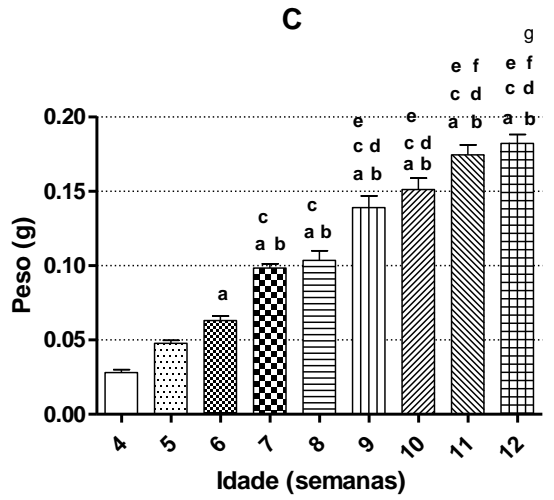

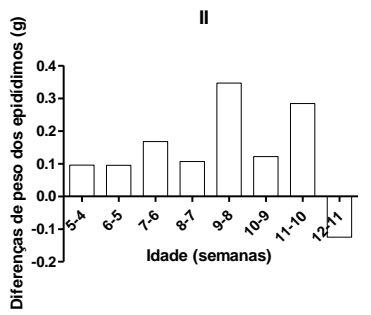
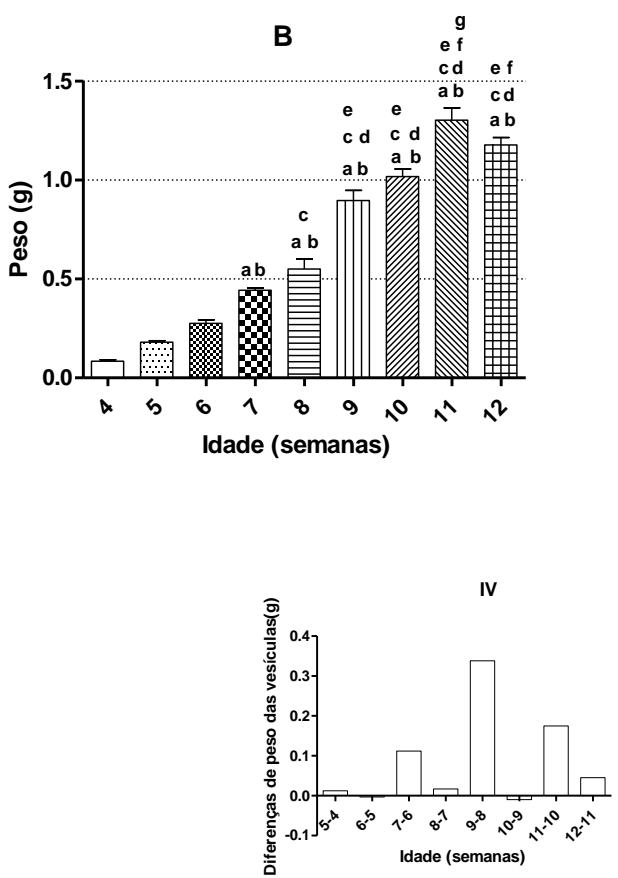

D

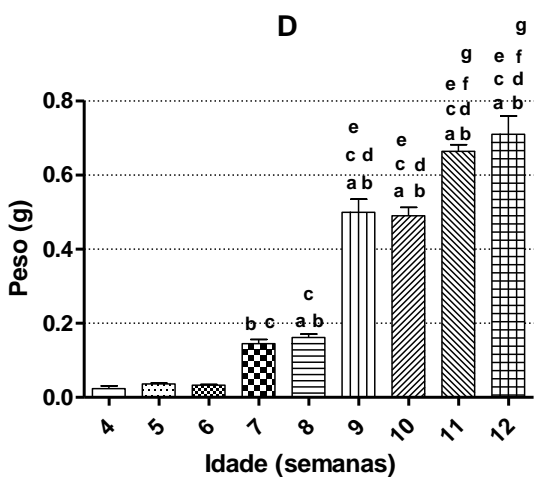

Peso (g) mensurado em diferentes grupos representativos de cada semana de vida $(n=8-11)$. Os valores expressos em gramas correspondem à média \pm EPM de cada semana do desenvolvimento do animal. (a. $p<0.05$ vs $4^{a}$ semana; $b . p<0.05$ vs $5^{a}$ semana; $c$. $p<0.05$ vs $6^{a}$ semana; $d$. $p<0.05$ vs $7^{a}$ semana; $e . p<0.05$ vs $8^{\underline{a}}$ semana; f. $p<0.05$ vs $9^{\underline{a}}$ semana; $g$. $p<0.05$ vs $10^{\underline{a}}$ semana). 
O aumento de peso dos testículos foi mais intenso nas semanas iniciais do desenvolvimento ( $5^{\mathrm{a}}$ a $7^{\mathrm{a}}$ semanas), enquanto as outras estruturas demonstraram este fenômeno mais tardiamente. O epidídimo apresentou incremento de peso mais intenso na $9^{\underline{a}}$ e na $11^{\underline{a}}$ semana, o canal deferente na $7^{\underline{a}}$ e na $9^{\underline{a}}$ semana e as vesículas seminais na9 ${ }^{a}$ semana de vida. Em outras palavras, o testículo foia primeira estrutura genital a ter seu crescimento acelerado e este ocorreu no mesmo período em que se observou o crescimento mais intenso dos outros parâmetros de desenvolvimento corporal e maturação sexual.

\subsection{Testosterona}

Figura 5 - Dosagem de testosterona no soro.

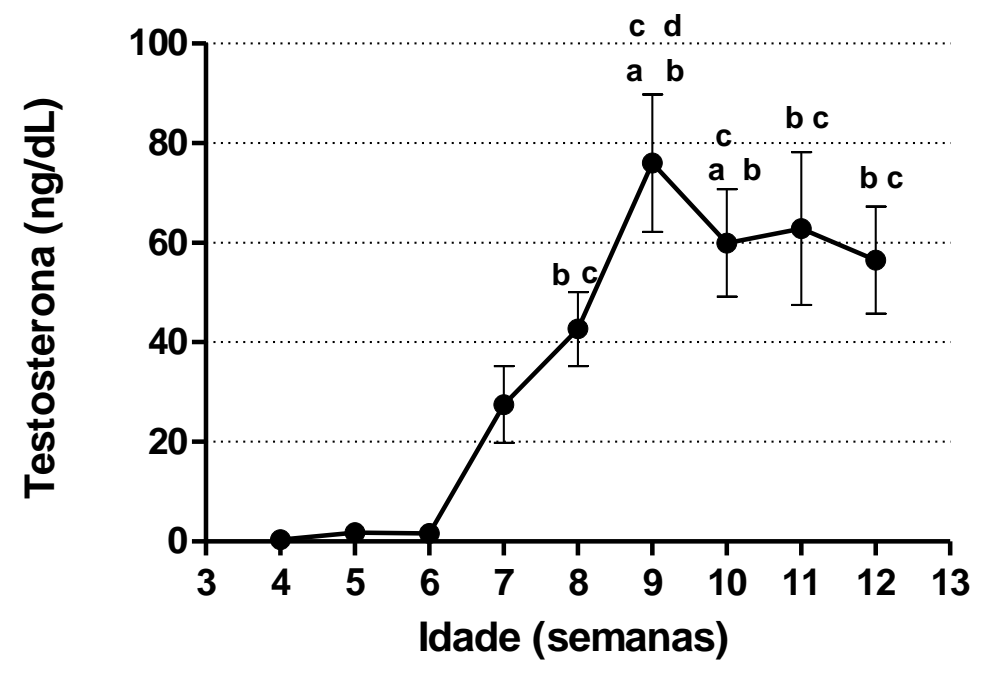

Testosterona sérica $(\mathrm{ng} / \mathrm{dL})$ mensurada em diferentes amostras de animais em cada semana de vida $(n=7-14)$. Os valores correspondem à média \pm EPM de cada semana do desenvolvimento do animal. (a. $p<0.05$ vs $4^{\underline{a}}$ semana; b. $p<0.05$ vs $5^{\underline{a}}$ semana; $c$. $p<0.05$ vs $6^{\underline{a}}$ semana; $d$. $p<0.05$ vs $7^{\underline{a}}$ semana).

O aumento da concentração de testosterona no soro iniciou-se a partir da $7^{a}$ semana de vida, atingindo um pico na 9a semana, estabilizando-se a partir de então. O início do aumento da testosteronemia correspondeu ao final do período em que foi observado aumento mais intenso dos testículos. 


\subsection{Teste oral de tolerância à glicose}

Figura 6 - Teste oral de tolerância à glicose. A. Curva glicêmica média de cada semana. B. Área Incremental sob a curva.

A

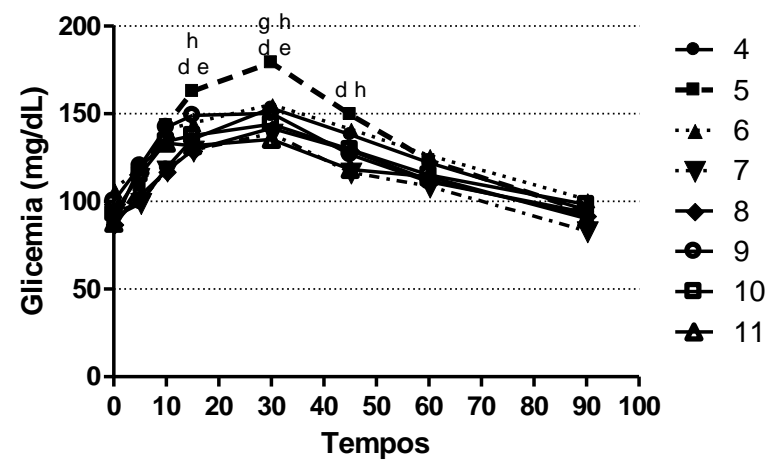

B

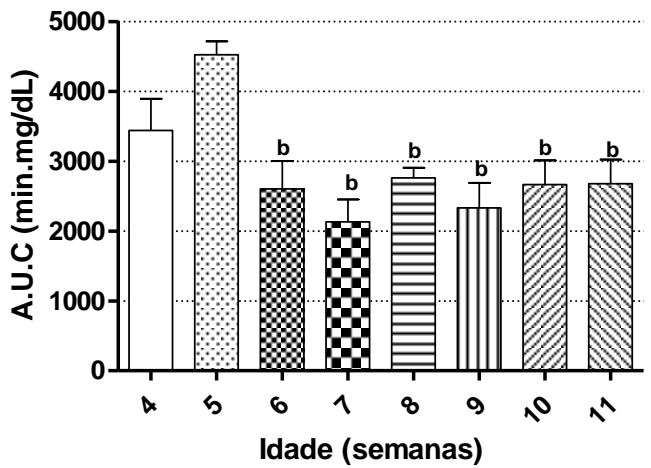

Teste oral de tolerância à glicose realizado em cada semana de vida em um mesmo grupo de animais $(n=6)$. Os valores correspondem à média \pm EPM de cada semana do desenvolvimento do animal. (b. $p<0.05$ vs $5^{\underline{a}}$ semana; $d$. $p<0.05$ vs $7^{\underline{a}}$ semana; e. $p<0.05$ vs $8^{\underline{a}}$ semana; $g$. $p<0.05$ vs $10^{a}$ semana; $h$. $p<0.05$ vs $11^{\text {a }}$ semana).

As curvas glicêmicas médias demonstraram que na $5^{\text {a }}$ semana de vida as glicemias atingem valores significativamente mais altos nos tempos $15 \mathrm{~min}, 30 \mathrm{~min}$ e 45 min do teste. A área incremental sob a curva do teste oral de tolerância à glicose apresentou maiores valores na $5^{\text {a }}$ semana de vida dos animais demonstrando uma menor tolerância à glicose neste período do desenvolvimento. 


\subsection{Glicemia e insulinemia de jejum}

Figura 7-Glicemia e insulinemia de jejum séricas. A. Glicemia de jejum. B. Insulinemia de jejum.

A

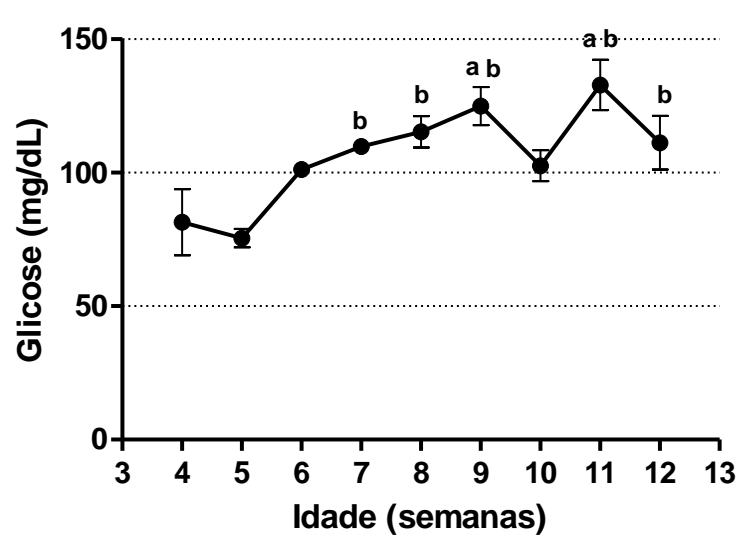

B

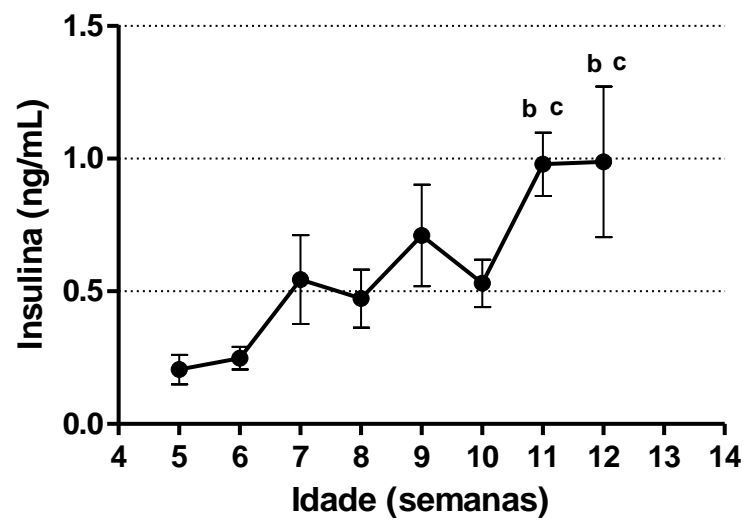

Glicose $(\mathrm{mg} / \mathrm{dL})$ e Insulina $(\mathrm{ng} / \mathrm{mL})$ mensuradas em amostras representativas de cada semana de vida $(n=5-8)$. Os valores expressos em $\mathrm{mg} / \mathrm{dL}$ e $\mathrm{ng} / \mathrm{mL}$ correspondem à média \pm EPM de cada semana de vida do animal. (a. $p<0.05$ vs $4^{\mathrm{a}}$ semana; b. $p<0.05$ vs $5^{\mathrm{a}}$ semana; $c$. $p<0.05$ vs $6^{\mathrm{a}}$ semana).

A glicemia de jejum apresentou menores valores (ao redor de $80 \mathrm{mg} / \mathrm{dL}$ ) nas semanas iniciais ( $4^{\underline{a}}$ e $5^{\mathrm{a}}$ semanas) com aumento a partir da $6^{\mathrm{a}}$ semana de vida quando atingiu novos patamares (cerca de $120 \mathrm{mg} / \mathrm{dL}$ ) assim permanecendo no restante do tempo estudado.

A concentração de insulina no soro aumentou gradualmente com o avanço das semanas atingindo valores significativamente diferentes dos iniciais na $11^{\underline{a}} \mathrm{e}$ $12^{\text {a }}$ semanas de vida.

Assim, ocorreu aumento gradual da glicemia e insulinemia de jejum ao longo das semanas estudadas. 


\subsection{Peso dos coxins adiposos}

Figura 8 - Peso dos coxins adiposos. A. Peso absoluto do coxim SC. B. Peso absoluto do coxim PE. C. Coxim SC mais PE por g de p.c. D. Diferença entre as médias das semanas do peso do coxim por g de p.c.

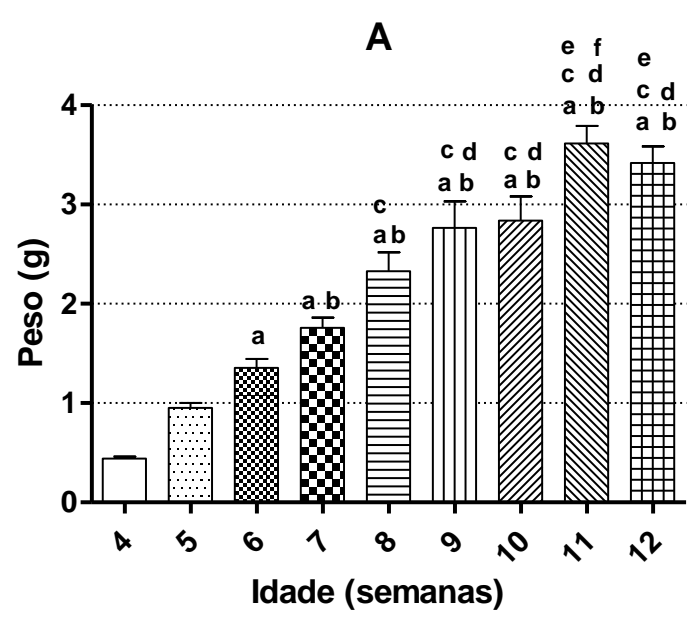

C

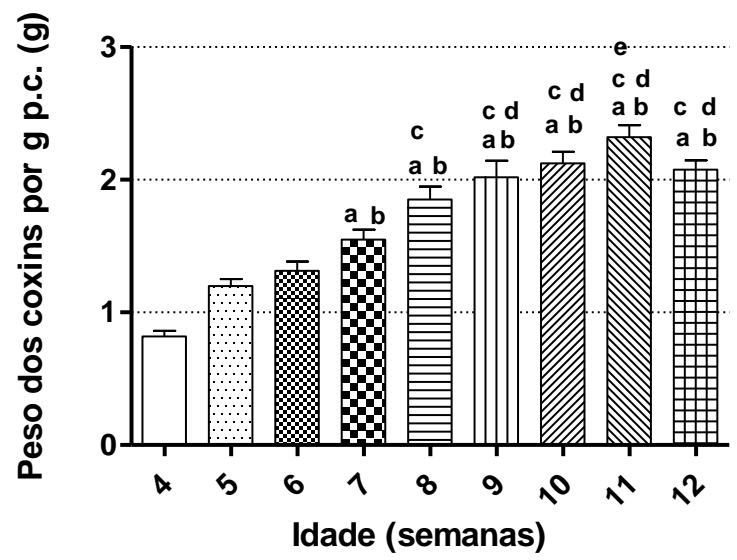



D

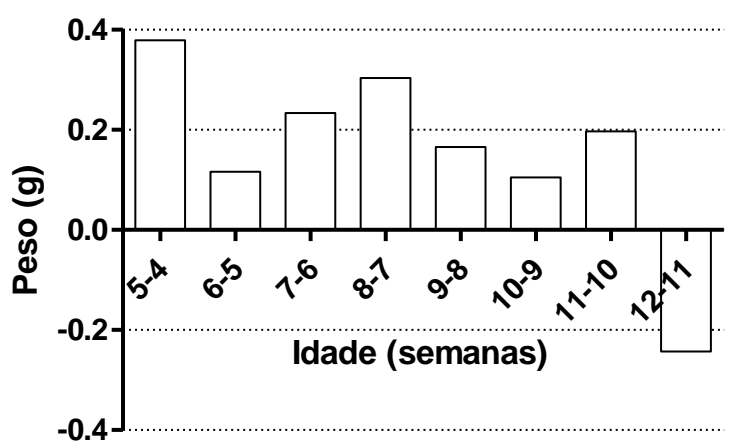

Peso (g)determinado em diferentes amostras representativas de cada semana de vida $(\mathrm{n}=8-24)$. Os valores expressos correspondem à média \pm EPM de cada semana do desenvolvimento do animal. (a. $p<0.05$ vs $4^{\underline{a}}$ semana; b. $p<0.05$ vs $5^{\underline{a}}$ semana; $c$. $p<0.05$ vs $6^{a}$ semana; $d$. $p<0.05$ vs $7^{\underline{a}}$ semana; e. $p<0.05$ vs $8^{a}$ semana; $f$. $p<0.05$ vs $9^{\underline{a}}$ semana).

Os coxins adiposos subcutâneo e periepididimal apresentaram aumento gradual de peso ao longo das semanas atingindo estabilidade a partir da $11^{\text {a }}$ semana de vida. $O$ aumento mais intenso do peso dos coxins ocorreu mais próximo 
do final do período estudado, na $11^{\text {a }}$ semana no coxim adiposo subcutâneo e na 9a semana no coxim periepididimal.

Porém, a análise da quantidade de tecido adiposo SC mais PE em relação ao peso corporal (soma dos pesos dos coxins por $\mathrm{g}$ de peso corporal) demonstrou aumentou mais intenso entre a $5^{\underline{a}}$ e a $8^{\underline{a}}$ semanas de vida. Assim, a fase em que observamos estirão de crescimento e maturação sexual correspondeu a este período de maior aumento da relação tecido adiposo $\mathrm{X}$ peso corporal.

\subsection{Diâmetro dos adipócitos e celularidade}

Figura 9 - Diâmetro dos adipócitos e celularidade.

SC

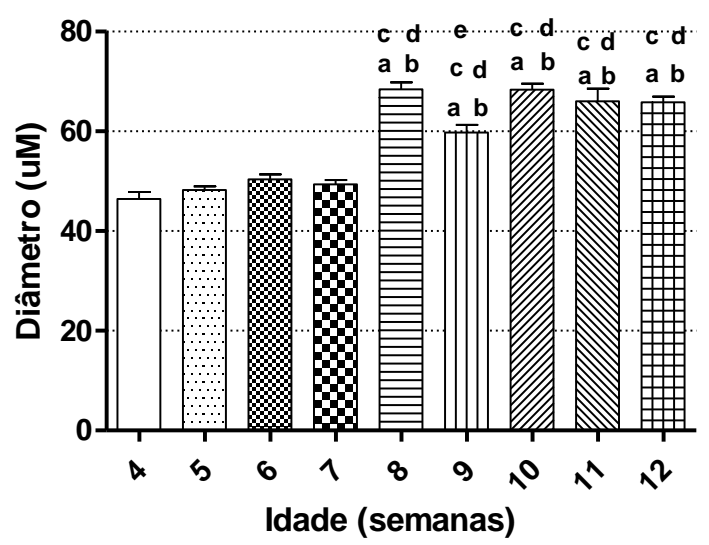

SC

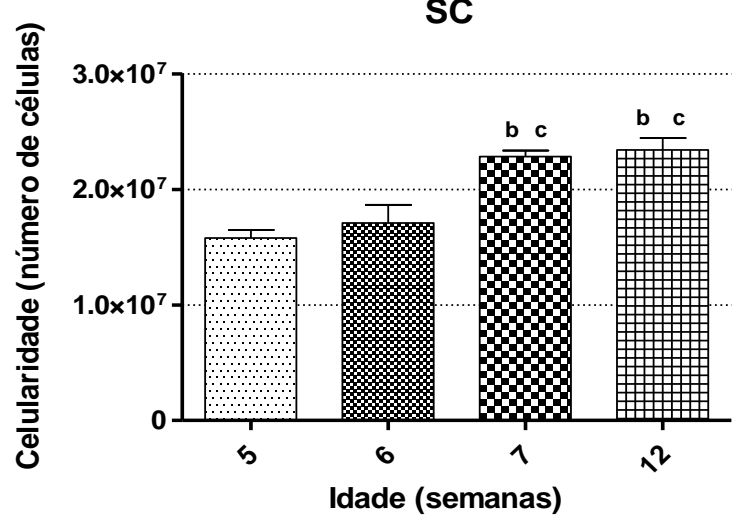

PE
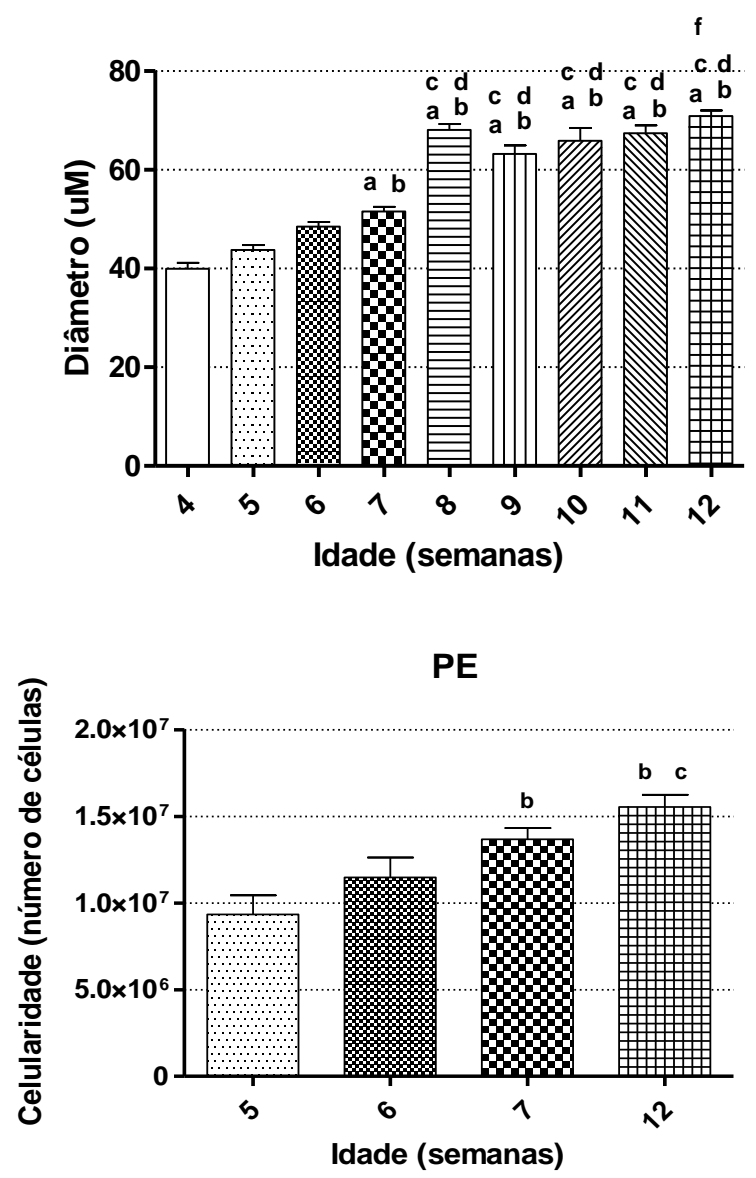

Diâmetro $(\mu \mathrm{M})$ e Celularidade (número de células) calculados em diferentes grupos de animais representativos de cada semana do desenvolvimento $(n=15)$. Os valores expressos correspondem à média \pm EPM em cada semana. (a. $p<0.05$ vs $4^{a}$ semana; b. $p<0.05$ vs $5^{\underline{a}}$ semana; $c$. $p<0.05$ vs $6^{\underline{a}}$ semana; $d$. $p<0.05$ vs $7^{\underline{a}}$ semana; $e$. $p<0.05$ vs $8^{\mathrm{a}}$ semana; f. $\mathrm{p}<0.05$ vs $9^{\mathrm{a}}$ semana). 
O diâmetro do adipócito apresentou duas faixas de distribuição: uma, com valores ao redor de $50 \mu \mathrm{m}$ no período compreendido entre a $4^{\underline{a}}$ e a $7^{\underline{a}}$ semanas de idade; e, outro, com valores ao redor de $70 \mu \mathrm{m}$, na faixa etária entre a $8^{\mathrm{a}}$ e $12^{\mathrm{a}}$ semanas.

A celularidade dos coxins adiposos - subcutâneo e periepididimal apresentou importante aumento na $7^{\mathrm{a}}$ semana de vida do animal, atingindo já neste período puberal valores semelhantes aos observados na idade adulta (12 semana).

\subsection{Leptina}

Figura 10 - Leptina no soro. A. Valores absolutos de leptina. B. Valores de leptina em relação ao peso dos coxins. I. Leptinemia (4 a 7semanas) versus (8 a 12 semanas).

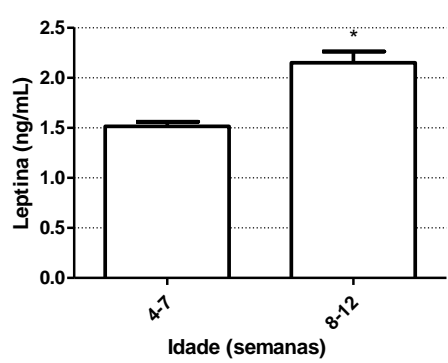

A
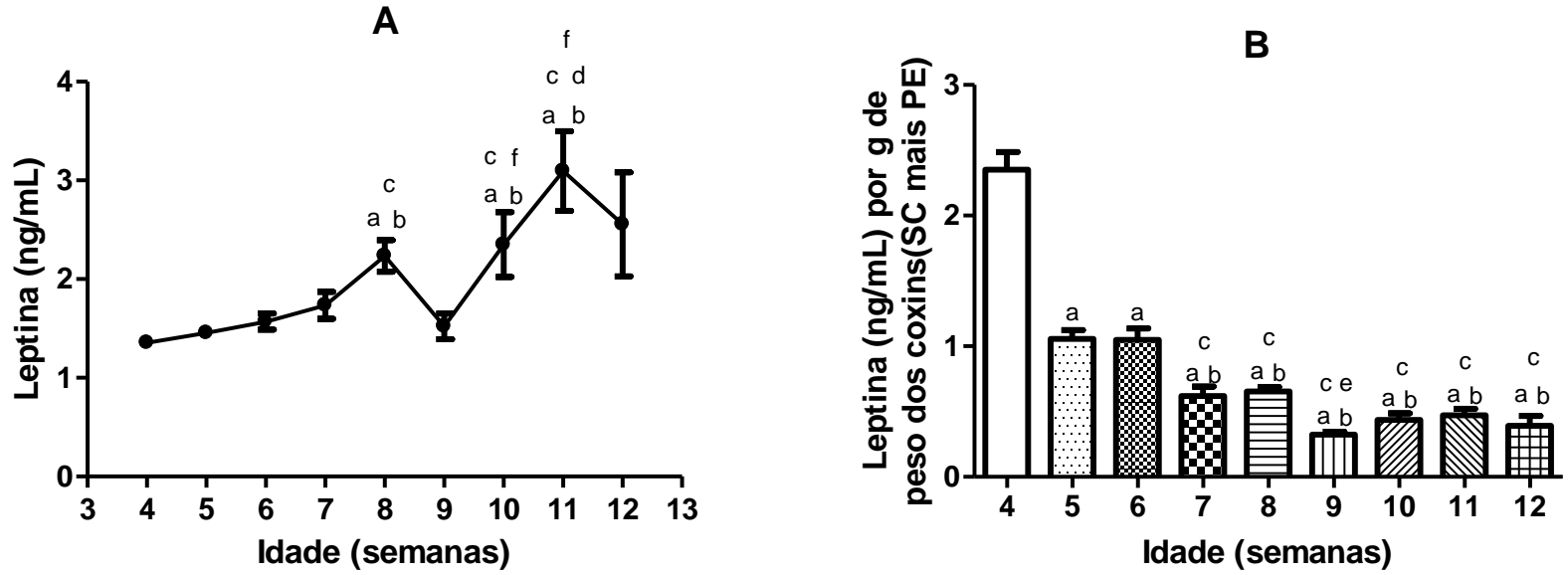

Leptina $(\mathrm{ng} / \mathrm{mL})$ nas diferentes faixas etárias semanalmente avaliadas $(\mathrm{n}=7-10)$.Os valores expressos em $\mathrm{ng} / \mathrm{mL}$ correspondem à média \pm EPM de cada semana do desenvolvimento do animal. (a. $p<0.05$ vs $4^{\underline{a}}$ semana; b. $p<0.05$ vs $5^{\underline{a}}$ semana; $c$. $p<0.05$ vs $6^{\underline{a}}$ semana; $d$. $p<0.05$ vs $7^{\underline{a}}$ semana; e. $p<0.05$ vs $8^{\underline{a}}$ semana; f. $p<0.05$ vs $9^{a}$ semana $g$. $p<0.05$ vs $10^{\underline{a}}$ semana). 
A concentração de leptina no soro apresentou aumento significativo a partir da $8^{\text {a }}$ semana de vida. Com este aumento, distinguem-se dois valores de leptinemia, um mais baixo, entre a $4^{\underline{a}}$ e $7^{\underline{a}}$ semanas, e um mais alto, entre a $8^{\underline{a}}$ e $12^{\mathrm{a}}$ semanas. Nas semanas iniciais (4⿳亠丷⿵冂丶, $5^{\underline{a}}$ e $6^{\underline{a}}$ semanas), apesar de haver menor concentração de leptina em valores absolutos, sua concentração relativizada por grama dos coxins adiposos (SC e PE) é maior.

\subsection{Adiponectina}

Figura 11 - Adiponectina no soro.

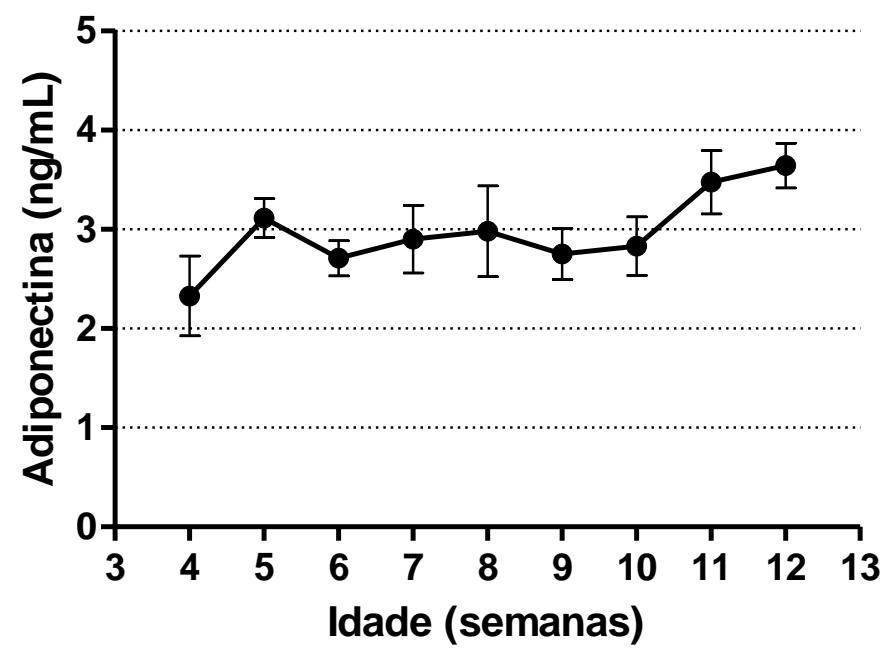

Adiponectina $(\mathrm{ng} / \mathrm{mL})$ mensurada em diferentes grupos representativos de cada semana de vida $(\mathrm{n}=$ 5-9). Os valores expressos em $\mathrm{ng} / \mathrm{mL}$ correspondem à média \pm EPM de cada semana do desenvolvimento do animal.

Não houve diferenças significativas na concentração de adiponectina no soro durante as semanas estudadas. 


\subsection{Captação específica de ${ }^{3} \mathrm{H}-2$-desoxiglicose ( $\left.{ }^{3} \mathrm{H}-2 \mathrm{DG}\right)$ em adipócitos isolados}

\subsubsection{Coxim Subcutâneo}

Figura 12 - Captação específica de ${ }^{3} \mathrm{H}-2$-desoxiglicose ( $\left.{ }^{3} \mathrm{H}-2 \mathrm{DG}\right)$ estimulada pela insulina em adipócitos isolados do coxim subcutâneo.
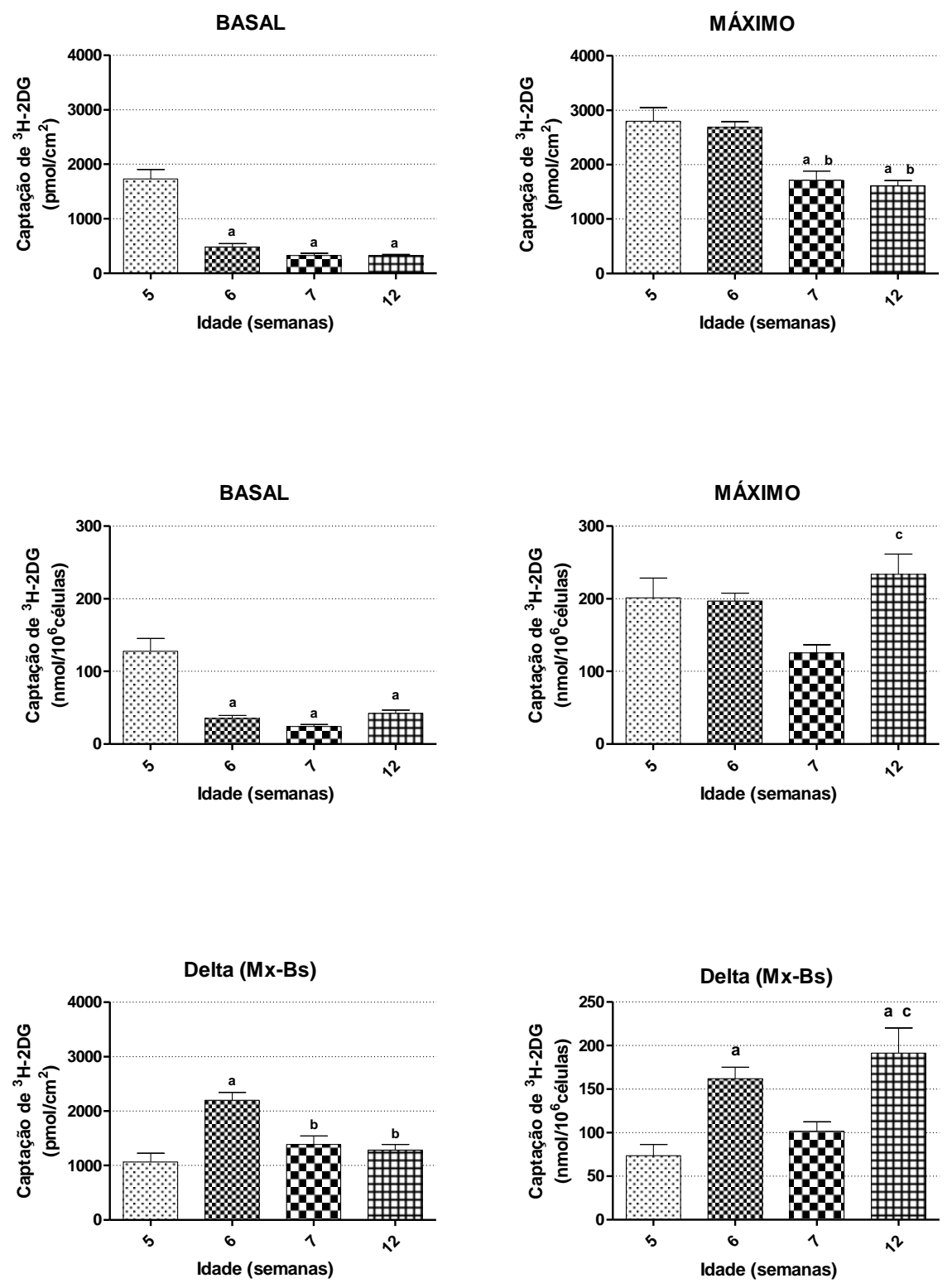

Captação específica de ${ }^{3} \mathrm{H}-2$-desoxiglicose $\left({ }^{3} \mathrm{H}-2 \mathrm{DG}\right)$ estimulada pela insulina em adipócitos isolados $\left(\mathrm{pmol} / \mathrm{cm}^{2}\right)$ e $\left(\mathrm{nmol} / 10^{6}\right.$ células)em diferentes grupos representativos de cada semana de vida $(\mathrm{n}=8)$. Os valores expressos em $\mathrm{pmol} / \mathrm{cm}^{2}$ enmol $/ 10^{6}$ células correspondem à média $\pm \mathrm{EPM}$ de cada semana do desenvolvimento do animal. (a. $p<0.05$ vs $5^{\underline{a}}$ semana; $b . p<0.05$ vs $6^{\underline{a}}$ semana; $c$. $p<0.05$ vs $7^{\text {a }}$ semana). 
A capacidade da célula adiposa em captar glicose estimulada ou não por insulina foi avaliada sob dois aspectos: 1) em relação à área de superfície de membrana (expressa em $\mathrm{pmol} / \mathrm{cm}^{2}$ ) e 2) em relação ao número de adipócitos (expressa em nmol/ $10^{-6}$ cels). A primeira abordagem permite visualizar a densidade de transportadores de glicose na membrana celular e a segunda, a quantidade total captada por célula.

Assim, a taxa de captação da glicose não estimulada (basal) dos adipócitos isolados do coxim adiposo SC por área de membrana foi 2-3 vezes maior na $5^{\mathrm{a}}$ semana de vidado que nas semanas subsequentes nas quais esta capacidade se manteve em patamares menores sem apresentar diferenças entre si. Quando estimulada por insulina, a captação foi maior na $5^{\underline{a}}$ e $6^{\underline{a}}$ semanas em relação à $7^{\underline{a}} \mathrm{e}$ $12^{\mathrm{a}}$ semanas em cerca de $50 \%$. Desta forma, revelou-se um maior aumento da densidade de transportadores em resposta ao estímulo da insulina na $5^{\underline{a}}$ e $6^{\text {a }}$ semanas. A maior responsividade à insulina, entendida como a diferença (delta) entre a taxa estimulada e a basal, na $5^{\underline{a}}$ semana de vida não ficou evidente por que nesta semana a captação basal também se encontrou alta.

Em relação à quantidade captada por célula, a taxa basal mostrou o perfil semelhante ao acima descrito, ou seja, houve maior capacidade de captação basal de glicose por célula na $5^{\text {a }}$ semana de vida. Quando estimulada, a taxa de transporte mostrou-se significativamente menor em adipócitos obtidos de ratos com 7 semanas de vida em relação a animais adultos jovens (12 semanas de vida). Isto se deveu ao fato de que os adipócitos de ratos adultos jovens eram significativamente maiores $\mathrm{e}$, portanto, possuidores de uma área total de membrana plasmática mais ampla (cerca de 2 vezes maior). 


\subsubsection{Coxim Periepididimal}

Figura 13- Captação específica de ${ }^{3} \mathrm{H}-2$-desoxiglicose ( $\left.{ }^{3} \mathrm{H}-2 \mathrm{DG}\right)$ estimulada pela insulina em adipócitos isolados do coxim periepididimal.
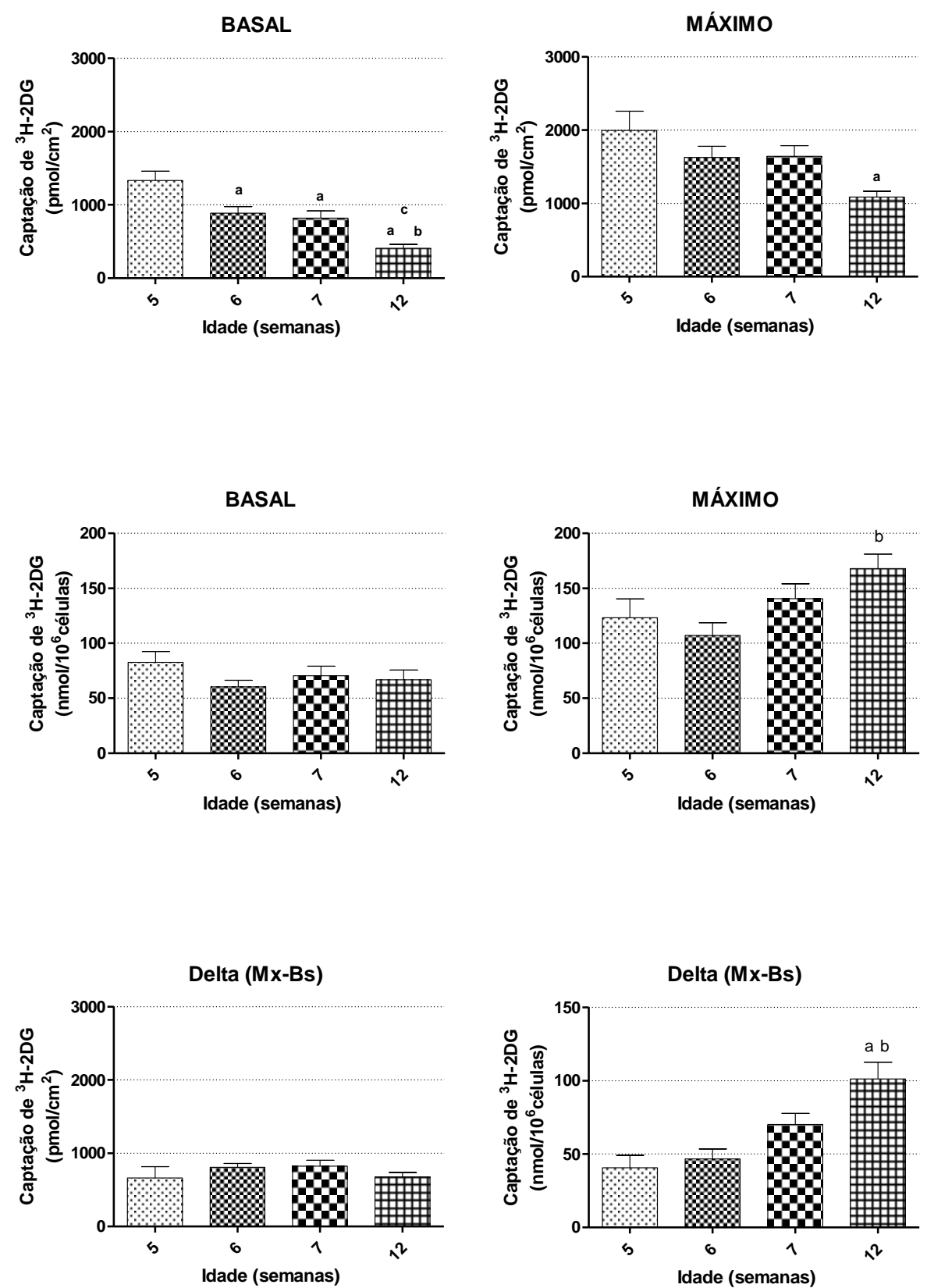

Captação específica de ${ }^{3} \mathrm{H}-2$-desoxiglicose $\left({ }^{3} \mathrm{H}-2 \mathrm{DG}\right)$ estimulada pela insulina em adipócitos isolados $\left(\mathrm{pmol} / \mathrm{cm}^{2}\right)$ e (nmol $/ 10^{6}$ células)mensurada em diferentes grupos representativos de cada semana de vida $(n=8)$. Os valores expressos em $\mathrm{pmol} / \mathrm{cm}^{2}$ e $\mathrm{nmol} / 10^{6}$ células correspondem à média \pm EPM de cada semana do desenvolvimento do animal. (a. $p<0.05$ vs $5^{\mathrm{a}}$ semana; b. $p<0.05$ vs $6^{\underline{a}}$ semana; $c$. $p<0.05$ vs $7^{\underline{a}}$ semana). 
Aplicando a mesma forma de análise em relação à gordura PE, a taxa de captação de glicose por área de membrana dos adipócitos apresentou uma redução ao longo das semanas de vida, tanto na situação basal quanto na maximamente estimulada por insulina. Não houve alteração na responsividade a este hormônio ao longo das semanas.

Quando a captação foi avaliada em $\mathrm{nmol} / 10^{6}$ células, não se detectaram diferenças entre as semanas na taxa basal. Quando estimulados por insulina, identificou-se diferença significativa entre a $6^{\underline{a}}$ e a $12^{\underline{a}}$ semana, com maior capacidade de captação na $12^{\mathrm{a}}$ semana. Desta forma, a responsividade à insulina foi maior na $12^{\text {a }}$ semana de vida.Isto ocorreu, pois na $12^{\text {a }}$ semana as células apresentaram uma densidade de transportadores de glicose semelhante às semanas anteriores (captação por área de membrana pmol/ $\mathrm{cm}^{2}$ ) com uma área de membrana aproximadamente duas vezes maior. 


\subsection{Capacidade de Incorporação de D-[U -14C]-glicose em lipídeos}

\subsubsection{Coxim Subcutâneo}

Figura 14 - Capacidade de incorporação de D-[U-14C]-glicose em lipídeos.

BASAL

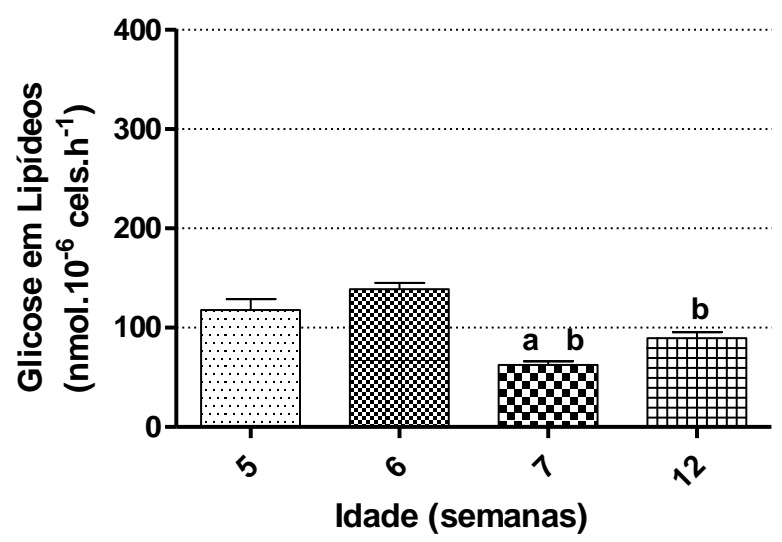

MÁXIMO

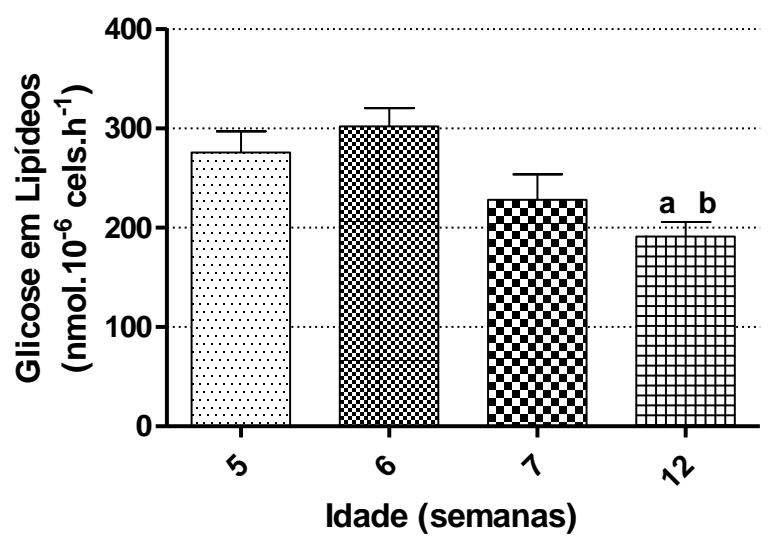

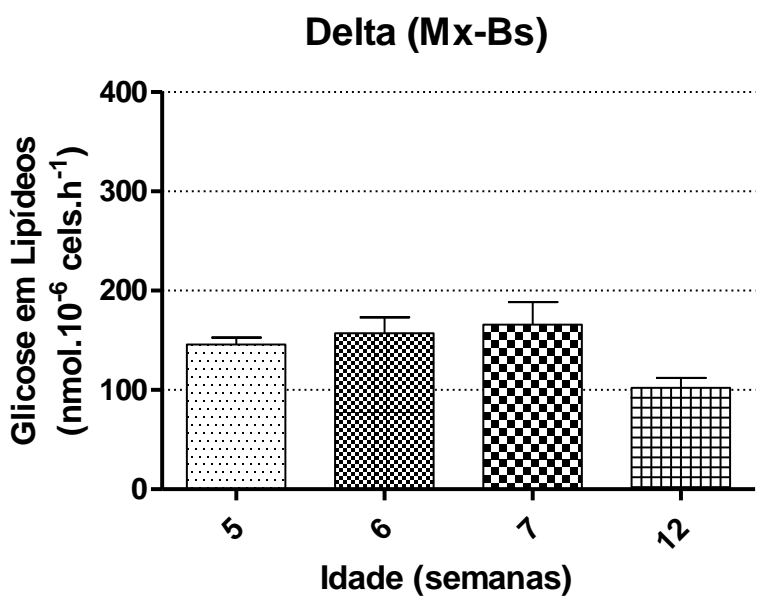

Capacidade de Incorporação de D-[U -14C]-Glicose em Lipídeos (nmol.10 $0^{-6}$ cels. ${ }^{-1}$ )mensurada em diferentes grupos representativos de cada semana de vida $(n=8)$. Os valores (em nmol. $10^{-6}$ cels. $h^{1}$ correspondem à média \pm EPM de cada semana. (a. $p<0.05$ vs $5^{\underline{a}}$ semana; $b$. $p<0.05$ vs $6^{\underline{a}}$ semana; c. $p<0.05$ vs $7^{\underline{a}}$ semana).

A capacidade dos adipócitos isolados do coxim adiposo subcutâneo de incorporar glicose em lipídeos em resposta ao estímulo de insulina apresentou-se maior na $5^{\underline{a}}$ e $6^{\underline{a}}$ semanas de vida em relação à idade adulta (12 semanas). A capacidade basal de incorporação também se mostrou maior na $5^{\mathrm{a}}$ e $6^{\mathrm{a}}$ semanas. 


\subsubsection{Coxim Periepididimal}

Figura 15 - Capacidade de incorporação de D-[U -14C]-glicose em lipídeos.

BASAL

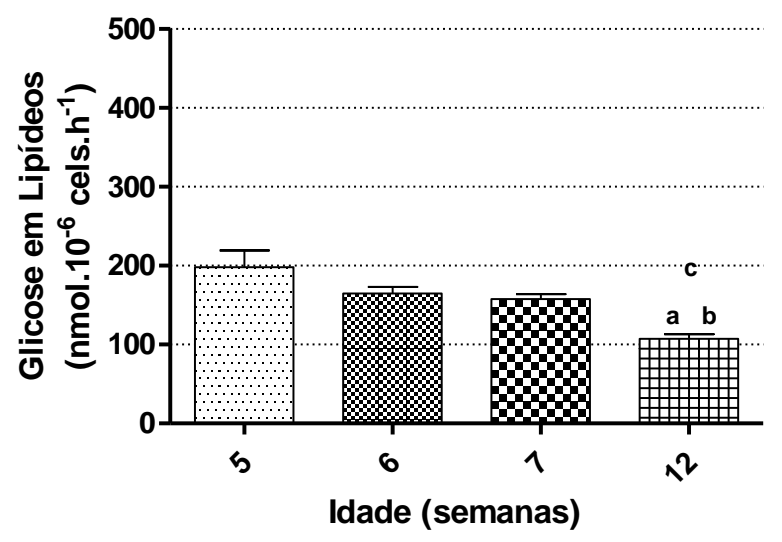

MÁXIMO

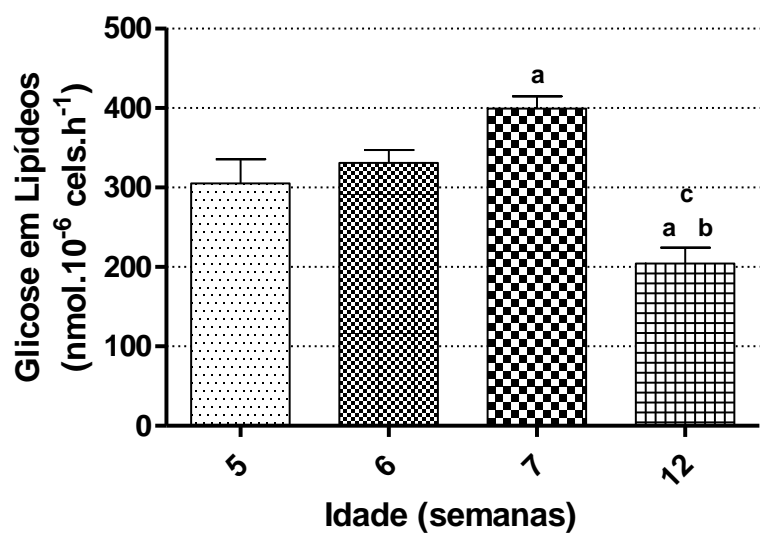

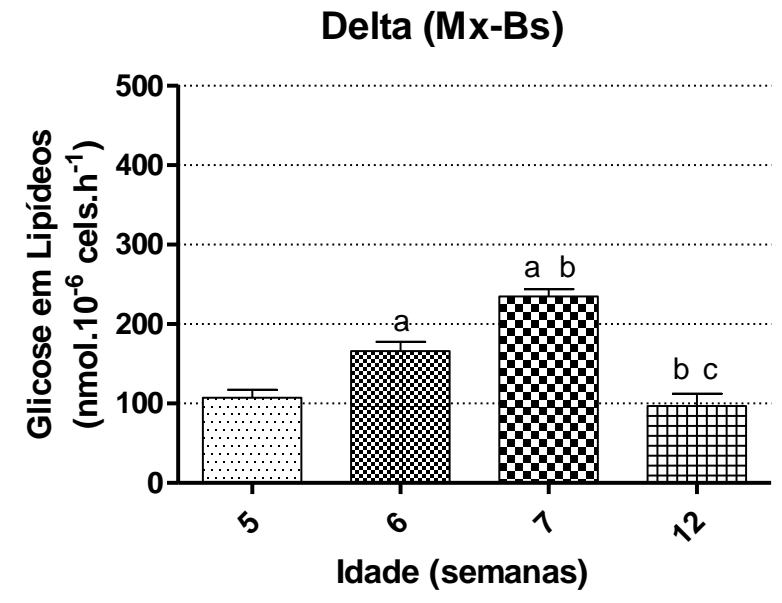

Capacidade de Incorporação de D-[U -14C]-Glicose em Lipídeos (nmol.10 $0^{-6}$ cels. $\mathrm{h}^{-1}$ ) mensurada em diferentes grupos representativos de cada semana de vida $(n=8)$. Os valores $\left(n\right.$ mol. $10^{-6}$ cels. $\left.h^{-1}\right)$ correspondem à média \pm EPM de cada semana. (a. $p<0.05$ vs $5^{\underline{a}}$ semana; $b . p<0.05$ vs $6^{\underline{a}}$ semana; c. $p<0.05$ vs $7^{\underline{a}}$ semana).

A capacidade basal e maximamente estimulada por insulina dos adipócitos isolados periepididimais de incorporar glicose em lipídeos mostrou-se maior na 5 $5^{\underline{a}}$, $6^{\underline{a}}$ e $7^{\text {a }}$ semanas de vida em relação à idade adulta. A diferença entre a resposta 
basal e máxima demonstrou haver uma maior responsividade à insulina na $6^{\underline{a}}$ e $7^{\underline{a}}$ semana em relação à $5^{\mathrm{a}}$ e $12^{\mathrm{a}}$ semanas. 


\subsection{Incorporação de D-[U $\left.-{ }^{14} \mathrm{C}\right]$-glicose em glicerol e ácidos graxos do triacilglicerol}

\subsubsection{Coxim Subcutâneo}

Figura 16 - Incorporação de D-[U -14C]-glicose em glicerol e ácidos graxos de triacilglicerol no coxim subcutâneo.

BASAL

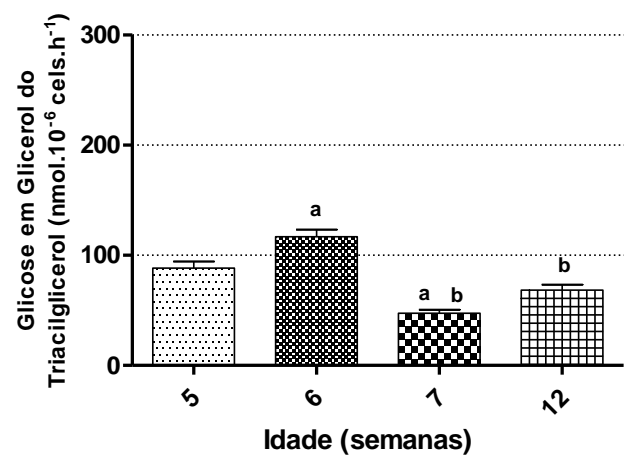

BASAL

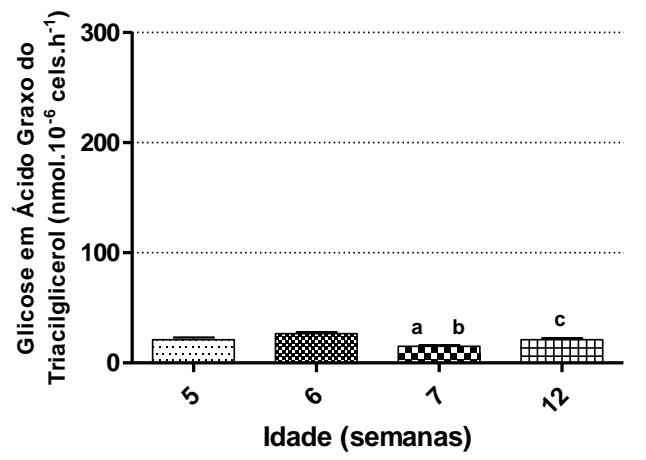

BASAL

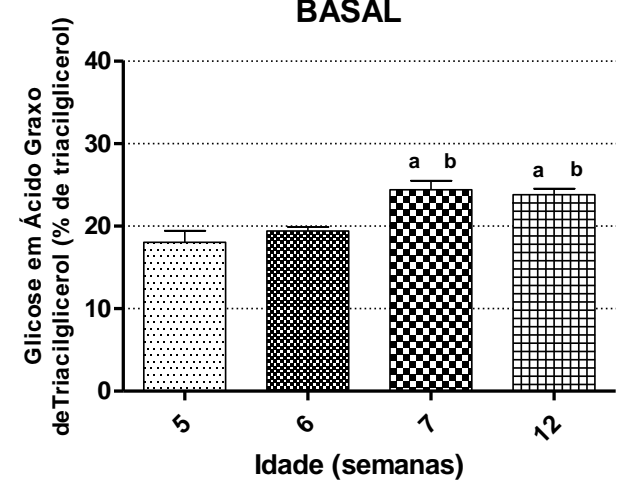

MÁXIMO

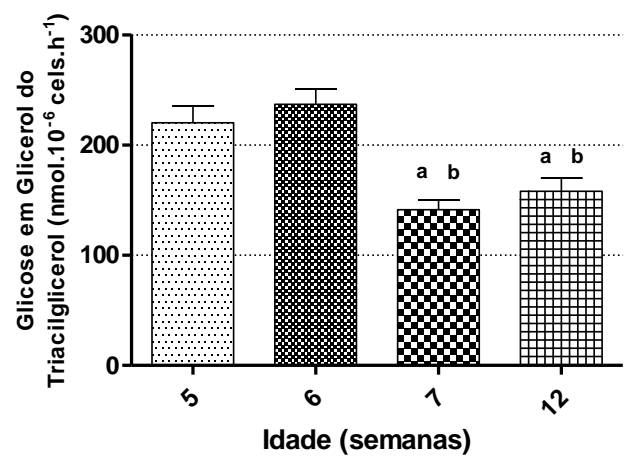

MÁXIMO

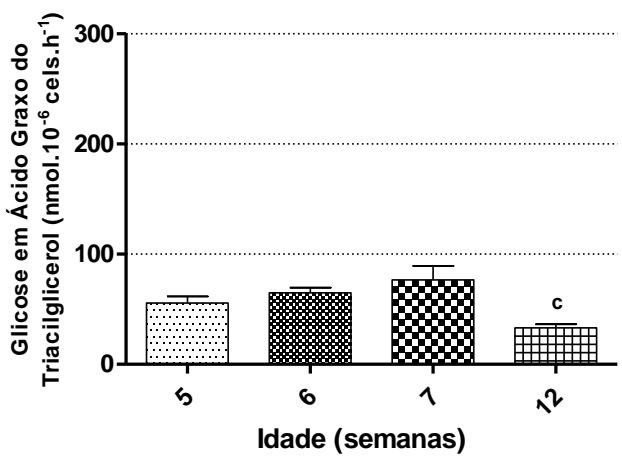

MÁXIMO

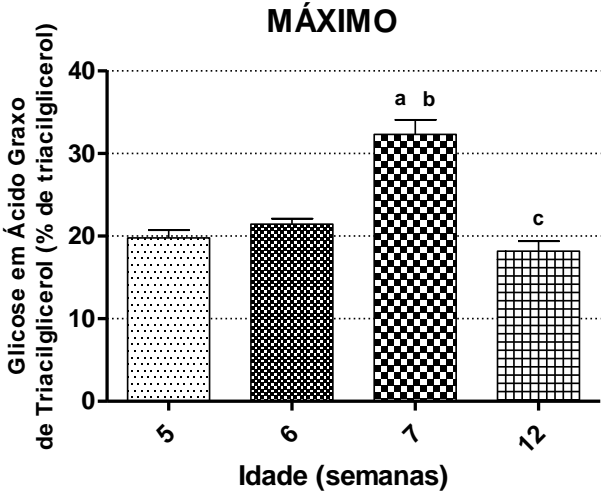

Quantidade de ácidos graxos e glicerol incorporados a triacilglicerol a partir da D-[U -14C]-Glicose em amostras representativas de cada semana de vida $(n=8)$. Os valores (em nmol. $10^{-6}$ cels. $h^{-1}$ e em $\%$ de triacilglicerol) correspondem à média \pm EPM. (a. $p<0.05$ vs $5^{\mathbf{a}}$ semana; b. $p<0.05$ vs $6^{\underline{a}}$ semana; c. $p<0.05$ vs $7^{a}$ semana). 
A incorporação de glicose em triacilglicerol foi,em sua maior parte,no resíduo glicerol em todas as semanas de vida, tanto na condição basal como na maximamente estimulada. A capacidade de incorporação de glicose em glicerol do triacilglicerol nestas duas condições apresentou-se diminuída na $7^{\underline{a}}$ e $12^{\underline{a}}$ semanas de vida. Perfil semelhante foi observado em relação à incorporação de glicose em ácidos graxos de triacilglicerol.

A porcentagem de incorporação não estimulada (basal) de glicose em ácidos graxos aumentou na $7^{\underline{a}}$ e $12^{a}$ semanas, apesar de estes valores serem menores em termos absolutos. Quando maximamente estimulada, o percentual de incorporação em ácidos graxos foi mais elevado apenas na $7^{\underline{a}}$ semana de vida. 


\subsubsection{Coxim Periepididimal}

Figura 17 - Incorporação de D-[U -14C]-glicose em glicerol e ácidos graxos de triacilglicerol no coxim periepididimal.

BASAL

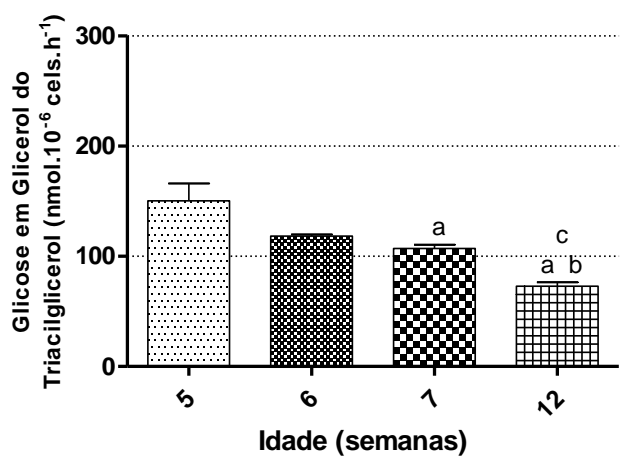

BASAL

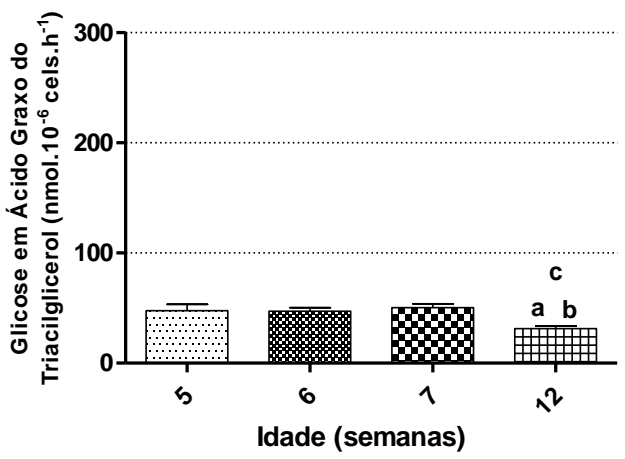

BASAL



MÁXIMO



MÁXIMO

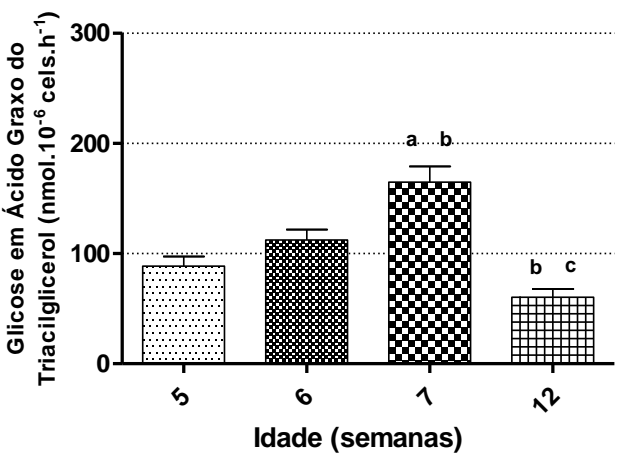

MÁXIMO



Quantidade de ácidos graxos e glicerol incorporados a triacilglicerol a partir da D-[U -14C]-Glicose em amostras representativas de cada semana de vida $(n=8)$. Os valores expressos (em nmol.10 ${ }^{-6}$ cels. $h^{-1}$ e em \% do triacilglicerol) correspondem à média \pm EPM. (a. $p<0.05$ vs $5^{\text {a }}$ semana; $b . p<0.05$ vs $6^{\underline{a}}$ semana; c. $p<0.05$ vs $7^{\underline{a}}$ semana). 
Tal como no coxim subcutâneo, a incorporação de glicose em triacilglicerol foi maior no resíduo glicerol em todas as semanas estudadas tanto em adipócitos não estimulados (basal) como maximamente estimulados por insulina. Quantitativamente a incorporação no resíduo glicerol apresentou valores menores na $12^{\underline{a}}$ semana de vida nas duas condições testadas (basal e máxima). Em relação ao resíduo ácido graxo, o mesmo ocorreu na $12^{\mathrm{a}}$ semana de vida em adipócitos não estimulados. Porém,na $7^{\text {a }}$ semana de vida, diferentemente dos demais períodos analisados, a incorporação de glicose em ácidos graxos foi maior em células estimuladas maximamente por insulina.

O percentual de incorporação de glicose em ácidos graxos foi menor na $5^{\mathrm{a}}$ semana de vida no ponto basal do teste, enquanto no ponto máximo do teste, houve aumento da incorporação de glicose em ácidos graxos na $7^{\underline{a}}$ semana de vida. 


\subsection{Atividade das enzimas lipogênicas - málica (EM), glicose 6- fosfato desidrogenase (G6PDH) e ácido graxo sintase (FAS)}

\subsubsection{Coxim Subcutâneo}

Figura 18 - Atividade das enzimas lipogênicas - málica (EM), glicose 6- fosfato desidrogenase (G6PDH) e ácido graxo sintase (FAS).

MÁLICA

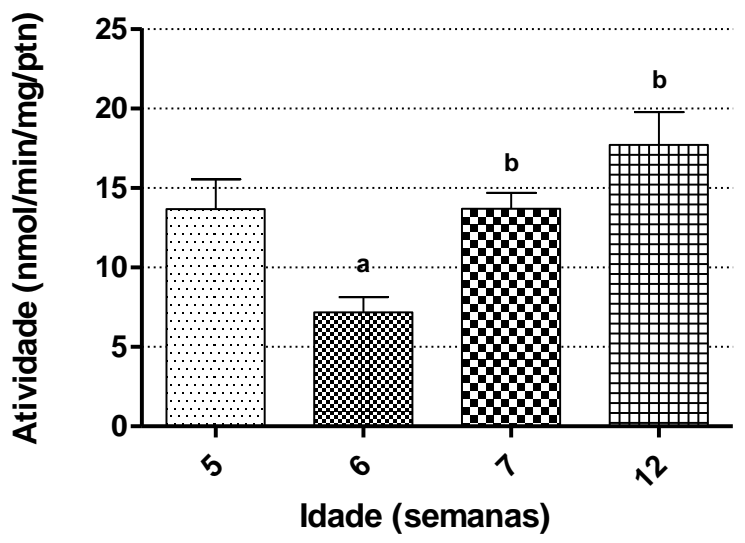

G6PDH

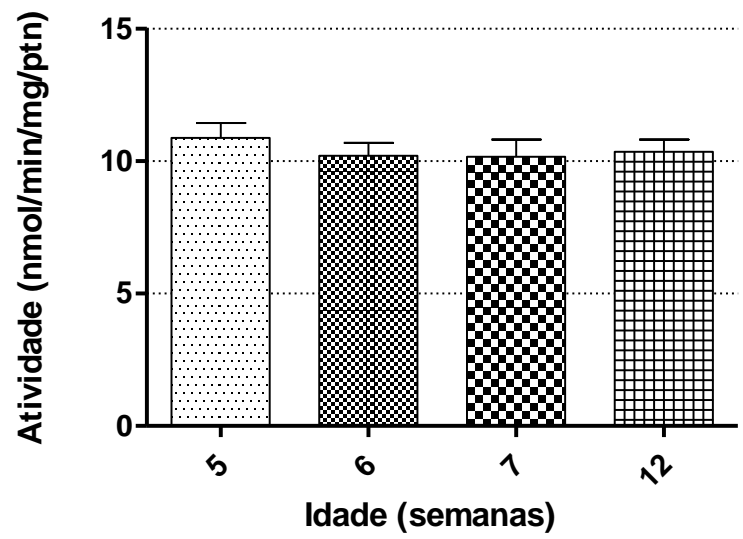

FAS

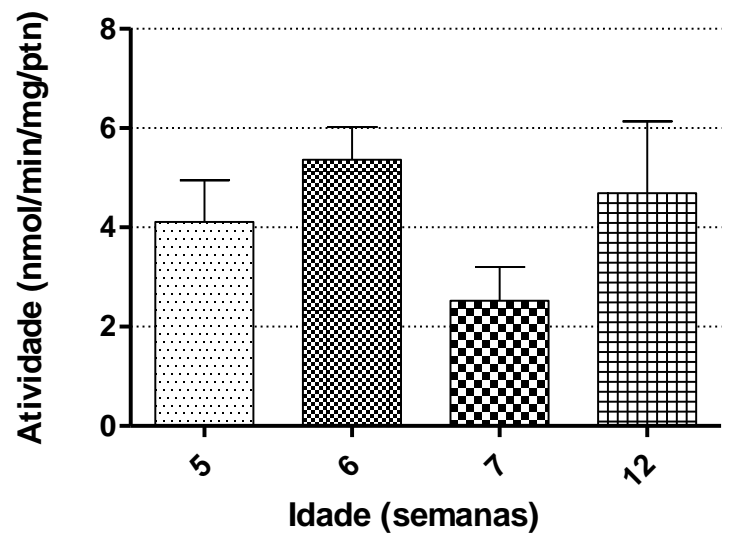

Atividade das enzimas lipogênicas do coxim subcutâneo $(n=9-10)$. Os valores expressos em $(\mathrm{nmol} / \mathrm{min} / \mathrm{mg} / \mathrm{proteína})$ correspondem à média \pm EPM em cada ponto. (a. $\mathrm{p}<0.05$ vs $5^{\underline{a}}$ semana; $b$. $p<0.05$ vs $6^{\underline{a}}$ semana; c. $p<0.05$ vs $7^{\text {a }}$ semana). 
Entre as enzimas lipogênicas estudadas, apenas a málica (EM) apresentou alterações durante o período estudado (5 $5^{a}, 6^{\underline{a}}$ e $7^{\underline{a}}$ e $12^{\underline{a}}$ semana de vida). A atividade máxima da enzima málica apresentou redução da $5^{\underline{a}}$ para a $6^{\underline{a}}$ semanas se recuperando nas demais. Por outro lado, as atividades das enzimas G6PDH e FAS não se modificaram. A G6PDH praticamente se manteve inalterada enquanto a FAS mostrou oscilações não significativas da sua atividade.

\subsubsection{Coxim Periepididimal}

Figura 19 - Atividade das enzimas lipogênicas - málica (EM), glicose 6- fosfato desidrogenase (G6PDH) e ácido graxo sintase (FAS).

MÁLICA

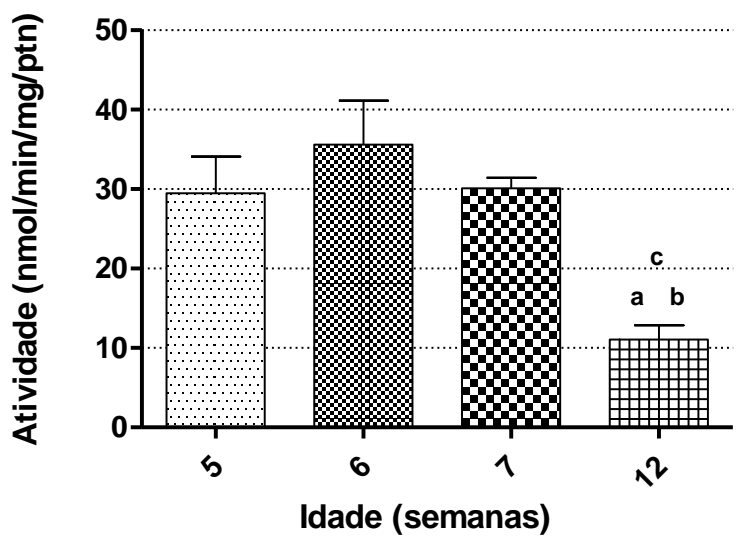

G6PDH

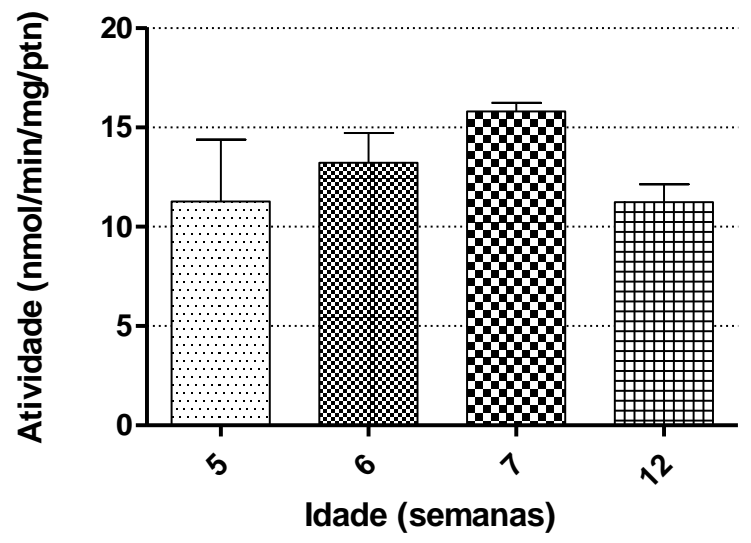

FAS

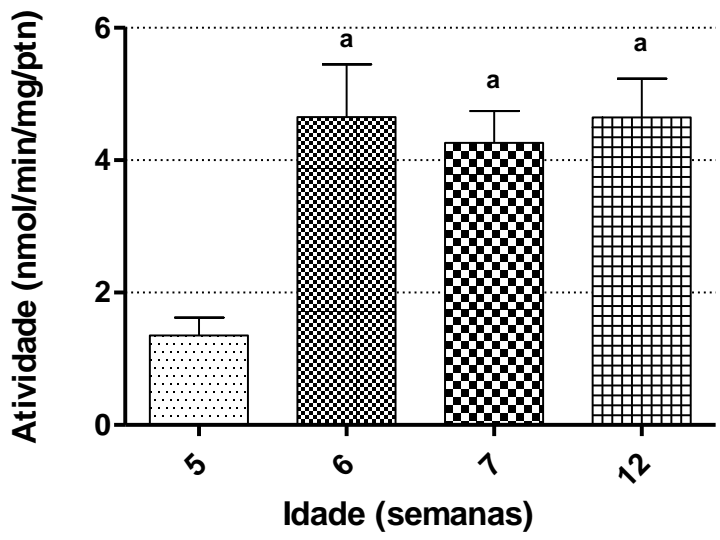

Atividade das enzimas lipogênicas do coxim periepididimal $(n=5-10)$. Os valores em (nmol/min/mg/proteína) correspondem à média \pm EPM em cada ponto. (a. $p<0.05$ vs 5a semana; $b$. $p<0.05$ vs $6^{\underline{a}}$ semana; c. $p<0.05$ vs $7^{\underline{a}}$ semana). 
No coxim adiposo periepididimal, ocorreram alterações apenas nas atividades das enzimas EM e FAS, enquanto a G6PDH manteve sua atividade constante ao longo das semanas de vida analisadas.

A EM apresentou menor atividade no animal adulto jovem, 12 semanas, em relação ao período inicial da puberdade (5 $5^{\underline{a}}, 6^{\underline{a}}$ e $7^{\underline{a}}$ semanas). A enzima FAS, por outro lado, apresentou um perfil contrário com crescimento de sua atividade a partir da $6^{\underline{a}}$ semana de vida a qual se manteve até a idade adulta.

\subsection{Expressão gênica de GLUT-1 e GLUT-4}

\subsubsection{Coxim Subcutâneo}

Figura 20 - Expressão gênica de GLUT-1(A) e GLUT-4 (B).

A

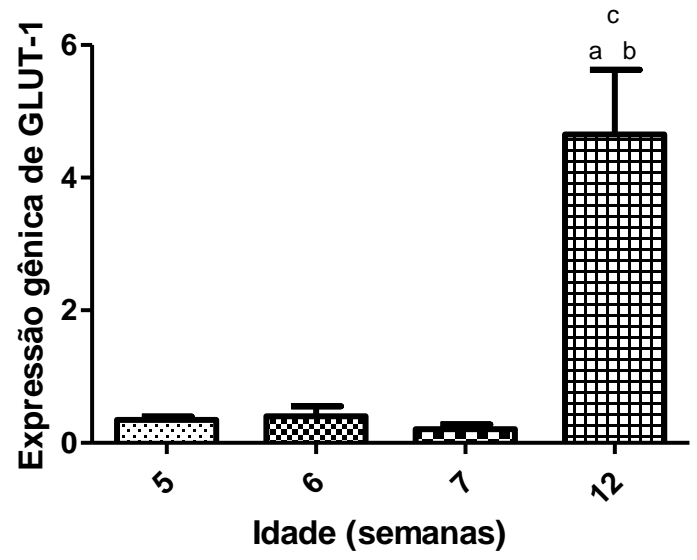

B

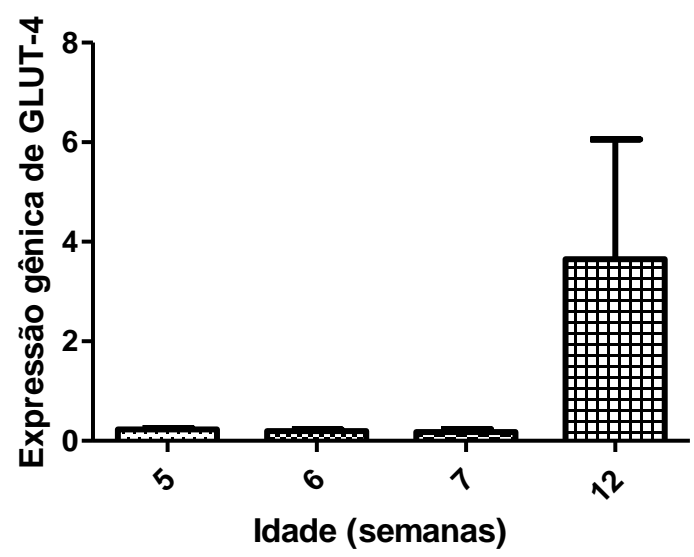

Expressão dos genes dos transportadores de glicose 1 e 4 (GLUT-1 e GLUT-4) no coxim adiposo $\mathrm{SC}$. Os valores expressos correspondem à média \pm EPM em cada ponto. (a. $p<0.05$ vs $5^{\mathrm{a}}$ semana; b. $p<0.05$ vs $6^{\underline{a}}$ semana; c. $p<0.05$ vs $7^{a}$ semana).

A expressão gênica de GLUT-1 foi significativamente maior na idade adulta $\left(12^{a}\right.$ semana). O mesmo perfil é observado em relação à expressão gênica de GLUT-4, apesar das diferenças não apresentarem significância estatística. 
Figura 21 - Expressão gênica de GLUT-1(A) e GLUT-4 (B).

A

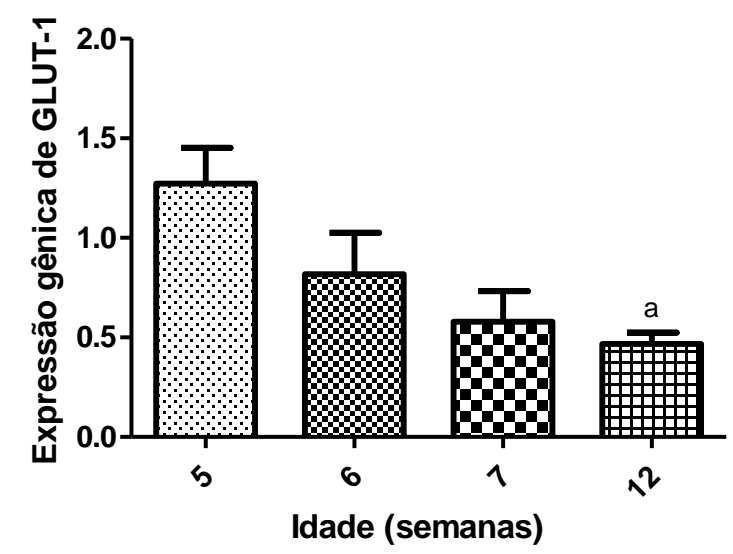

B

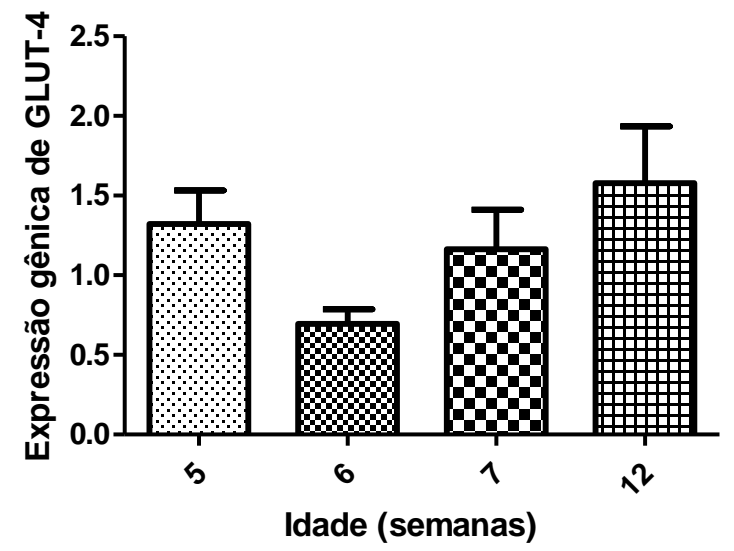

Expressão dos genes dos transportadores de glicose 1 e 4 (GLUT-1 e GLUT-4) no coxim adiposo $P E$. Os valores expressos correspondem à média \pm EPM em cada ponto. ( $\mathrm{a}$. $\mathrm{p}<0.05$ vs $5^{\mathrm{a}}$ semana; b. $p<0.05$ vs $6^{\underline{a}}$ semana; c. $p<0.05$ vs $7^{\underline{a}}$ semana).

A expressão gênica de GLUT-1 apresentou-se menor na $12^{\mathrm{a}}$ semana de vida, enquanto a expressão gênica de GLUT-4 não exibiu diferença significativa entre as semanas. 


\subsection{Expressão gênica de leptina e adiponectina}

\subsubsection{Coxim Subcutâneo}

Figura 22 - Expressão gênica de leptina (A) e adiponectina (B).
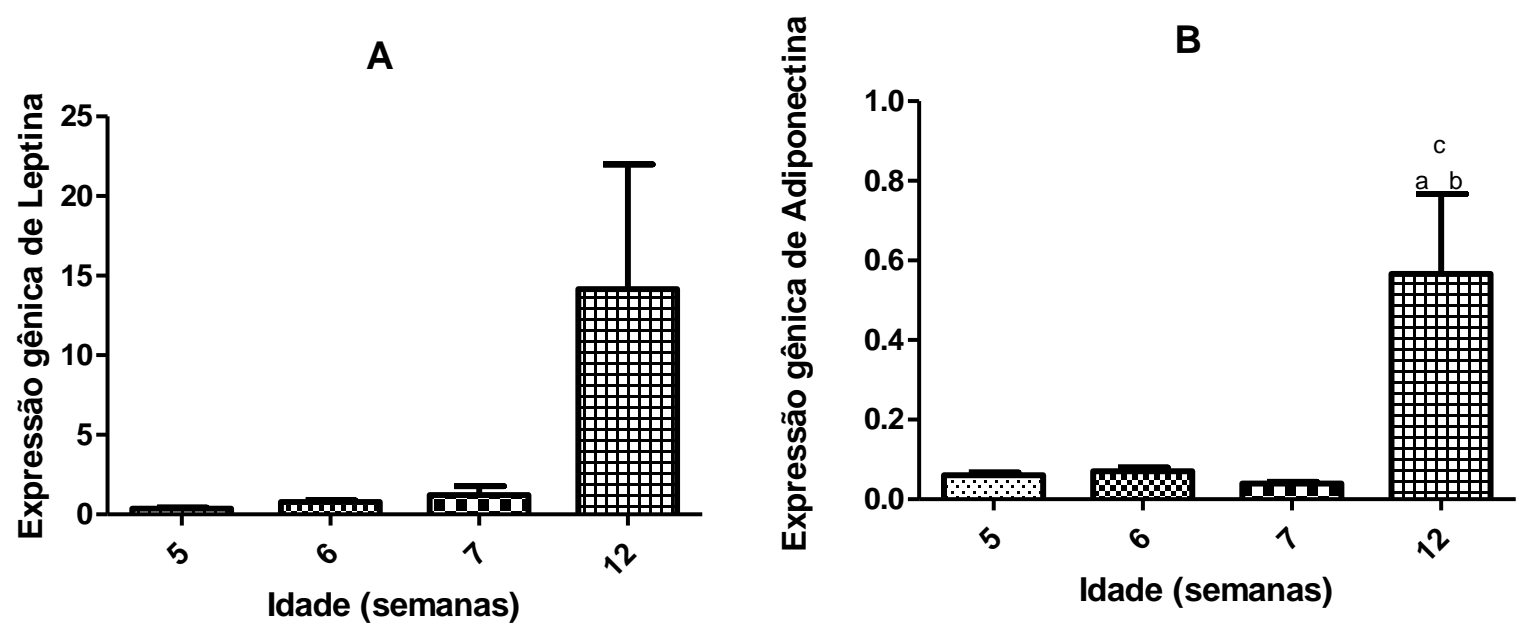

Expressão dos genes da Leptina e da Adiponectina no coxim adiposo SC. Os valores expressos correspondem à média \pm EPM em cada ponto. (a. $p<0.05$ vs $5^{\underline{a}}$ semana; $b$. $p<0.05$ vs $6^{a}$ semana; $c$. $\mathrm{p}<0.05$ vs $7^{\mathrm{a}}$ semana).

A expressão gênica de leptina e adiponectina no coxim adiposo SC apresentou perfis semelhantes, com maior expressão destes genes na $12^{\underline{a}}$ semana de vida, apesar desta diferença ser estatisticamente significativa apenas no perfil de expressão gênica da adiponectina. 
Figura 23 - Expressão gênica de leptina (A) e adiponectina (B).
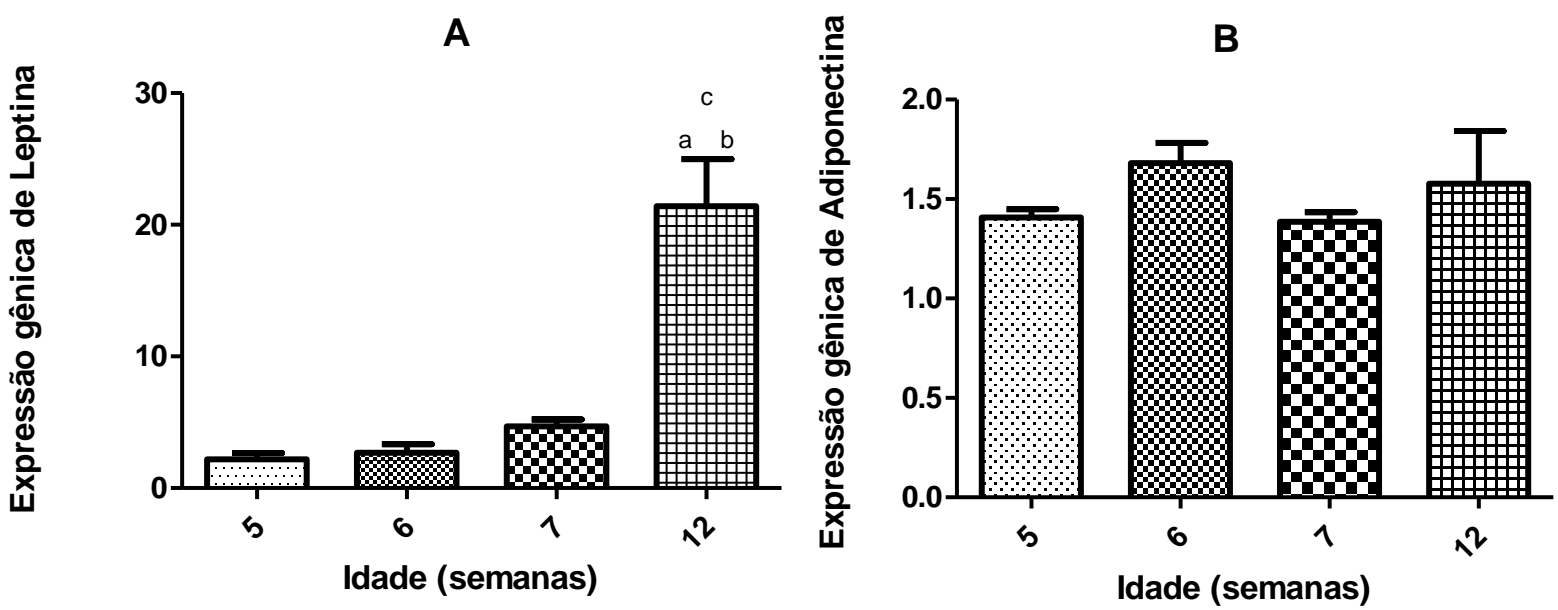

Expressão dos genes da Leptina e da Adiponectina no coxim adiposo PE. Os valores expressos correspondem à média \pm EPM em cada ponto. (a. $p<0.05$ vs $5^{a}$ semana; b. $p<0.05$ vs $6^{a}$ semana; $c$. $\mathrm{p}<0.05$ vs $7^{\mathrm{a}}$ semana).

A expressão gênica da leptina no coxim adiposo PE apresentou perfil semelhante ao observado no coxim SC, com maior expressão de leptina na $12^{\mathrm{a}}$ semana. Já a expressão gênica de adiponectina, não apresentou alterações ao longo das semanas de vida. 


\subsection{Expressão gênica do Receptor de Andrógeno}

4.18.1Coxim Subcutâneo

Figura 24 - Expressão gênica de receptor de andrógeno.



Expressão do gene do receptor de andrógeno no coxim adiposo SC. Os valores expressos correspondem à média \pm EPM em cada ponto. (a. $\mathrm{p}<0.05$ vs $5^{\mathrm{a}}$ semana; $\mathrm{b}$. $\mathrm{p}<0.05$ vs $6^{\mathrm{a}}$ semana; $\mathrm{c}$. $\mathrm{p}<0.05$ vs $7^{\underline{a}}$ semana).

A expressão gênica do receptor de andrógeno foi maior na 12a semana de vida. 


\subsubsection{Coxim Periepididimal}

Figura 25 - Expressão gênica de receptor de andrógeno.

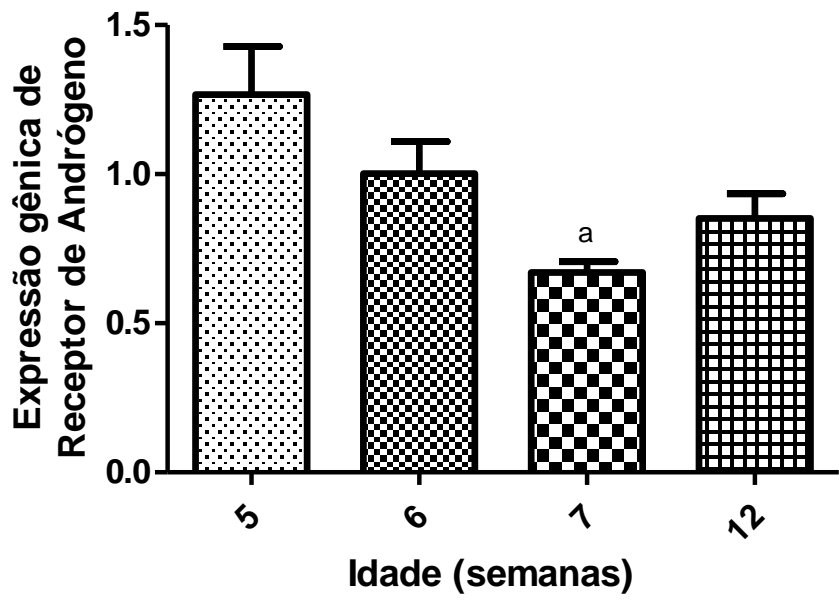

Expressão do gene do receptor de andrógeno no coxim adiposo PE. Os valores expressos correspondem à média \pm EPM em cada ponto. (a. $p<0.05$ vs $5^{\underline{a}}$ semana; $b$. $p<0.05$ vs $6^{\underline{a}}$ semana; $c$. $\mathrm{p}<0.05$ vs $7^{\mathrm{a}}$ semana).

A expressão gênica do receptor de andrógeno no coxim adiposo PE apresentou-se reduzida na $7^{\text {a }}$ semana de vida com diferença significativa em relação à 5aㅗ semana de vida. 


\section{DISCUSSÃO}

\subsection{Caracterização do período puberal}

Os parâmetros de desenvolvimento corporal e sexual analisados neste estudo auxiliaram na identificação e caracterização do período puberal, desde o seu início até o seu término. Os estudos compreenderam da $4^{\underline{a}}$ à $11^{\underline{a}}$ ou $12^{\underline{a}}$ semanas de vida e está detalhado a seguir.

Ojeda e colaboradores (1980) classificaram o desenvolvimento sexual em ratos baseados em parâmetros morfológicos e fisiológicos em 4 períodos distintos: 1) Período Neonatal que compreende a primeira semana de vida após o nascimento; 2)Período da Infância (do $8^{\circ}$ ao $21^{\circ}$ dia de vida);3) Juventude (do $22^{\circ}$ ao $35^{\circ}$ dia de vida); e, 4) Período Peripuberal (do $36^{\circ}$ ao $55^{\circ}-60^{\circ}$ dia de vida) com o aparecimento do espermatozoide maduro no canal deferente.

Em nossos animais, o consumo hídrico e alimentar, peso corporal, comprimento naso-anal, peso de testículos, epidídimo, canal deferente, vesículas seminais e concentração de testosterona no soro foram utilizados para identificar e caracterizar o período de rápido crescimento corporal e maturação sexual que culminam com a capacitação do indivíduo para a função reprodutora.

$\mathrm{O}$ aumento do consumo energético em nossos animais, assim como o aumento do ritmo de crescimento corporal característicos do período puberal aconteceram nas seguintes semanas: os consumos hídrico e alimentar apresentaram incremento mais intenso por volta da $6^{\text {a }}$ semana de vida, acompanhados de aumento de peso corporal mais intenso entre a $6^{\mathrm{a}}$ e a $8^{\mathrm{a}}$ semanas; o ritmo de aumento do comprimento naso-anal foi mais intenso entre a $5^{\text {a }}$ e a $7^{\text {a }}$ semanas de vida.

O estirão de crescimento puberal obviamente produz aumento das necessidades energéticas exigindo, portanto, aumento da ingestão hídrica e alimentar (BRONSON; RISSMAN, 1986; LLOYD, 2010; SHOMAKER, 2010). Em nossos animais, este aumento foi concomitante aos períodos em que o ritmo de crescimento se acentuou, corroborando os indícios de início da ocorrência da puberdade nestes momentos ( $5^{\underline{a}}, 6^{\underline{a}}$ e $7^{\mathrm{a}}$ semanas de vida). 
O estirão de crescimento puberal é resultado do aumento gradativo da secreção de testosterona e da amplitude dos pulsos de secreção de GH (CLARK; ROGOL, 1996; MAURAS, 1987;ROGOL; ROEMMICH; CLARK, 2002; TANNER, 1976).

O primeiro e mais intenso (dez vezes) aumento da amplitude dos pulsos de secreção de $\mathrm{GH}$ em ratos ocorre entre 33 e 40 dias de vida, seguidos de um segundo aumento entre 41 e 54 dias de idade (GABRIEL; RONCANCIO; RUIZ, 1992). O momento característico do aumento da amplitude de secreção de GH em ratos descrito no trabalho de Gabriel e colaboradores (1992) correspondeu ao período mais intenso de crescimento identificado em nossos animais (aumento do comprimento naso-anal entre a $5^{\underline{a}}$ e $7^{\text {a }}$ semanas de vida).

A análise do perfil de desenvolvimento dos órgãos sexuais permitiu inferir sobre o processo de maturação do eixo hipotálamo-hipófise-gônadas, orientandonos sobre o período da puberdade em nossos animais. O crescimento mais intenso dos testículos ocorreu entre 5 e 7 semanas de idade. Após o qual, observou-se um pico inicial de aumento da testosterona que ocorreu na $7^{\underline{a}}$ semana de vida. Este aumento da testosterona promoveu a maturação do epidídimo, canal deferente e vesículas seminais.

O epidídimo apresentou aumento intenso na $7^{\mathrm{a}}$ semana, correspondente ao primeiro pico de secreção de testosterona e também na $9^{\text {a }}$ semana de vida, período em que a concentração de testosterona atingiu valores observados no adulto jovem (12 semanas). Os aumentos mais intensos do peso do canal deferente foram observados também nestes períodos ( $7^{a}$ e $9^{a}$ semanas).

O crescimento mais intenso das vesículas seminais ocorreu na 9a semana de vida, correspondendo, portanto, ao período de maiores níveis de testosterona. Os andrógenos são essenciais para a morfogênese das ramificações da vesícula seminal responsáveis por seu crescimento, assim como para a manutenção da quantidade adequada destas ramificações (THOMSON; MARKER, 2006; TSUJ;; SHIMA; CUNHA, 1991).

Pesquisa publicada por Campion e colaboradores (2013) apresentou conclusões que corroboram nossos resultados. Neste estudo com ratos Wistar Han, a separação balono-prepucial, sinal externo que indica o início da puberdade e é dependente de andrógenos, ocorreu em uma faixa entre $36\left(1^{\circ}\right.$ dia da $6^{\underline{a}}$ 
semana) e 48 (7 semanas) dias de vida. Além disso, Campion e colaboradores (2013) descreveram início do aumento do número de espermátides no $42^{\circ}$ dia de vida (6 semanas) e do número de espermatozóides no epidídimo por volta da $49^{\circ}$ dia ( 7 semanas).

Payne e colaboradores (1977) estudaram o perfil de secreção de hormônio liberador de gonadotrofinas $(\mathrm{GnRH})$ e caracterizaram seu aumento gradual, atingindo-se um patamar com valores característicos do animal adulto aos 52 dias de vidas (8 semanas) dos ratos. A concentração de hormônio luteinizante (LH) atinge valores adultos entre 35 (5 semanas) e 45 (7 semanas) dias de vida, enquanto os valores do hormônio folículo estimulante (FSH) atingem estes patamares entre 25 (4 semanas) e 35 (5 semanas) dias vida (DEBELJUK; ARIMURA; SCHALLY, 1972; DULLAART, 1977; PAYNE, 1977).

Assim, a partir das observações dos padrões de desenvolvimento corporal e de maturação sexual estudados e descritos acima, identificamos a $5^{\underline{a}}$, $6^{\underline{a}}$ e $7^{\underline{a}}$ semanas de vida como o início do período puberal em que se iniciam as principais alterações que capacitam o animal para a vida reprodutiva, sendo este o momento de interesse para estudarmos o desenvolvimento do tecido adiposo. As características do tecido adiposo puberal foram comparadas com as do adulto jovem (12 $2^{\text {a }}$ semana), quando o processo de alterações fisiológicas puberaisjá ocorreue estas variações já se estabilizaram.

\subsection{Metabolismo do Tecido Adiposo}

Os primeiros estudos metabólicos realizados foram o teste oral de tolerância à glicose (OGTT)e dosagem sérica de glicose e insulina a fim de averiguarmos o panorama sistêmico do metabolismo de glicose durante a puberdade, uma vez que pesquisadores têm relatado resistência fisiológica à insulina neste período em humanos (AMIEL, 1991; BLOCH; CLEMONS; SPERLING, 1987; MORAN, 1999; POTAU, 1997; ROEMMICH, 2002).

Os animais apresentaram intolerância à glicose na $5^{\underline{a}}$ semana de vida a qual retornou ao normal a partir da $6^{\text {a }}$ semana (Figura 6). O quadro de intolerância à glicose pode decorrer de dois possíveis fatores: secreção deficiente de insulina 
pelo pâncreas ou devido à presença da resistência à ação deste hormônio nos tecidos insulino-sensíveis.

Devido ao fato de já estar bem descrito o episódio de resistência fisiológica à insulina no período puberal em humanos (GORAN; GOWER, 2001; MORAN, 1999; ROEMMICH, 2002; SANTORO, 2009) assim como a ocorrência de resistência puberal à insulina em músculo de ratos Sprague Dawley (GOODMAN, 1983), acreditamos que o quadro de intolerância à glicose observada em nossos animais possa ser decorrente de uma possível resistência fisiológica à insulina nesta etapa do desenvolvimento puberal, apesar de não termos conseguido caracterizar este fato em razão dos resultados inconclusivos do ITT (resultados não apresentados).

A glicemia e a insulinemia de jejum dosadas no soro não demonstraram alterações condizentes com o quadro de intolerância à glicose, isto é, insulinemia insuficiente para a manutenção de normoglicemia, na 5a semana de vida (Figura 7). Nesta semana, a glicemia e a insulinemia de jejum apresentaram valores mais baixos do que os observados nas semanas seguintes, indicando que a secreção basal de insulina na $5^{\text {a }}$ semana foi suficiente para a manutenção da homeostase glicêmica, apesar do quadro de deficiência (absoluta ou relativa) de secreção de insulina nesta semana revelado pela resposta glicêmica ao OGTT.

Além disso, a capacidade de captação basal de glicose dos adipócitos isolados do coxim adiposo SC estava aumentada no período em que foi observada a intolerância à glicose (5⿳亠丷厂 semana) (Figura 12) o que pode ter contribuído para o controle glicêmico evitando alterações na glicemia de jejum.

O perfil de glicemia e insulinemia de jejum dosados no soro demonstrou um aumento gradativo destes parâmetros metabólicos ao longo das semanas estudadas, ou seja, no decorrer do desenvolvimento foram necessárias maiores concentrações de insulina para manutenção da normoglicemia, a qual se mostrou também aumentada em relação às semanas iniciais.

Em estudo realizado por Raghavan (1997), os pesquisadores identificaram a instalação de resistência à insulina pós puberal em músculos de ratos SpragueDawley (menor que a resistência puberal) com redução da captação de glicose estimulada por insulina quando comparado com os valores pré-puberais.

Desta forma, nossos dados de glicemia e insulinemia de jejum (soro) somados ao estudo de Raghavan (1997) levam a crer que assim como nos animais 
Sprague-Dawley, nossos animais Wistar tem a instalação de uma resistência à insulina pós-puberal.

A responsividade à insulina dos adipócitos isolados do coxim adiposo SC verificada através do teste de captação de ${ }^{3} \mathrm{H}$-2-desoxiglicose $\left({ }^{3} \mathrm{H}-2 \mathrm{DG}\right)$ por área de membrana foi maior na $5^{\underline{a}}$ e $6^{\underline{a}}$ semanas de vida (Figura 12) demonstrando que apesar da alteração do controle glicêmico na $5^{\text {a }}$ semana revelada pelo OGTT, o tecido adiposo não teve prejuízo em sua resposta ao estímulo da insulina neste período.

Assim, nesta idade onde houve alteração do controle glicêmico e, portanto, prejuízo da utilização de glicose pelos tecidos insulino sensíveis, um deles, o tecido adiposo, apresentou capacidade de captação de glicose normal levando a crer que pode haver um desvio deste substrato energético para sua utilização pelo tecido adiposo SC.

Poder-se-ia pensar que esta melhor responsividade à insulina na $5^{\underline{a}}$ e $6^{\text {a }}$ semanas ocorreu devido ao menor volume celular dos adipócitos SC nestas semanas, já que muitos estudos relatam correlação inversa entre o tamanho do adipócito e a sensibilidade à insulina (LIVINGSTON; CUATRECASA; LOCKWOOD, 1972; LUNDGREN, 2007; SALANS; KNITTLE; HIRSCH, 1968; SALANS;DOUGHERTY, 1971). Por outro lado, as diferenças de responsividade à insulina entre as semanas estudadas não corresponderam às variações do diâmetro do adipócito, já que na $5^{\underline{a}}, 6^{\underline{a}}$ e $7^{\underline{a}}$ semanas os diâmetros apresentaram-se semelhantes, porém com capacidades de resposta diferentes à insulina.

A responsividade à insulina aumentada no período da $5^{\text {a }}$ e $6^{\text {a }}$ semanas no coxim adiposo SC, claramente observada pela análise da captação de glicose por área de membrana, é corroborada por seus resultados expressos por número de células. Estes demonstram maior capacidade de captação de glicose na $5^{\mathbf{a}}$ e $6^{\underline{a}}$ semanas, com uma redução na $7^{a}$ a semana de vida. Esta redução pode ser decorrente do primeiro pico de testosterona neste período, pois este hormônio exerce efeito inibitório sobre a sensibilidade à insulina no tecido adiposo (MACOTELA, 2009).

A leptina e $\circ \mathrm{GH}$, dois hormônios chaves do período puberal, também possuem efeito de redução da ação da insulina no tecido adiposo (DOMINICI, 2005; MULLER, 1997), porém, o início do aumento da concentração plasmática 
destes [leptina: 8 ${ }^{a}$ semana (Figura 10) e segundo trabalho de Gabriel e colaboradores (1992) $\mathrm{GH}: 5^{\mathrm{a}}$ (33 dias) e $6^{\underline{a}}$ semanas (40 dias)] não corresponderam ao período em que se observaram alterações na capacidade de captação de glicose no tecido adiposo puberal.Logo, a testosterona parece ter desempenhado um papel preponderante sobre as mudanças da capacidade de captação de glicose no TAB puberal.

Os valores da capacidade de captação de glicose por célula na $12^{\underline{a}}$ semana são semelhantes aos observados na $5^{\underline{a}}$ e $6^{\underline{a}}$ semanas. Isto pode ser explicado pelo fato de os adipócitos serem maiores nesta idade e, portanto, apesar de uma menor densidade de transportadores de glicose (demonstrada pela menor captação de glicose por área de membrana), uma maior área de membrana total resultou em uma capacidade de captação total semelhante.

A análise da expressão gênica de GLUT-1 no tecido adiposo SC demonstrou que há uma maior expressão gênica de GLUT-1 na 12 $2^{-a}$ semana de vida (Figura 20 A), levando a crer que as diferenças na capacidade de captação basal de glicose observadas no teste (maior capacidade na $5^{\underline{a}}$ semana) possam ser devidas a alterações nas quantidades de proteína GLUT-1 na fração de membrana, uma vez que a expressão gênica total deste transportador não corroborou os resultados dos ensaios biológicos.

Da mesma forma, o perfil de expressão gênica de GLUT-4 (Figura 20 B) não acompanhou os resultados dos ensaios biológicos em que houve menor capacidade de captação máxima de glicose na $7^{\underline{a}}$ semana de vida. Assim, as variações nos valores de captação máxima de glicose (estimulada por insulina) devem ter ocorrido em razão de alterações da capacidade de translocação de GLUT-4 para a membrana celular.

A expressão gênica do receptor de andrógeno (AR) no coxim adiposo SC aumentou na $12^{\underline{a}}$ semana de vida, período em que houve maior concentração de testosterona no soro indicando up-regulation da expressão gênica de AR neste coxim pela testosterona. Este fenômeno não resultou em maior efeito da testosterona sobre o metabolismo do tecido adiposo, uma vez que o possível efeito inibitório deste hormônio sobre a ação da insulina não foi observado na $12^{\text {a }}$ semana. 
A capacidade de incorporação de glicose em lipídeos também se apresentou aumentada nas $5^{\text {a }}$ e $6^{\text {a }}$ semanas puberais nos adipócitos isolados do coxim adiposo SC (Figura 14). Assim, nas semanas iniciais da puberdade (5 e $6^{\underline{a}}$ semanas), tem-se uma capacidade de captação de glicose normal acompanhada por maior capacidade de incorporação de glicose em lipídeos incrementando o aproveitamento deste substrato pelo tecido adiposo SC. O aumento da testosteronemia verificado a partir da $7^{\underline{a}}$ semana de vida (Figura 5) pode ter causado esta redução da capacidade de incorporação de glicose em lipídeos, uma vez que se demonstrou que a testosterona inibe síntese de lipídeos a partir da glicose (HANSEN; FAHMY;NIELSEN, 1980; MACOTELA, 2009). Além disso, o aumento da leptinemia observado na $8^{\text {a }}$ semana (Figura 10) pode ter contribuído para a redução da capacidade de incorporação de glicose em lipídeos estimulada por insulina na $12^{\underline{a}}$ semana de vida (Figura 14), uma vez que Ceddia e colaboradores (1998) concluíram que leptina inibe a incorporação de glicose em lipídeos em TAB.

A expressão gênica de leptina no coxim adiposo SC (Figura 22 A) acompanhou o perfil de leptinemia no soro apresentando maiores valores durante a idade adulta quando temos maior número de células no coxim, assim como células de maior tamanho.

Sabendo-se que a glicose incorporada em triacilglicerol pode fazê-lo ocupando o resíduo glicerol ou o resíduo ácido graxo, nossos resultados indicam que a maior quantidade da glicose destinou-se ao glicerol independentemente das diferentes intensidades de incorporação de glicose em lipídeos observadas.

Quando ocorreu redução no montante incorporado em lipídeos em termos absolutos, o que se verificou nas $7^{\underline{a}}$ e $12^{\underline{a}}$ semanas nos adipócitos isolados do coxim adiposo SC, percentualmente, houve uma elevação do montante incorporado em ácidos graxos do triacilglicerol.

A atividade das enzimas lipogênicas málica, glicose-6-fosfato desidrogenase (G6PDH) e do complexo enzimático ácido graxo sintase (FAS) foi analisada no coxim SC e demonstrou-se que as variações da capacidade de incorporação de glicose em lipídeos não apresentaram correspondência com o nível de atividade máxima destas enzimas. 
No coxim SC, as atividades das enzimas G6PDH e FAS não variaram ao longo da puberdade. A atividade da enzima málica, que catalisa a transformação de malato a piruvato e é uma das responsáveis pela geração de NADPH e importante fornecedor deste fator para a síntese de ácidos graxos (WISE; BALL, 1964), teve sua atividade reduzida na $6^{\mathrm{a}}$ semana de vida (Figura 18).

Assim, a maior capacidade puberal de incorporação de glicose em lipídeos não pôde ser explicada pelas alterações observadas na mensuração da atividade máxima das enzimas lipogênicas, já que estas não acompanharam as alterações observadas nas capacidades de incorporação de glicose em lipídeos no tecido adiposo SC.

O tecido adiposo PE não apresentou variações importantes em sua capacidade de captação basal de glicose por célula (Figura 13). Quando estimulado por insulina, este coxim apresentou maior capacidade de captação de glicose na $12^{\mathrm{a}}$ semana. Desta forma, não houve prejuízo da capacidade de captação de glicose neste coxim no início da puberdade (5 $5^{\underline{a}}$ semana) (Figura 6) quando se observou a intolerância à glicose através do OGTT.

As alterações na taxa de captação de glicose por unidade de área de membrana no coxim PE se reduziram ao longo do desenvolvimento. Esta redução parece estar mais relacionada ao aumento do volume celular.

Um interessante estudo (FRANCK, 2007) mostrou que a quantidade de receptor de insulina (IR), do substrato do receptor de insulina 1 (IRS-1) e de transportador de glicose (GLUT-4) não variam entre células de diferentes tamanhos, assim como não varia a capacidade de fosforilação de IR, IRS-1 e Akt. Porém, o estímulo da insulina sobre os adipócitos maiores resulta em um menor translocação destes transportadores por área de membrana celular. Assim, as diferentes capacidades de captação de glicose por área de membrana observadas em nossos animais parecem ser resultado desta menor densidade de transportadores de glicose.

As células maiores (como as encontradas na 12a semana) com menor densidade de transportadores de glicose apresentaram menor taxa de captação de glicose por área de membrana, porém no total (por célula) captaram mais (Figura 13). 
A expressão gênica de GLUT-1 no coxim adiposo PE (Figura 21 A) apresentou uma redução ao longo das semanas de vida a qual não acompanhou os resultados observados na captação basal de glicose. O nosso achado de que a captação basal não apresentou variações de seus valores ao longo das semanas estudadas, sugere que apesar de a expressão gênica estar alterada (redução ao longo das semanas), a quantidade de proteína GLUT-1 na membrana não foi alterada de forma evidente entre as semanas. A expressão gênica de GLUT-4 (Figura 21 B) por outro lado, apresentou perfil semelhante ao observado na captação máxima de glicose (estimulada por insulina).

A capacidade de incorporação de glicose em lipídeos dos adipócitos isolados do coxim adiposo PE apresentou-se maior nas $5^{\underline{a}}, 6^{\underline{a}}$ e $7^{\underline{a}}$ semanas puberais. Como observado no coxim adiposo SC, a elevação da testosteronemia pode ter contribuído para estas alterações da capacidade de incorporação de glicose em lipídeos. A testosterona exerce efeito inibitório sobre a incorporação de glicose em lipídeos tanto em coxim SC como em gordura perigonadal de ratos machos (HANSEN; FAHMY; NIELSEN, 1980; MACOTELA, 2009). Porém, no tecido adiposo PE, o efeito da testosterona parece ter ocorrido apenas quando a concentração deste hormônio atingiu valores característicos da idade adulta (12 $2^{\mathrm{a}}$ semana).

A expressão gênica do receptor de andrógeno (AR) no coxim PE apresentou-se reduzida na $7^{\underline{a}}$ semana de vida em relação à semana inicial ( $5^{\underline{a}}$ semana), período que corresponde ao primeiro pico de testosterona no soro dos animais, indicando um efeito de down-regulation, efeito contrário ao observado no coxim SC. Esta alteração da expressão do AR na $7^{\text {a }}$ semana poderia explicar a possível ação inibitória da testosterona sobre a incorporação de glicose em lipídeos apenas na $12^{\underline{a}}$ semana, apesar de seu aumento ter se iniciado na $7^{\text {a }}$ semana.

No coxim PE, a leptinemia parece ter desempenhado um papel preponderante nas alterações da capacidade lipogênica do TAB puberal. A leptinemia aumentou na $8^{\text {a }}$ semana de vida e a partir daí manteve-se em um mesmo patamar mais alto do que nas semanas iniciais (Figura 10). Este maior patamar de leptinemia pode ter contribuído para a redução da capacidade lipogênica na $12^{\text {a }}$ semana de vida (Figura 15) e tal hipótese se apoia em estudos (CEDDIA, 1998) em que a leptina inibiu a incorporação de glicose em lipídeos em 
TAB. A expressão gênica de leptina no coxim adiposo PE (Figura 23 A) assim como o que foi observado no coxim SC, acompanhou o perfil de leptinemia no soro com maiores valores durante a idade adulta quando as células têm tamanho maior e o tecido uma maior celularidade.

As mudanças nas atividades das enzimas lipogênicas do coxim adiposo PE apresentaram correspondência com as alterações nas capacidades lipogênicas observadas durante a puberdade neste coxim.

A FAS apresentou aumento de sua atividade da $5^{\mathrm{a}}$ para a $6^{\mathrm{a}}$ semana e esta alteração se manteve nas semanas seguintes. Esta atividade aumentada não foi acompanhada de aumento da capacidade lipogênica neste tecido, pelo contrário, a capacidade lipogênica se reduziu com a idade adulta. Porém, a atividade máxima da enzima málica apresentou-se diminuída na $12^{\mathrm{a}}$ semana, o que pode ter contribuído para a redução da capacidade lipogênica visto que ela colabora com a lipogênese pelo fornecimento de NADPH essencial para que a síntese de ácidos graxos ocorra. Assim, a redução na oferta de NADPH pode estar contribuindo para a diminuição observada na capacidade lipogênica ao longo do desenvolvimento no coxim adiposo $\mathrm{PE}$.

A redução da atividade da enzima málica na $12^{\mathrm{a}}$ semana acrescenta mais um indício da possível participação da leptina na redução da capacidade lipogênica observada (Figura 19), já que a incubação de adipócitos com doses supra fisiológicas de leptina resultam em redução da atividade da enzima málica (CEDDIA, 1998).

\subsection{Análise Morfológica do Tecido Adiposo}

O tecido adiposo revelou um aumento mais intenso da sua massa após as fases iniciais do período puberal. O peso dos coxins aumentou gradualmente, mas foi mais intenso na $11^{\text {a }}$ no coxim SC e na $9^{\text {a }}$ semana de vida no PE. O peso dos coxins (SC mais PE) por grama de peso corporal revelou, porém, um aumento mais intenso nas semanas puberais ( $5^{\mathrm{a}}$ a $8^{\mathrm{a}}$ semanas) o que foi ao encontro da maior capacidade de incorporação de glicose em lipídeos observada nesses mesmos períodos em ambos os coxins. 
O aumento da massa adiposa ocorre em razão de dois processos: aumento do tamanho das células (hipertrofia) e aumento do número de células (hiperplasia) (JO, 2009).

Pela análise do aumento do diâmetro dos adipócitos constatamos uma importante hipertrofia dos adipócitos entre a $7^{\underline{a}}$ e a $8^{\underline{a}}$ semanas de vida resultando em novos valores que se mantiveram até a $12^{\text {a }}$ semana de vida.

A capacidade de incorporação de glicose em lipídeos aumentada nas semanas puberais tanto no coxim adiposo SC quanto no PE resultou em importante aumento do diâmetro dos adipócitos neste período com intensa hipertrofia do tecido adiposo puberal que implicou na formação de adipócitos característicos do adulto já no fim deste período (8ª semana).

Observaram-se duas fases em relação ao diâmetro dos adipócitos: uma fase inicial com valores menores (diâmetro médio SC: 48,58 $\mu \mathrm{M}$ e média PE: 45,94 $\mu \mathrm{M}$ ) e outra fase com adipócitos mais hipertrofiados (diâmetro médio SC: 65,69 $\mu \mathrm{M}$ e média PE: 67,11 $\mu \mathrm{M}$ ) ao final da puberdade até a vida adulta. Este mesmo perfil de aumento é observado em relação à leptina sérica, visto que seus níveis se elevaram acompanhando as alterações descritas em relação ao aumento do diâmetro do adipócito.

A avaliação da leptinemia por grama de coxim adiposo ( $\mathrm{SC}+\mathrm{PE})$ demonstrou que, apesar da menor leptinemia em valores absolutos nas semanas puberais, a concentração de leptinapor grama de coxim adiposo é maior no período puberal.

A adiponectinemia, por outro lado, não apresentou alterações em sua concentração no soro durante as diferentes semanas do desenvolvimento. A expressão gênica de adiponectina no coxim SC apresentou perfil semelhante ao da expressão gênica de leptina com maiores valores na idade adulta (12 semanas), diferindo da adiponectinemia dosada no soro dos animais a qual não apresentou variação ao longo das semanas. Já a expressão gênica de adiponectina no coxim adiposo PE não apresentou diferenças entre as semanas de vida estudadas acompanhando o perfil de adiponectinemia dosado no soro dos animais.

O cálculo indireto da celularidade revelou um importante aumento do número de células entre a $6^{\underline{a}}$ e $7^{\underline{a}}$ semanas de vida até atingir valores semelhantes aos encontrados na idade adulta (12 semanas). 
A análise do desenvolvimento global do tecido adiposo através da observação do aumento de peso dos coxins adiposos SC e PE, assim como do diâmetro destes adipócitos e do número de células demonstraram um importante desenvolvimento puberal deste tecido que resultou em um tecido adiposo característico do animal adulto já na8 ${ }^{\mathrm{a}}$ semana de vida. 


\section{CONCLUSÕES}

- Na puberdade, paralelamente à intolerância à glicose transitória que ocorre nas semanas iniciais, e, portanto, prejuízo da utilização da glicose pelos tecidos insulino-dependentes, o tecido adiposo SC e PE têm sua responsividade à insulina normal e uma melhor capacidade de incorporação de glicose em lipídeos o que leva a crer que há um desvio da utilização deste substrato energético, a glicose, para a formação do tecido adiposo o qual tem um papel permissivo para maturação do eixo reprodutor;

- as alterações metabólicas puberais do tecido adiposo são mais evidentes no coxim SC do que no $\mathrm{PE}$, ao contrário do que se poderia supor em razão da gordura PE ser anatomicamente relacionada ao sistema reprodutor;

- a intolerância à glicose puberal (5 ${ }^{\mathrm{a}}$ semana) parece promover um desvio deste substrato energético para o tecido adiposo SC e PE;

- a puberdade altera a responsividade à insulina do coxim adiposo SC;

- a puberdade altera a capacidade lipogênica dos coxins adiposos SC e PE;

- as alterações do metabolismo do tecido adiposo no período puberal não guardaram relação com o aumento do volume celular ao longo das semanas. 


\section{REFERÊNCIAS*}

AHIMA, R. S.; DUSHAY, J.; FLIER, S. N.; PRABAKARAN, D.; FLIER, J. S. Leptin accelerates the onset of puberty in normal female mice. J. Clin. Invest.,v. 99, p. 391-395, 1997.

AHIMA, R. S.; FLIER, J. S. Adipose tissue as an endocrine organ. Trends Endocrinol. Metab.,v. 11, p. 327-332, 2000.

AHIMA, R. S. Adipose tissue as an endocrine organ. Obesity (Silver Spring),v. 14, p. 242S-249S, 2006.Suppl 5.

AMIEL, S. A.; CAPRIO, S.; SHERWIN, R. S.; PLEWE, G.; HAYMOND, M. W.; TAMBORLANE, W. V. Insulin resistance of puberty: a defect restricted to peripheral glucose metabolism. J. Clin. Endocrinol. Metab.,v. 72, p. 277-282, 1991.

APTER, D. The role of leptin in female adolescence. Ann. N. Y. Acad. Sci.,v. 997, p. 6476, 2003.

ARNER, P. Effects of testosterone on fat cell lipolysis. Species differences and possible role in polycystic ovarian syndrome. Biochimie,v. 87, p. 39-43, 2005.

BARZILAI, N.; WANG, J.; MASSILON, D.; VUGUIN, P.; HAWKINS, M.; ROSSETTI, L. Leptin selectively decreases visceral adiposity and enhances insulin action.J. Clin. Invest., v. 100, p. $3105-3110,1998$.

BATES, S. H.; DUNDON, T. A.; SEIFERT, M.; CARLSON, M.; MARATOS-FLIER, E.; MYERS, M. G., JR. LRb-STAT3 signaling is required for the neuroendocrine regulation of energy expenditure by leptin. Diabetes,v. 53, p. 3067-3073, 2004.

BAZIN, R.; FERRE, P. Assays of lipogenic enzymes. In: AILHAUD, G. (Ed.). Methods in molecular biology.Totowa: Human Press, 2001.v. 155, p. 121-127.

BERG, A. H.; COMBS, T. P.; DU, X.; BROWNLEE, M.; SCHERER, P. E. The adipocytesecreted protein Acrp30 enhances hepatic insulin action. Nat. Med.,v. 7, p. 947-953, 2001.

BERG, J.M.; TYMOCZKO, J.L.; STRYER, L. Bioquímica.Rio de Janeiro: Guanabara Koogan, 2004.

BERGMEYER, H. U.; BERNT, E.; SCHMIDT, F.; STORK, H. In: BERGMEYER, H. U. (Ed.). Methods of enzymatic analysis. Orlando: Academic Press, 1974. p. 1196-1201.

BLOCH, C. A.; CLEMONS, P.; SPERLING, M. A. Puberty decreases insulin sensitivity. J. Pediatr.,v. 110, p. 481-487, 1987.

BRANN, D. W.; WADE, M. F.; DHANDAPANI, K. M.; MAHESH, V. B.; BUCHANAN, C. D. Leptin and reproduction. Steroids,v. 67, p. 95-104, 2002.

\footnotetext{
* De acordo com:

ASSOCIAÇÃO BRASILEIRA DE NORMAS TÉCNICAS. NBR 6023: informação e documentação: referências: elaboração. Rio de Janeiro, 2002.
} 
BRONSON, F. H.; RISSMAN, E. F. The biology of puberty. Biol. Rev. Camb. Philos. Soc.,v. 61, p. 157-195, 1986.

BUDAK, E.; FERNANDEZ SANCHEZ, M.; BELLVER, J.; CERVERO, A.; SIMON, C.; PELLICER, A. Interactions of the hormones leptin, ghrelin, adiponectin, resistin, and PYY336 with the reproductive system. Fertil. Steril.,v. 85, p. 1563-1581, 2006.

BUETTNER, C.; MUSE, E. D.; CHENG, A.; CHEN, L.; SCHERER, T.; POCAI, A.; SU, K.; CHENG, B.; LI, X.; HARVEY-WHITE, J.; SCHWARTZ, G. J.; KUNOS, G.; ROSSETTI, L. Leptin controls adipose tissue lipogenesis via central, STAT3-independent mechanisms. Nat. Med.,v. 14, p. 667-675, 2008.

CAMPION, S. N.; CARVALLO, F. R.; CHAPIN, R. E.; NOWLAND, W. S.; BEAUCHAMP, D.; JAMON, R.; KOITZ, R.; WINTON, T. R.; CAPPON, G. D.; HURTT, M. E. Comparative assessment of the timing of sexual maturation in male Wistar Han and Sprague-Dawley rats. Reprod. Toxicol.,v. 38C, p. 16-24, 2013.

CAO, Z.; UMEK, R. M.; MCKNIGHT, S. L. Regulated expression of three C/EBP isoforms during adipose conversion of 3T3-L1 cells. Genes. Dev.,v. 5, p. 1538-1552, 1991.

CARREL, A. L.; ALLEN, D. B. Effects of growth hormone on adipose tissue. J. Pediatr. Endocrinol. Metab.,v. 13, p. 1003-1009, 2000.Suppl 2.

CASABIELL, X.; PINEIRO, V.; VEGA, F.; DE LA CRUZ, L. F.; DIEGUEZ, C.; CASANUEVA, F. F. Leptin, reproduction and sex steroids. Pituitary,v. 4, p. 93-99, 2001.

CASTELLANO, J. M.; BENTSEN, A. H.; SANCHEZ-GARRIDO, M. A.; RUIZ-PINO, F.; ROMERO, M.; GARCIA-GALIANO, D.; AGUILAR, E.; PINILLA, L.; DIEGUEZ, C.; MIKKELSEN, J. D.; TENA-SEMPERE, M. Early metabolic programming of puberty onset: impact of changes in postnatal feeding and rearing conditions on the timing of puberty and development of the hypothalamic kisspeptin system. Endocrinology,v. 152, p. 3396-3408, 2011.

CEDDIA, R. B.; WILLIAM, W. N., JR.; LIMA, F. B.; CURI, R. Leptin inhibits insulinstimulated incorporation of glucose into lipids and stimulates glucose decarboxylation in isolated rat adipocytes. J. Endocrinol.,v. 158, p. R7-9, 1998.

CEDDIA, R. B.; WILLIAM, W. N., JR.; LIMA, F. B.; FLANDIN, P.; CURI, R.; GIACOBINO, J. $P$. Leptin stimulates uncoupling protein-2 mRNA expression and Krebs cycle activity and inhibits lipid synthesis in isolated rat white adipocytes. Eur. J. Biochem.,v. 267, p. 59525958, 2000.

CHEN, G.; KOYAMA, K.; YUAN, X.; LEE, Y.; ZHOU, Y. T.; O'DOHERTY, R.; NEWGARD, C. B.; UNGER, R. H. Disappearance of body fat in normal rats induced by adenovirusmediated leptin gene therapy. Proc. Natl. Acad. Sci. U.S .A.,v. 93, p. 14795-14799, 1996.

CHRISTY, R. J.; YANG, V. W.; NTAMBI, J. M.; GEIMAN, D. E.; LANDSCHULZ, W. H.; FRIEDMAN, A. D.; NAKABEPPU, Y.; KELLY, T. J.; LANE, M. D. Differentiation-induced gene expression in 3T3-L1 preadipocytes: CCAAT/enhancer binding protein interacts with and activates the promoters of two adipocyte-specific genes. Genes Dev.,v. 3, p. 13231335, 1989. 
CHU, Y.; HUDDLESTON, G. G.; CLANCY, A. N.; HARRIS, R. B.; BARTNESS, T. J. Epididymal fat is necessary for spermatogenesis, but not testosterone production or copulatory behavior. Endocrinology,v. 151, p. 5669-5679, 2010.

CLARK, P. A.; ROGOL, A. D. Growth hormones and sex steroid interactions at puberty. Endocrinol. Metab. Clin. North Am.,v. 25, p. 665-681, 1996.

CLEMMONS, D. R. Roles of insulin-like growth factor-I and growth hormone in mediating insulin resistance in acromegaly. Pituitary,v. 5, p. 181-183, 2002.

COLEMAN, R. A.; LEWIN, T. M.; MUOIO, D. M. Physiological and nutritional regulation of enzymes of triacylglycerol synthesis. Annu. Rev. Nutr.,v. 20, p. 77-103, 2000.

COMBS, T. P.; WAGNER, J. A.; BERGER, J.; DOEBBER, T.; WANG, W. J.; ZHANG, B. B.; TANEN, M.; BERG, A. H.; O'RAHILLY, S.; SAVAGE, D. B.; CHATTERJEE, K.; WEISS, S.; LARSON, P. J.; GOTTESDIENER, K. M.; GERTZ, B. J.; CHARRON, M. J.; SCHERER, P. E.; MOLLER, D. E. Induction of adipocyte complement-related protein of 30 kilodaltons by PPARgamma agonists: a potential mechanism of insulin sensitization. Endocrinology,v. 143, p. 998-1007, 2002.

CUNNINGHAM, M. J.; CLIFTON, D. K.; STEINER, R. A. Leptin's actions on the reproductive axis: perspectives and mechanisms. Biol. Reprod.,v. 60, p. 216-222, 1999.

DE SOUZA, M. J.; WILLIAMS, N. I. Physiological aspects and clinical sequelae of energy deficiency and hypoestrogenism in exercising women. Hum. Reprod. Update,v. 10, p. 433448, 2004.

DEBELJUK, L.; ARIMURA, A.; SCHALLY, A. V. Studies on the pituitary responsiveness to luteinizing hormone-releasing hormone $(\mathrm{LH}-\mathrm{RH})$ in intact male rats of different ages. Endocrinology,v. 90, p. 585-588, 1972.

DIETZ, J.; SCHWARTZ, J. Growth hormone alters lipolysis and hormone-sensitive lipase activity in 3T3-F442A adipocytes. Metabolism,v. 40, p. 800-806, 1991.

DIGIROLAMO, M.; MEDLINGER, S.; FERTIG, W.A.A simple method to determine fat cell size and number in four mammalian species.American Journal of Physiology, v. 221, n. 3, p. 850-888, 1971.

DOLE, V.P.; MEINERTZ, H. Microdetermination of long-chain fatty-acids in plasma and tissues. The Journal of Biological Chemistry, v.235, n. 9, p. 2595-2599, 1960.

DOMINICI, F. P.; ARGENTINO, D. P.; MUNOZ, M. C.; MIQUET, J. G.; SOTELO, A. I.; TURYN, D. Influence of the crosstalk between growth hormone and insulin signalling on the modulation of insulin sensitivity. Growth Horm. IGF Res.,v. 15, p. 324-336, 2005.

DULLAART, J. Immature rat pituitary glands in vitro: age- and sex-related changes in luteinizing hormone releasing hormone-stimulated gonadotrophin release. J. Endocrinol.,v. 73, p. 309-319, 1977.

DUNCAN, R. E.; AHMADIAN, M.; JAWORSKI, K.; SARKADI-NAGY, E.; SUL, H. S. Regulation of lipolysis in adipocytes. Annu. Rev. Nutr.,v. 27, p. 79-101, 2007. 
ELIAS, C. F. Leptin action in pubertal development: recent advances and unanswered questions. Trends in Endocrinology and Metabolism,v. 23, p. 9-15, 2012.

FAROOQI, I. S. Leptin and the onset of puberty: insights from rodent and human genetics. Semin. Reprod. Med.,v. 20, p. 139-144, 2002.

FLORYK, D.; KUROSAKA, S.; TANIMOTO, R.; YANG, G.; GOLTSOV, A.; PARK, S.; THOMPSON, T. C. Castration-induced changes in mouse epididymal white adipose tissue. Mol. Cell Endocrinol.,v. 345, p. 58-67, 2011.

FONSECA-ALANIZ, M. H.; TAKADA, J.; ALONSO-VALE, M. I.; LIMA, F. B. The adipose tissue as a regulatory center of the metabolism. Arq. Bras. Endocrinol. Metabol.,v. 50, p. 216-229, 2006.

FRANCK, N.; STENKULA, K. G.; OST, A.; LINDSTROM, T.; STRALFORS, P.; NYSTROM, F. H. Insulin-induced GLUT4 translocation to the plasma membrane is blunted in large compared with small primary fat cells isolated from the same individual. Diabetologia,v. 50, p. 1716-1722, 2007.

FRAYN, K. N.; KARPE, F.; FIELDING, B. A.; MACDONALD, I. A.; COPPACK, S. W. Integrative physiology of human adipose tissue. Int. J. Obes. Relat. Metab. Disord.,v. 27, p. 875-888, 2003.

FRISCH, R. E.; REVELLE, R. Height and Weight at Menarche and a Hypothesis of Critical Body Weights and Adolescent Events. Science,v. 169, p. 397-399, 1970.

FRUEBIS, J.; TSAO, T. S.; JAVORSCHI, S.; EBBETS-REED, D.; ERICKSON, M. R.; YEN, F. T.; BIHAIN, B. E.; LODISH, H. F. Proteolytic cleavage product of 30-kDa adipocyte complement-related protein increases fatty acid oxidation in muscle and causes weight loss in mice. Proc. Natl. Acad. Sci. U. S. A.,v. 98, p. 2005-2010, 2001.

FRUHBECK, G.; GOMEZ-AMBROSI, J.; SALVADOR, J. Leptin-induced lipolysis opposes the tonic inhibition of endogenous adenosine in white adipocytes. FASEB J.,v. 15, p. 333340, 2001.

GABRIEL, S. M.; RONCANCIO, J. R.; RUIZ, N. S. Growth hormone pulsatility and the endocrine milieu during sexual maturation in male and female rats. Neuroendocrinology,v. 56, p. 619-625, 1992.

GALIC, S.; OAKHILL, J. S.; STEINBERG, G. R. Adipose tissue as an endocrine organ. Mol. Cell Endocrinol.,v. 316, p. 129-139, 2010.

GAO, S.; KINZIG, K. P.; AJA, S.; SCOTT, K. A.; KEUNG, W.; KELLY, S.; STRYNADKA, K.; CHOHNAN, S.; SMITH, W. W.; TAMASHIRO, K. L.; LADENHEIM, E. E.; RONNETT, G. V.; TU, Y.; BIRNBAUM, M. J.; LOPASCHUK, G. D.; MORAN, T. H. Leptin activates hypothalamic acetyl-CoA carboxylase to inhibit food intake. Proc. Natl. Acad. Sci. U. S. A.,v. 104, p. 17358-17363, 2007.

GARG, A. Lipodystrophies: genetic and acquired body fat disorders. Journal of Clinical Endocrinology \& Metabolism,v. 96, p. 3313-3325, 2011.

GIMENO, R. E.; KLAMAN, L. D. Adipose tissue as an active endocrine organ: recent advances. Curr. Opin. Pharmacol.,v. 5, p. 122-128, 2005. 
GOODMAN, M. N.; DLUZ, S. M.; MCELANEY, M. A.; BELUR, E.; RUDERMAN, N. B. Glucose uptake and insulin sensitivity in rat muscle: changes during 3-96 weeks of age. Am. J. Physiol.,v. 244, p. E93-100, 1983.

GORAN, M. I.; GOWER, B. A. Longitudinal study on pubertal insulin resistance. Diabetes,v. 50, p. 2444-2450, 2001.

GUEORGUIEV, M.; GOTH, M. L.; KORBONITS, M. Leptin and puberty: a review. Pituitary,v. 4, p. 79-86, 2001

GUERRE-MILLO, M. Adiponectin: an update. Diabetes Metab.,v. 34, p. 12-18, 2008.

HANSEL, W. The essentiality of the epididymal fat pad for spermatogenesis. Endocrinology,v. 151, p. 5565-5567, 2010.

HANSEN, F. M.; FAHMY, N.; NIELSEN, J. H. The influence of sexual hormones on lipogenesis and lipolysis in rat fat cells. Acta Endocrinol. (Copenh).,v. 95, p. 566-570, 1980.

HAUG, A.; HOSTMARK, A. T.; SPYDEVOLD, O.; EILERTSEN, E. Hypercholesterolaemia, hypotriacylglycerolaemia and increased lipoprotein lipase activity following orchidectomy in rats. Acta Endocrinol. (Copenh).,v. 113, p. 133-139, 1986.

HELLERSTEIN, M. K.; SCHWARZ, J. M.; NEESE, R. A. Regulation of hepatic de novo lipogenesis in humans. Annu. Rev. Nutr.,v. 16, p. 523-557, 1996.

HOLM, C. Molecular mechanisms regulating hormone-sensitive lipase and lipolysis. Biochem. Soc. Trans.,v. 31, p. 1120-1124, 2003.

HOLMANG, A.; BJORNTORP, P. The effects of testosterone on insulin sensitivity in male rats. Acta. Physiol. Scand.,v. 146, p. 505-510, 1992.

HOTAMISLIGIL, G. S.; SHARGILL, N. S.; SPIEGELMAN, B. M. Adipose expression of tumor necrosis factor-alpha: direct role in obesity-linked insulin resistance. Science,v. 259, p. 87-91, 1993.

HOTAMISLIGIL, G. S.; ARNER, P.; CARO, J. F.; ATKINSON, R. L.; SPIEGELMAN, B. M. Increased adipose tissue expression of tumor necrosis factor-alpha in human obesity and insulin resistance. J. Clin. Invest.,v. 95, p. 2409-2415, 1995.

HOUSEKNECHT, K. L.; BAILE, C. A.; MATTERI, R. L.; SPURLOCK, M. E. The biology of leptin: a review. J. Anim. Sci.,v. 76, p. 1405-1420, 1998.

HUO, L.; MUNZBERG, H.; NILLNI, E. A.; BJORBAEK, C. Role of signal transducer and activator of transcription 3 in regulation of hypothalamic trh gene expression by leptin. Endocrinology,v. 145, p. 2516-2523, 2004.

JAWORSKI, K.; SARKADI-NAGY, E.; DUNCAN, R. E.; AHMADIAN, M.; SUL, H. S. Regulation of triglyceride metabolism. IV. Hormonal regulation of lipolysis in adipose tissue. Am. J. Physiol. Gastrointest. Liver. Physiol.,v. 293, p. G1-4, 2007.

JEQUIER, E. Leptin signaling, adiposity, and energy balance. Ann. N. Y. Acad. Sci.,v. 967, p. 379-388, 2002. 
JO, J.; GAVRILOVA, O.; PACK, S.; JOU, W.; MULLEN, S.; SUMNER, A. E.; CUSHMAN, S. W.; PERIWAL, V. Hypertrophy and/or hyperplasia: dynamics of adipose tissue growth. PLoS Comput. Biol., v. 5, p. e1000324, 2009.

JOHANSEN, T.; RICHELSEN, B.; HANSEN, H. S.; DIN, N.; MALMLOF, K. Growth hormone-mediated breakdown of body fat: effects of $\mathrm{GH}$ on lipases in adipose tissue and skeletal muscle of old rats fed different diets. Horm. Metab. Res., v. 35, p. 243-250, 2003.

KAMOHARA, S.; BURCELIN, R.; HALAAS, J. L.; FRIEDMAN, J. M.; CHARRON, M. J. Acute stimulation of glucose metabolism in mice by leptin treatment. Nature, v. 389, p. 374$377,1997$.

KENNEDY, G. C.; MITRA, J. Body weight and food intake as initiating factors for puberty in rat. Journal of Physiology-London, v. 166, p. 408-418, 1963.

KENNEDY, G. C. Interactions between feeding behavior and hormones during growth. Ann. N. Y. Acad. Sci.,v. 157, p. 1049-1061, 1969.

KERSHAW, E. E.; FLIER, J. S. Adipose tissue as an endocrine organ. J. Clin. Endocrinol. Metab.,v. 89, p. 2548-2556, 2004.

KIESS, W.; BLUM, W. F.; AUBERT, M. L. Leptin, puberty and reproductive function: lessons from animal studies and observations in humans. Eur. J. Endocrinol., v. 138, p. 26-29, 1998.

KLEIN, S.; COPPACK, S. W.; MOHAMED-ALI, V.; LANDT, M. Adipose tissue leptin production and plasma leptin kinetics in humans. Diabetes,v. 45, p. 984-987, 1996.

KORNACKER, M. S.; BALL, E. G. Citrate cleavage in adipose tissue. Proc. Natl. Acad. Sci. U. S. A., v. 54, p. 899-904, 1965.

LAFONTAN, M.; LANGIN, D. Lipolysis and lipid mobilization in human adipose tissue. Prog. Lipid. Res.,v. 48, p. 275-297, 2009.

LANE, M. D.; TANG, Q. Q.; JIANG, M. S. Role of the CCAAT enhancer binding proteins (C/EBPs) in adipocyte differentiation. Biochem. Biophys. Res. Commun.,v. 266, p. 677683, 1999.

LASS, A.; ZIMMERMANN, R.; OBERER, M.; ZECHNER, R. Lipolysis - a highly regulated multi-enzyme complex mediates the catabolism of cellular fat stores. Prog. Lipid. Res.,v. 50, p. 14-27, 2011.

LAUGHLIN, G. A.; YEN, S. S. Hypoleptinemia in women athletes: absence of a diurnal rhythm with amenorrhea. J. Clin. Endocrinol. Metab.,v. 82, p. 318-321, 1997.

LIMA, F. B.; BAO, S.; GARVEY, W. T. Biological actions of insulin are differentially regulated by glucose and insulin in primary cultured adipocytes. Chronic ability to increase glycogen synthase activity. Diabetes,v. 43, p. 53-62, 1994.

LIVINGSTON, J. N.; CUATRECASA, P.; LOCKWOOD, D. H. Insulin insensitivity of large fat cells. Science,v. 177, p. 626-628, 1972. 
LIVINGSTONE, C.; COLLISON, M. Sex steroids and insulin resistance. Clin. Sci. (Lond).,v. 102, p. 151-166, 2002.

LLOYD, B.; RAVI, P.; MENDES, N.; KLIBANSKI, A.; MISRA, M. Peptide YY levels across pubertal stages and associations with growth hormone. J. Clin. Endocrinol. Metab.,v. 95, p. 2957-2962, 2010.

LOTT, J. A.; TURNER, K. Evaluation of Trinder's glucose oxidase method for measuring glucose in serum and urine. Clinical Chemistry, v. 21, p. 1754-1760, 1975.

LUNDGREN, M.; SVENSSON, M.; LINDMARK, S.; RENSTROM, F.; RUGE, T.; ERIKSSON, J. W. Fat cell enlargement is an independent marker of insulin resistance and 'hyperleptinaemia'. Diabetologia,v. 50, p. 625-633, 2007.

MACDOUGALD, O. A.; LANE, M. D. Transcriptional regulation of gene expression during adipocyte differentiation. Annu. Rev. Biochem.,v. 64, p. 345-373, 1995.

MACOTELA, Y.; BOUCHER, J.; TRAN, T. T.; KAHN, C. R. Sex and depot differences in adipocyte insulin sensitivity and glucose metabolism. Diabetes,v. 58, p. 803-812, 2009.

MAFFEI, M.; HALAAS, J.; RAVUSSIN, E.; PRATLEY, R. E.; LEE, G. H.; ZHANG, Y.; FEI, H.; KIM, S.; LALLONE, R.; RANGANATHAN, S. Leptin levels in human and rodent: measurement of plasma leptin and ob RNA in obese and weight-reduced subjects. Nat. Med.,v. 1, p. 1155-1161, 1995.

MAURAS, N.; BLIZZARD, R. M.; LINK, K.; JOHNSON, M. L.; ROGOL, A. D.; VELDHUIS, J. D. Augmentation of growth hormone secretion during puberty: evidence for a pulse amplitude-modulated phenomenon. J. Clin. Endocrinol. Metab.,v. 64, p. 596-601, 1987.

MAURY, E.; BRICHARD, S. M. Adipokine dysregulation, adipose tissue inflammation and metabolic syndrome. Mol. Cell Endocrinol.,v. 314, p. 1-16, 2010.

MOHAMED-ALI, V.; PINKNEY, J. H.; COPPACK, S. W. Adipose tissue as an endocrine and paracrine organ. Int. J. Obes. Relat. Metab. Disord.,v. 22, p. 1145-1158, 1998.

MORAN, A.; JACOBS, D. R., JR.; STEINBERGER, J.; HONG, C. P.; PRINEAS, R.; LUEPKER, R.; SINAIKO, A. R. Insulin resistance during puberty: results from clamp studies in 357 children. Diabetes,v. 48, p. 2039-2044, 1999.

MULLER, G.; ERTL, J.; GERL, M.; PREIBISCH, G. Leptin impairs metabolic actions of insulin in isolated rat adipocytes. J. Biol. Chem. v. 272, p. 10585-10593, 1997.

MURASE, T.; YAMADA, N.; MATSUZAKI, F. The in vitro effect of growth hormone on adipose tissue lipoprotein lipase in rats. Life Sci.,v. 28, p. 199-201, 1981.

NG, S. F.; STORLIEN, L. H.; KRAEGEN, E. W.; STUART, M. C.; CHAPMAN, G. E.; LAZARUS, L. Effect of biosynthetic human growth hormone on insulin action in individual tissues of the rat in vivo. Metabolism,v. 39, p. 264-268, 1990.

NILLNI, E. A.; VASLET, C.; HARRIS, M.; HOLLENBERG, A.; BJORBAK, C.; FLIER, J. S. Leptin regulates prothyrotropin-releasing hormone biosynthesis. Evidence for direct and indirect pathways. J. Biol. Chem.,v. 275, p. 36124-36133, 2000. 
OJEDA, S. R.; ANDREWS, W. W.; ADVIS, J. P.; WHITE, S. S. Recent advances in the endocrinology of puberty. Endocr. Rev.,v. 1, p. 228-257, 1980.

OSCARSSON, J.; OTTOSSON, M.; EDEN, S. Effects of growth hormone on lipoprotein lipase and hepatic lipase. J. Endocrinol. Invest.,v. 22, p. 2-9, 1999.

OTTOSSON, M.; VIKMAN-ADOLFSSON, K.; ENERBACK, S.; ELANDER, A.; BJORNTORP, P.; EDEN, S. Growth hormone inhibits lipoprotein lipase activity in human adipose tissue. J. Clin. Endocrinol. Metab.,v. 80, p. 936-941, 1995.

PAJVANI, U. B.; DU, X.; COMBS, T. P.; BERG, A. H.; RAJALA, M. W.; SCHULTHESS, T.; ENGEL, J.; BROWNLEE, M.; SCHERER, P. E. Structure-function studies of the adipocytesecreted hormone Acrp30/adiponectin. Implications fpr metabolic regulation and bioactivity. J. Biol. Chem.,v. 278, p. 9073-9085, 2003.

PAYNE, A. H.; KELCH, R. P.; MURONO, E. P.; KERLAN, J. T. Hypothalamic, pituitary and testicular function during sexual maturation of the male rat. J. Endocrinol.,v. 72, p. 17-26, 1977.

PINHAS-HAMIEL, O.; ZEITLER, P. The global spread of type 2 diabetes mellitus in children and adolescents. J. Pediatr.,v. 146, p. 693-700, 2005.

PITTELOUD, N.; MOOTHA, V. K.; DWYER, A. A.; HARDIN, M.; LEE, H.; ERIKSSON, K. F.; TRIPATHY, D.; YIALAMAS, M.; GROOP, L.; ELAHI, D.; HAYES, F. J. Relationship between testosterone levels, insulin sensitivity, and mitochondrial function in men. Diabetes Care,v. 28, p. 1636-1642, 2005.

POTAU, N.; IBANEZ, L.; RIQUE, S.; CARRASCOSA, A. Pubertal changes in insulin secretion and peripheral insulin sensitivity. Horm. Res.,v. 48, p. 219-226, 1997.

RAGHAVAN, S.; SAENGER, P.; HU, M.; BARZILAI, N. Intracellular pathways of insulinmediated glucose uptake before and after puberty in conscious rats. Pediatr. Res.,v. 41, p. 340-345, 1997.

RODBELL M. Metabolism of isolated fat cells. Effects of hormones on glucose metabolism and lipids. Journal of Biological Chemistry, v. 239, p. 357-380, 1964.

ROEMMICH, J. N.; CLARK, P. A.; LUSK, M.; FRIEL, A.; WELTMAN, A.; EPSTEIN, L. H.; ROGOL, A. D. Pubertal alterations in growth and body composition. VI. Pubertal insulin resistance: relation to adiposity, body fat distribution and hormone release. Int. J. Obes. Relat. Metab. Disord., v. 26, p. 701-709, 2002.

ROGOL, A. D.; ROEMMICH, J. N.; CLARK, P. A. Growth at puberty. J. Adolesc. Health., v. 31, p. 192-200, 2002.

ROSE, D. R.; CLEMMONS, D. R. Growth hormone receptor antagonist improves insulin resistance in acromegaly. Growth Horm. IGF Res., v. 12, p. 418-424, 2002.

ROSEN, E. D.; SPIEGELMAN, B. M. Molecular regulation of adipogenesis. Annu. Rev. Cell Dev. Biol., v. 16, p. 145-171, 2000. 
ROSENBLOOM, A. L.; SILVERSTEIN, J. H.; AMEMIYA, S.; ZEITLER, P.; KLINGENSMITH, G. J. Type 2 diabetes in children and adolescents. Pediatr. Diabetes,v. 10, p. 17-32, 2009.Suppl 12.

SALANS, L. B.; KNITTLE, J. L.; HIRSCH, J. The role of adipose cell size and adipose tissue insulin sensitivity in the carbohydrate intolerance of human obesity. J. Clin. Invest., v. 47 , p. $153-165,1968$.

SALANS, L. B.; DOUGHERTY, J. W. The effect of insulin upon glucose metabolism by adipose cells of different size. Influence of cell lipid and protein content, age, and nutritional state. J. Clin. Invest., v. 50, p. 1399-1410, 1971.

SALMA, N.; XIAO, H.; IMBALZANO, A. N. Temporal recruitment of CCAAT/enhancerbinding proteins to early and late adipogenic promoters in vivo. J. Mol. Endocrinol., v. 36, p. 139-151, 2006.

SANTORO, N.; PERRONE, L.; CIRILLO, G.; BRIENZA, C.; GRANDONE, A.; CRESTA, N.; MIRAGLIA DEL GIUDICE, E. Variations of retinol binding protein 4 levels are not associated with changes in insulin resistance during puberty. J. Endocrinol. Invest., v. 32, p. 411-414, 2009.

SCHWARTZ, M. W.; WOODS, S. C.; PORTE, D., JR.; SEELEY, R. J.; BASKIN, D. G. Central nervous system control of food intake. Nature,v. 404, p. 661-671, 2000.

SEIP, M.; TRYGSTAD, O. Generalized lipodystrophy, congenital and acquired (lipoatrophy). Acta Paediatr. Suppl., v. 413, p. 2-28, 1996.

SETHI, J. K.; HOTAMISLIGIL, G. S. The role of TNF alpha in adipocyte metabolism. Semin. Cell Dev. Biol., v. 10, p. 19-29, 1999.

SHOMAKER, L. B.; TANOFSKY-KRAFF, M.; SAVASTANO, D. M.; KOZLOSKY, M.; COLUMBO, K. M.; WOLKOFF, L. E.; ZOCCA, J. M.; BRADY, S. M.; YANOVSKI, S. Z.; CROCKER, M. K.; ALI, A.; YANOVSKI, J. A. Puberty and observed energy intake: boy, can they eat! Am. J. Clin. Nutr., v. 92, p. 123-129, 2010.

SIVITZ, W. I.; WALSH, S. A.; MORGAN, D. A.; THOMAS, M. J.; HAYNES, W. G. Effects of leptin on insulin sensitivity in normal rats. Endocrinology,v. 138, p. 3395-3401, 1997.

SORISKY, A.; GAGNON, A.M. Clinical implications of adipose tissue remodelling: adipogenesis and apoptosis. Canadian Journal of Diabetes, v.26, p.232-240, 2002.

SPIEGELMAN, B. M.; FLIER, J. S. Obesity and the regulation of energy balance. Cell,v. 104, p. 531-543, 2001.

SU, C. L.; SZTALRYD, C.; CONTRERAS, J. A.; HOLM, C.; KIMMEL, A. R.; LONDOS, C. Mutational analysis of the hormone-sensitive lipase translocation reaction in adipocytes. $\mathbf{J}$. Biol. Chem.,v. 278, p. 43615-43619, 2003.

SUL, H. S.; WANG, D. Nutritional and hormonal regulation of enzymes in fat synthesis: Studies of fatty acid synthase and mitochondrial glycerol-3-phosphate acyltransferase gene transcription. Annual Review of Nutrition,v. 18, p. 331-351, 1998. 
TANG, Q. Q.; LANE, M. D. Activation and centromeric localization of CCAAT/enhancerbinding proteins during the mitotic clonal expansion of adipocyte differentiation.Genes Dev.,v. 13, p. 2231-2241, 1999.

TANG, Q. Q.; OTTO, T. C.; LANE, M. D. CCAAT/enhancer-binding protein beta is required for mitotic clonal expansion during adipogenesis. Proc. Natl. Acad. Sci. U. S. A.,v. 100, p. 850-855, 2003a.

TANG, Q. Q.; OTTO, T. C.; LANE, M. D. Mitotic clonal expansion: a synchronous process required for adipogenesis. Proc. Natl. Acad. Sci. U. S. A.,v. 100, p. 44-49, 2003b.

TANG, Q. Q.; GRONBORG, M.; HUANG, H.; KIM, J. W.; OTTO, T. C.; PANDEY, A.; LANE, M. D. Sequential phosphorylation of CCAAT enhancer-binding protein beta by MAPK and glycogen synthase kinase 3 beta is required for adipogenesis. Proc. Natl. Acad. Sci. U. S. A.,v. 102, p. 9766-97671, 2005.

TANNER, J. M.; WHITEHOUSE, R. H.; HUGHES, P. C.; CARTER, B. S. Relative importance of growth hormone and sex steroids for the growth at puberty of trunk length, limb length, and muscle width in growth hormone-deficient children. J. Pediatr.,v. 89, p. 1000-1008, 1976.

TAO, H.; UMEK, R. M. C/EBPalpha is required to maintain postmitotic growth arrest in adipocytes. DNA Cell Biol.,v. 19, p. 9-18, 2000.

THOMSON, A. A.; MARKER, P. C. Branching morphogenesis in the prostate gland and seminal vesicles.Differentiation,v. 74, p. 382-392, 2006.

TRAYHURN, P.; BEATTIE, J. H. Physiological role of adipose tissue: white adipose tissue as an endocrine and secretory organ. Proc. Nutr.Soc.,v. 60, p. 329-339, 2001.

TSUJI, M.; SHIMA, H.; CUNHA, G. R. Morphogenetic and proliferative effects of testosterone and insulin on the neonatal mouse seminal vesicle in vitro.Endocrinology,v. 129, p. 2289-2297, 1991.

UMEK, R. M.; FRIEDMAN, A. D.; MCKNIGHT, S. L. CCAAT-enhancer binding protein: a component of a differentiation switch. Science,v. 251, p. 288-292, 1991.

WAKIL, S. J.; STOOPS, J. K.; JOSHI, V. C. Fatty acid synthesis and its regulation.Annu.Rev. Biochem.,v. 52, p. 537-579, 1983.

WANG, J. L.; CHINOOKOSWONG, N.; SCULLY, S.; QI, M.; SHI, Z. Q. Differential effects of leptin in regulation of tissue glucose utilization in vivo. Endocrinology,v. 140, p. 21172124, 1999.

WANG, Y.; MONTEIRO, C.; POPKIN, B. M. Trends of obesity and underweight in older children and adolescents in the United States, Brazil, China, and Russia.Am. J. Clin.Nutr.,v. 75, p. 971-977, 2002.

WARREN, M. P.; PERLROTH, N. E.The effects of intense exercise on the female reproductive system.J. Endocrinol.,v. 170, p. 3-11, 2001. 
WATANOBE, H.; SCHIOTH, H. B. Postnatal profile of plasma leptin concentrations in male and female rats: relation with the maturation of the pituitary-gonadal axis. Regul.Pept.,v. 105, p. 23-28, 2002.

WATT, M. J.; SPRIET, L. L. Triacylglycerol lipases and metabolic control: implications for health and disease. Am. J. Physiol. Endocrinol.Metab.,v. 299, p. E162-168, 2010.

WELLEN, K. E.; HOTAMISLIGIL, G. S. Inflammation, stress, and diabetes. J. Clin.Invest.,v. 115, p. 1111-1119, 2005.

WISE, E. M., JR.; BALL, E. G. Malic Enzyme and Lipogenesis.Proc. Natl. Acad. Sci. U. S. A.,v. 52, p. 1255-1263, 1964.

WOZNIAK, S. E.; GEE, L. L.; WACHTEL, M. S.; FREZZA, E. E. Adipose tissue: the new endocrine organ? A review article.Dig.Dis. Sci.,v. 54, p. 1847-1856, 2009.

WU, Z.; XIE, Y.; BUCHER, N. L.; FARMER, S. R. Conditional ectopic expression of C/EBP beta in NIH-3T3 cells induces PPAR gamma and stimulates adipogenesis. Genes Dev.,v. 9, p. 2350-2363, 1995.

XU, X. F.; DE PERGOLA, G.; BJORNTORP, P. Testosterone increases lipolysis and the number of beta-adrenoceptors in male rat adipocytes. Endocrinology,v. 128, p. 379-382, 1991.

XU, X.; DE PERGOLA, G.; ERIKSSON, P. S.; FU, L.; CARLSSON, B.; YANG, S.; EDEN, S.; BJORNTORP, P. Postreceptor events involved in the up-regulation of beta-adrenergic receptor mediated lipolysis by testosterone in rat white adipocytes. Endocrinology,v. 132, p. 1651-1657, 1993.

XU, X. J.; GAUTHIER, M. S.; HESS, D. T.; APOVIAN, C. M.; CACICEDO, J. M.; GOKCE, N.; FARB, M.; VALENTINE, R. J.; RUDERMAN, N. B. Insulin sensitive and resistant obesity in humans: AMPK activity, oxidative stress, and depot-specific changes in gene expression in adipose tissue. J. Lipid.Res.,v. 53, p. 792-801, 2012.

YAMAUCHI, T.; KAMON, J.; WAKI, H.; TERAUCHI, Y.; KUBOTA, N.; HARA, K.; MORI, Y.; IDE, T.; MURAKAMI, K.; TSUBOYAMA-KASAOKA, N.; EZAKI, O.; AKANUMA, Y.; GAVRILOVA, O.; VINSON, C.; REITMAN, M. L.; KAGECHIKA, H.; SHUDO, K.; YODA, M.; NAKANO, Y.; TOBE, K.; NAGAI, R.; KIMURA, S.; TOMITA, M.; FROGUEL, P.; KADOWAKI, $T$. The fat-derived hormone adiponectin reverses insulin resistance associated with both lipoatrophy and obesity. Nat. Med.,v. 7, p. 941-946, 2001.

YAMAUCHI, T.; KAMON, J.; MINOKOSHI, Y.; ITO, Y.; WAKI, H.; UCHIDA, S.; YAMASHITA, S.; NODA, M.; KITA, S.; UEKI, K.; ETO, K.; AKANUMA, Y.; FROGUEL, P.; FOUFELLE, F.; FERRE, P.; CARLING, D.; KIMURA, S.; NAGAI, R.; KAHN, B. B.; KADOWAKI, T. Adiponectin stimulates glucose utilization and fatty-acid oxidation by activating AMP-activated protein kinase. Nat. Med.,v. 8, p. 1288-1295, 2002.

YEH, W. C.; CAO, Z.; CLASSON, M.; MCKNIGHT, S. L. Cascade regulation of terminal adipocyte differentiation by three members of the C/EBP family of leucine zipper proteins.Genes Dev.,v. 9, p. 168-181, 1995a. 
YEH, W. C.; LI, T. K.; BIERER, B. E.; MCKNIGHT, S. L. Identification and characterization of an immunophilin expressed during the clonal expansion phase of adipocyte differentiation. Proc. Natl. Acad. Sci. U. S. A.,v. 92, p. 11081-11085, 1995 b.

YURA, S.; OGAWA, Y.; SAGAWA, N.; MASUZAKI, H.; ITOH, H.; EBIHARA, K.; AIZAWAABE, M.; FUJII, S.; NAKAO, K. Accelerated puberty and late-onset hypothalamic hypogonadism in female transgenic skinny mice overexpressing leptin. J. Clin. Invest.,v. 105, p. 749-755, 2000. 